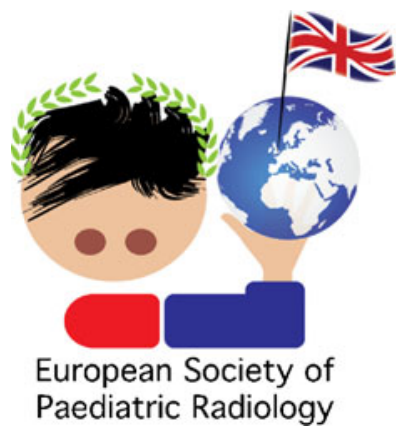

\title{
The Joint Societies of Paediatric Radiology \\ 6th Congress and Exhibition
}

\author{
27-31 May 2011 \\ Hilton London Metropole Hotel, London, United \\ Kingdom
}

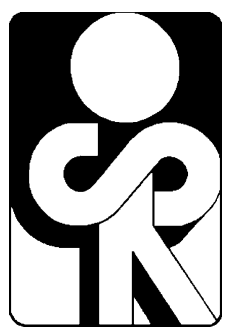

\section{Table of contents}

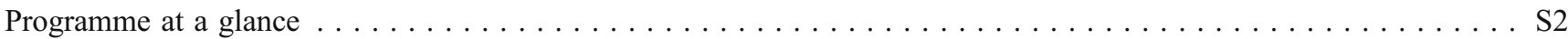

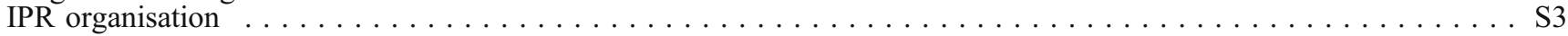

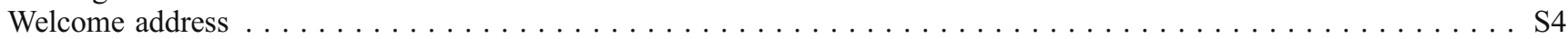

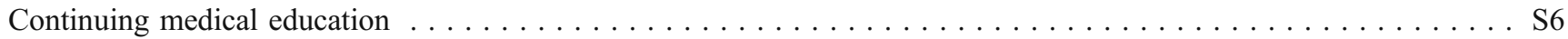

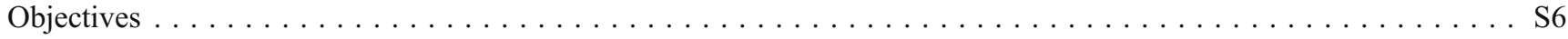

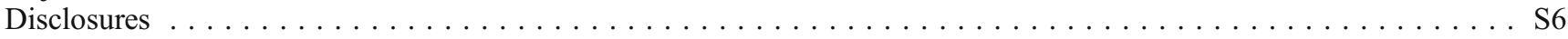

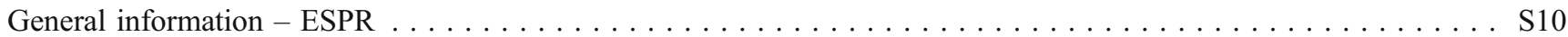

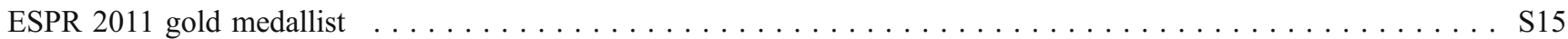

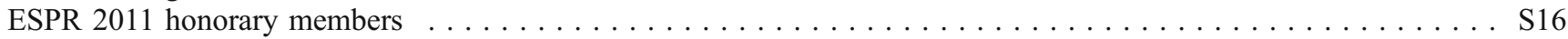

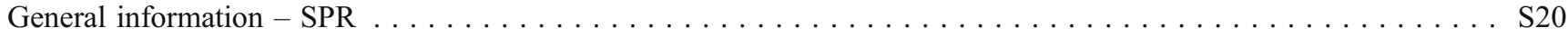

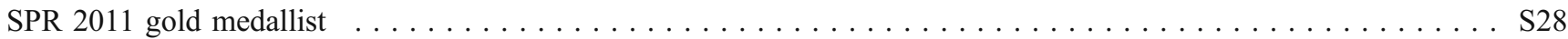

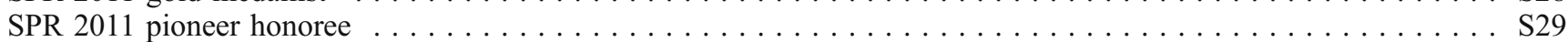

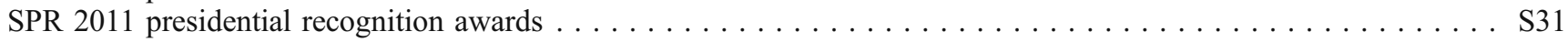

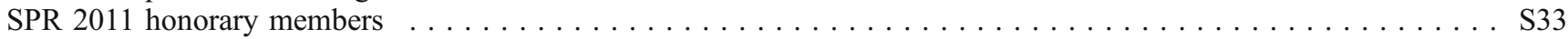

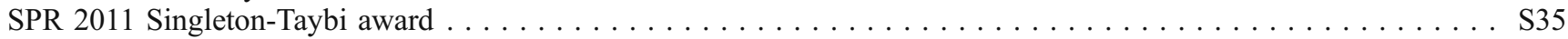

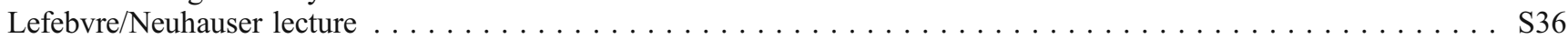

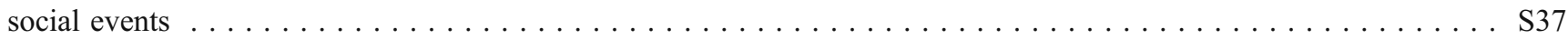

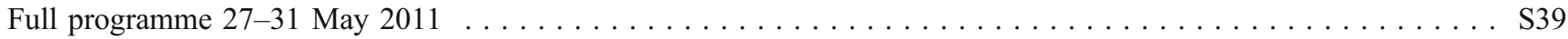

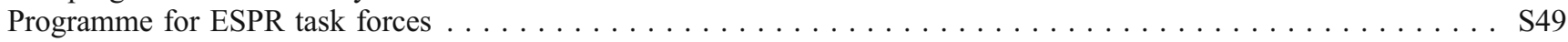

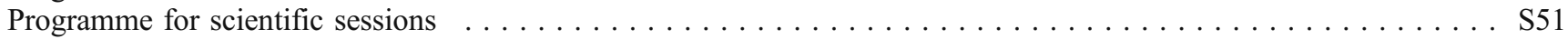

Syllabus

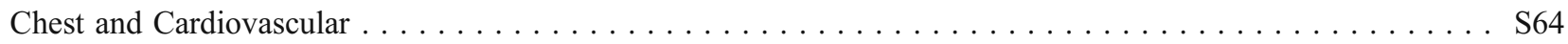

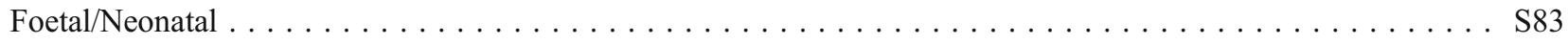

Functional Imaging and Emerging Techniques $\ldots \ldots \ldots \ldots \ldots \ldots \ldots \ldots \ldots \ldots \ldots \ldots \ldots \ldots$

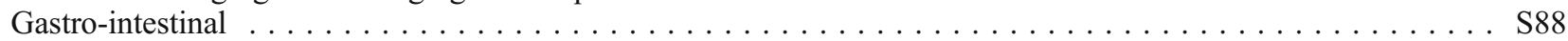

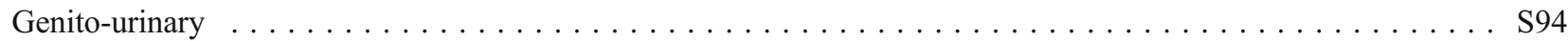

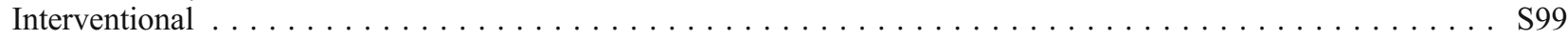

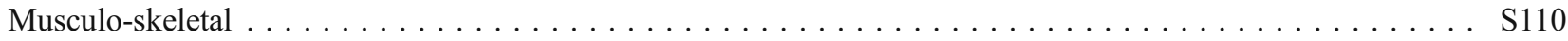

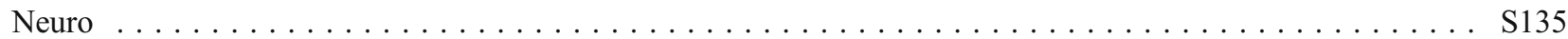

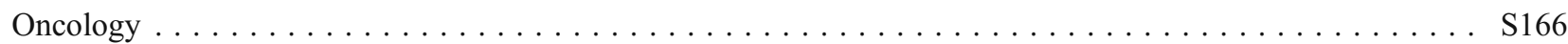

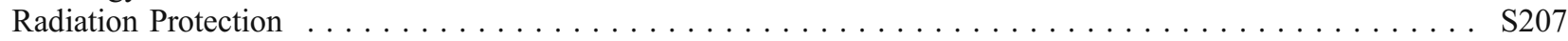

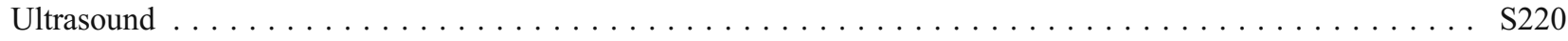

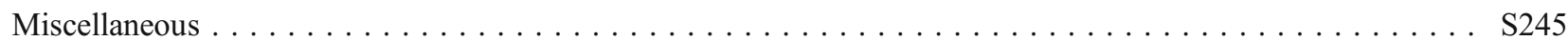

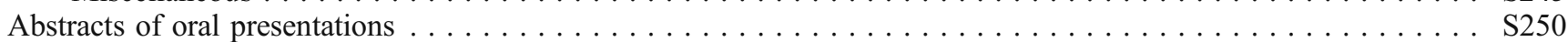

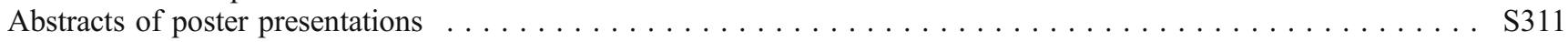

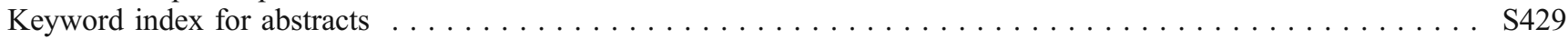

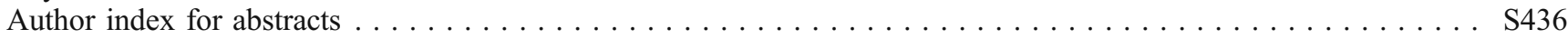

IPR and its affiliated associations would like to kindly thank Guerbet Laboratories, EOS Imaging, Siemens Healthcare and GE Healthcare for their sponsorship of the industry symposia at International Paediatric Radiology 2011. IPR would also like to thank all further sponsors and exhibitors for their support.

This supplement was not sponsored by outside commercial interests. It was funded entirely by the publisher. 
IPR London 2011, Programme at a Glance

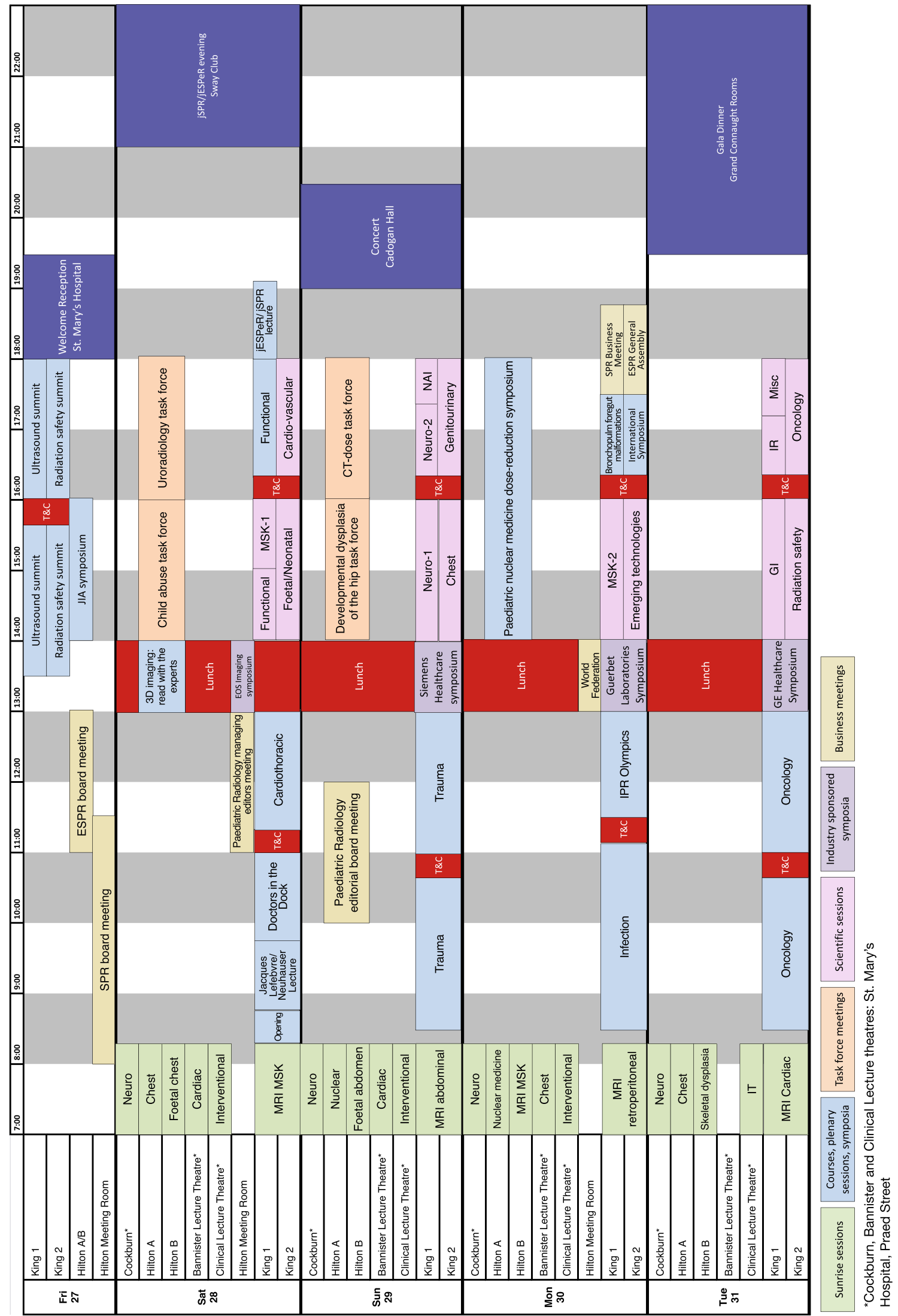


IPR Organisation

President

Catherine M. Owens (ESPR)

\section{Co-President}

Dorothy I. Bulas (SPR)

\section{Scientific Committee}

Led by:

Øystein E. Olsen (ESPR)

Sub committee leads from SPR:

Dorothy I. Bulas

Lisa H. Lowe

ESPR and SPR committee members:

See General Information about the respective organisations

\section{Local Organising Committee}

Catherine M. Owens

Øystein E. Olsen

Lil-Sofie Ording-Müller

\section{Conference Secretariat}

Fitwise Management Ltd

Drumcross Hall

Bathgate

West Lothian EH48 4JT

IPR 2011-The 6th Congress and Exhibition of the joint Societies of Paediatric Radiology, 27-31 May 2011, Hilton London Metropole, London, United Kingdom 

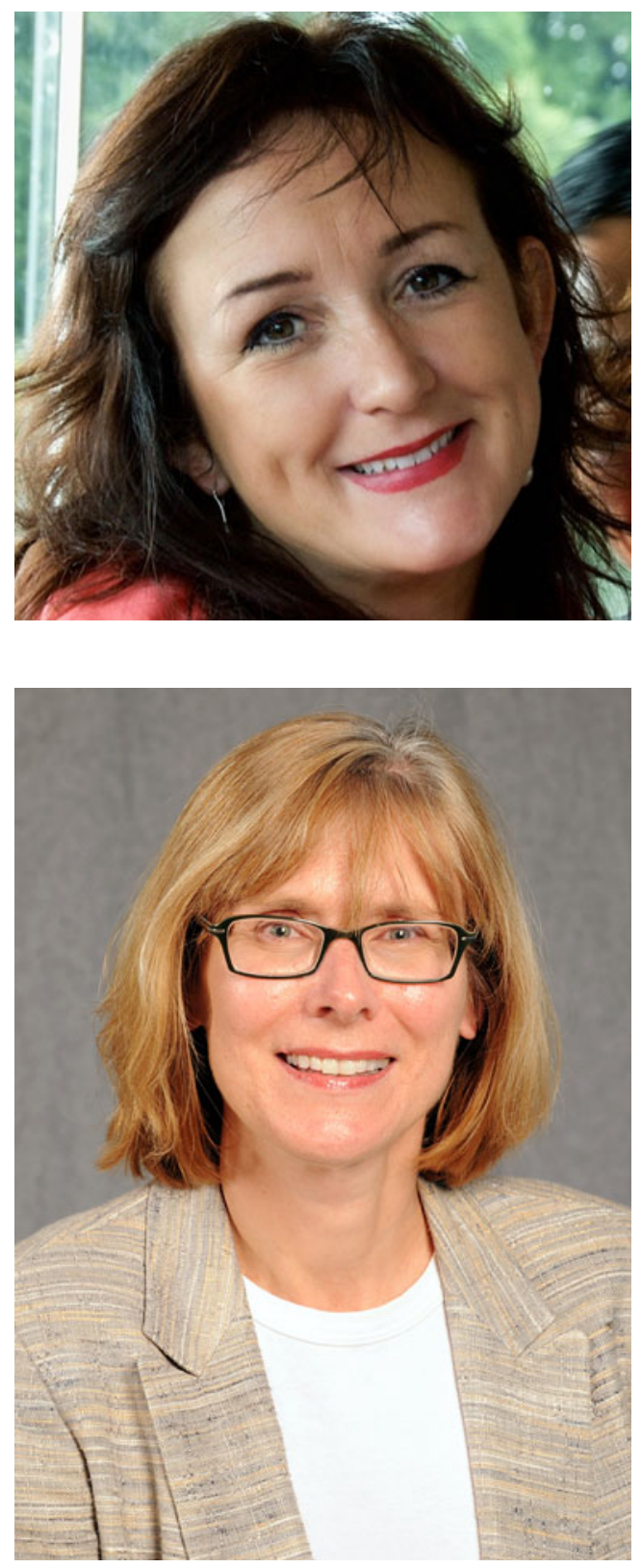

Dear friends and colleagues,

London is one of the most cosmopolitan cities in the world, holding an enviable record in the evolution of medicine over the centuries. For these reasons (and many others), it is the perfect venue for our International Paediatric Radiology Congress, held every tenth year in Europe. We feel proud to have IPR 2011 working towards global synergy to promote excellence throughout the world of paediatric imaging.

This meeting will address the importance of a true global perspective within children's imaging and the challenges we face in an international setting with wide variations in finance, equipment, human resources and expertise. We feel it particularly pertinent that in London 2011 we will launch the World Federation of Paediatric Imaging, a committed visionary group with a strategic plan to explore global inequalities (well documented by WHO), and address them tactically with a focus on education, training and partnership across all nations. This model is already underway, based on the field experiences of international nongovernmental organisations, and we need to find solutions for optimising imaging in children, as a first step in this chain. This will require detailed strategy and partnership between all existing societies, and commitment and 'buyin' from individual members and societies. More ubiquitous (albeit sometimes basic) computer facilities mean that we can network to more remote medical sites requiring our help, where there is a dearth of trained medical staff. Basic radiology equipment and internet link, a digital camera and willingness to share expertise are good basic requirements to start this global network, which is so badly required. We hope that you will join us at this important time for the World Federation launch at IPR 2011.

The IPR programme includes a selection of world renowned speakers, debates, competitions, a choice of six different sunrise sessions each morning, 400 posters and a series of state-of-the-art mini-symposia, not to mention a social programme which makes the most of London's legendary and unique artistic, historic and architectural heritage.

You will be spoilt for choice, kept on your toes, and have your intellectual capabilities stretched to the fullest, in what promises to be an action-packed week!

If you've been to an IPR meeting before, you may be expecting a two-day course followed by a three-day conference. We're doing things differently this year, and the days are being split into course sessions in the morning and scientific sessions in the afternoon.

We are delighted to welcome Professor Sam Gambhir from Stanford USA, a world leader in molecular imaging, who will present the Jacques Lefebvre/Neuhauser Lecture on this theme, one of the highlights of a strong scientific programme. We are fortunate to have many global medical leaders at hand, who are resident in London, and on whom we have called to 
make this an important clinico-radiological experience. We will be holding debates, and the IPR 2011 'Olympics', very topical, as London will host the 2012 Olympic Games.

The whole event swings into action in the afternoon of Friday 27 May with two important summits — one on ultrasound, the other on radiation safety.

We are using two venues for the conference. The main venue is the Hilton London Metropole Hotel where most of the congress sessions and exhibition take place, whilst a number of the sunrise sessions will take place in the St. Mary's Hospital medical school. This is an historic venue (less than a 5-minute walk away), where Professor Sir Alexander Fleming discovered penicillin, and Sir Roger Bannister worked (the first man to complete a 4-minute mile — his original stopwatch still housed in the lecture theatre we will be occupying).

The excellent social programme offers you a welcome reception at St. Mary's Hospital, a wonderful baroque concert featuring the London Handel Players and the beautiful soprano diva Ms Ruby Hughes. We are very fortunate to hold the concert in the superb, world famous and architecturally important Cadogan Hall (one of the city's most significant listed buildings; its perfect acoustics host the BBC Proms lunchtime concerts), and the final gala dinner at the Grand Connaught Rooms/Freemasons Hall—one of London's most famous buildings, originally built in 1775 in Covent Garden (also the headquarters of the television series Spooks!)

There are comprehensive tours within London during the conference.

We will have a mesmeric and wonderful meeting, and we need you to complete the perfect experience!

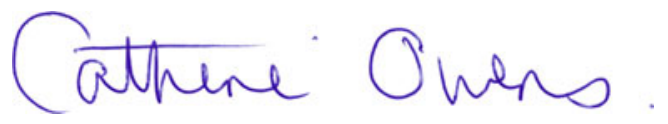

Dr Catherine M Owens IPR President

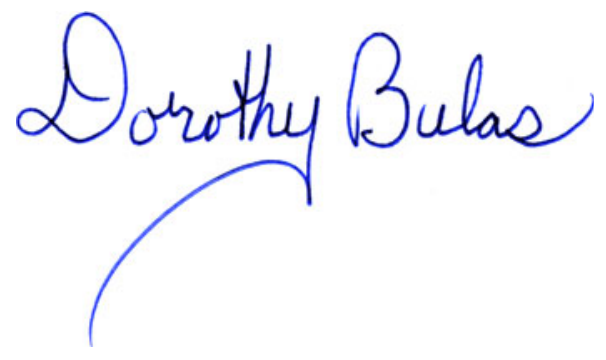

Dr Dorothy Bulas IPR Co-President 


\section{Continuing medical education}

\section{European accreditation}

European accreditation is granted by the European Accreditation Council for Continuing Medical Education (EACCME) in order to allow participants who attend the above-mentioned activity to validate their credits in their own country. The EACCME is an institution of the European Union of Medical Specialists (UEMS), www.uems.net. The 6th International Paediatric Radiology Congress is designated for a maximum of $27 \mathrm{~h}$ of European external CME credits. Each medical specialist should claim only those hours of credit that he/she actually spent in the educational activity. The EACCME credit system is based on 1 ECMEC per hour with a maximum of 3 ECMECs for half a day and 6 ECMECs for a full-day event.

\section{American accreditation}

EACCME credits are recognised by the American Medical Association towards the Physician's Recognition Award (PRA). To convert EACCME credit to AMA PRA category 1 credit, contact the AMA.

\section{Objectives}

The joint meeting of the societies of paediatric radiology takes place every 5 years, and in 2011 is held in London, United Kingdom. The programme comprises a combination of specialist courses, interactive sessions and state-of-the-art plenary sessions as well as hands-on workshops. The meeting is designed for radiologists, radiographers, physicians, cardiologists and other specialists with an interest in paediatric medical imaging.

The event will cover all aspects of paediatric imaging and combine a diverse range of teaching methods by international experts. Pathology, clinical applications, radiation protection and safety issues will be highlighted by multidisciplinary teams of international experts. In addition there will be a series of sunrise sessions each morning for small groups to work with experts in their chosen field. The event will be evaluated using an online evaluation system.

\section{Disclosure}

The scientific presenters and faculty members of the 2011 International Paediatric Radiology Congress listed below have indicated that they have no relevant financial relationships or potential conflicts of interest related to the material presented. They also do not intend to discuss the use of a medical device or pharmaceutical that is classified by the FDA as investigational for the intended use or that is "off label" e.g. a use not described on the product label.

Hamzaini Abdul Hamid
Roberto Accorsi
Afshin Alavi
Marianne Alison
Torre Andrews
Savaas Andronikou
Mehrak Anooshiravani
Evelyn Anthony
Sudha A. Anupindi
Peter Armstrong
Owen Arthurs
Omolola Atalbi
Freddy Avni
Shivaram Avula
Paul Babyn
Ignasi Barber
Brett Bartz
Anna Ben Ely
Lorenzo Biassoni
Krista Birkemeier
George Bisset
E Springer

Sarah Bixby

Lene Bjerke Laborie

Giles Boland

Phillip Bonhoeffer

Tim Booth

Lise Borgwardt

Peter Brader

Alan Brody

Stephen Brown

Simon Bruce Greenberg

Francis Brunelle

Dorothy Bulas

Patricia Burrows

Anne Marie Cahill

Timothy Cain

Jim Carmichael

Lucia Carpineta

Guilherme Cassia

Frandics Chan

Cyril Chantler

Jean-Francois Chateil 
Gulraiz Chaudry

Kathia Chaumoitre

Kling Chong

Jeanne Chow

Antonio Ciccarone

Chris Clark

Bob Cleveland

Ronald Cohen

Brian Coley

Andrew Cook

Carlo Cosimo Quattrocchi

Alan Craft

Seth Crapp

Stephan D. Voss

Heike Daldrup-Link

Michael D'Alessandro

Pedro Daltro

Alan Daneman

Kassa Darge

Raj Das

Jorge Davila

Vincenza De Iorgi

Charlotte de Lange

Diego de Palma

Maria de Rosario Perez

John Deanfield

Sarah Deitch

Gloria del Pozo Garcia

Eithne DeLappe

Molly Dempsey-Robertson

Jie Deng

Erika Denton

Johnathan Dillman

Michael Ditchfield

Nathan Dobbs

Jim Donaldson

Veronica Donoghue

Andrea Doria

Josée Dubois

Shauna Duigenan

Hal Dunlap

Jerry Dwek

Martin Elliott

Nick Emerson

Ingvild Engesæter

Monica Epelman

Judy Estroff

Frederic Fahey

Ricardo Faingold

Tamara Feygin

Katharine Foster

Richard Fotter

Stephanie Franchi-Abella
Christian Franzius

Seth Friedman

Sam Gambhir

Pilar Garcia-Peña

Catherine Garel

Laurent Garel

Ingmar Gassner

Michael Gee

Michael Gelfand

Babita Ghai

Nadine Girard

Marilyn Goske

Ellen Grant

Frederick Grant

Damien Grattan-Smith

Mary-Louise Greer

Gerald Greil

Trude Gundersen Lehmann

Christine Hall

Katherine Halliday

David Hansell

Laura Hayes

Emma Helm

Wolfgang Hirsch

Frederic Hoffer

Chenn Hoffmann

Mark Hogan

Albert Hsiao

Thierry Huisman

Terry Humphrey

Paul Humphries

Ji Hye Kim

Michael Jackson

Joseph Jacob

Lennart Jans

Diego Jaramillo

Philip John

Neil Johnson

Richard Jones

Chirag Kamal Ahuja

Boaz Karmazyn

Andrea Kassner

Sue Kaste

Christian Kellenberger

Peter Kelly

Paul Kleinman

Beth Kline-Fath

Damjana Kljucevsek

Rajesh Krishnamurthy

David Kushner

Ralph Lachman

Wendy Lam

Henrique Lederman 
Edward Lee

Maya Leitner

Neil Lester

Mike Levin

Yun-jung Lim

Cristina Lo Zupone

Frederick Long

Jovan Lovrenski

Sandra M. Allbery

Shobhit Madan

Jaroslaw Madzik

Nasreen Mahomed

Massoud Majd

Kelley Marshall

Robert Marterer

Carlo Martinoli

Beth McCarville

Adeka McIntosh

Robert C. McKinstry

Jane McMillan

Santiago Medina

Zhu Ming

Susan Morris

Helen Nadel

Rutger A.J. Nievelstein

Katerina Ntoulia

Amaka Offiah

Oystein Olsen

Ella Onikul

Lil-Sophie Ording Muller

Susan Palasis

Harriet Paltiel

Ashok Panigrahy

Danièle Pariente

Marguerite Parisi

Robert Paul Guillerman

Jeannette Perez-Rossello

Phillippe Petit

Thomas Pfluger

Daniel Podberesky

Andrada Popescu

Kathy Pritchard Jones

Ingrid Prosser

Shonit Punwani

John Racadio

Maria Raissaki

Charles Raybaud

Madan Rehani

Michael Riccabona

Luis Rirea Soler

Tim Roberts

Firazia Rodjan

Derek Roebuck
Karen Rosendahl

Andres Rossi

Zinayida Rozhkova

Erika Rubesova

Carol Rumack

Francoise Rypens

Akshay Saxena

Pierre Schmit

Jacques Schnider

Erin Schwartz

Guy Sebag

Neil Sebire

Mike Seed

Michael Seidenbusch

Laureen Sena

Ali Shaibani

Susan Sharp

Dennis Shaw

William Shiels

Manohar Shroff

Marilyn Siegel

Cicero Silva

Natalia Simanovsky

Thomas Slovis

Yulia Smal

Ethan A. Smith

Antonio Soares-Souza

Salil Soman

Erich Sorantin

Michalle Soudack

Michael Steward

Keith Strauss

David Stringer

Peter Strouse

Pia Sundgren

Raymond Sze

Oliver Tann

Andrew Taylor

George Taylor

Rita Teele

Tyler Ternes

Karen Thomas

Jean Tkach

Paolo Toma

Alexander Towbin

Richard Towbin

Donald A. Tracy

Maura Valle

Rick van Rijn

Ildikó Várkonyi

Shreyas Vasanawala

Elida Vazquez

Suzanne Verlhac 


\section{Gilbert Vezina \\ Teresa Victoria \\ Arastoo Vossough \\ Pranav Vyas \\ Colin Wallis \\ Janaka Wansapura \\ Tom Watson \\ Edward Weinberger \\ Sjirk Westra \\ Graham Wilkinson}

\author{
Clemens Wirth \\ Hyun Woo Goo \\ Sheng Xie \\ Yevgeniya Yershova \\ Zhi Yie Judith Tan \\ Shi-Joon Yoo \\ JI Young Kim \\ Xinyu Yuan \\ Xiaowei Zhu
}

The faculty members listed below have disclosed the following relevant financial relationships or potential conflicts of interest. Potential conflicts have been resolved.

\begin{tabular}{|c|c|}
\hline Phillip Bonhoeffer & Medtronic - Fees/Royalties - Consultant \\
\hline & NuMed - Fees - Consultant \\
\hline & Xeltis - Fees - Consultant \\
\hline Richard Fotter & Financial Research Compensation - Independent Research Contractor \\
\hline Sam Gambhir & Arresto - Consultant \\
\hline & Bayer Schering - Grant, Honorarium \\
\hline & Cellsight - Stock, Founder \\
\hline & Centella, Centre for Molecular Imaging India - Advisory Committee Member \\
\hline & Elsevier - Royalties \\
\hline & Endra Inc, Boston, Enlight Inc, Boston - Advisory Board Member, Stock \\
\hline & General Electric - Scientific Advisory Board/ Grant \\
\hline & $\begin{array}{l}\text { Imagin AB; Lumen Therapeutics; MagArray; Visual Sonics/ Sonosite; Reflection Medical } \\
\text { Inc - Scientific Advisory Board/ Stock }\end{array}$ \\
\hline & MDS Nordion - Honorarium \\
\hline & MiLabs; Varian Medical Inc - Scientific Advisory Board \\
\hline & NinePoint Medical Centre, Spectrum Dynamics - Consultant Stock \\
\hline & Prolume - Stock \\
\hline & Schering-Plough - Honorarium, Grant \\
\hline David Hansell & Astra Zeneca - Consulting Fee - Advisory \\
\hline & Boehringer Ingelheim - Consulting Fee - Advisory \\
\hline Wolfgang Hirsch & Support of Bayer-Scherring/Study Gadovist in Children \\
\hline Neil Johnson & Merge/ Amicas - Royalties \\
\hline Santiago Medina & Springer book on Evidence based Imaging - Co Editor - Royalties \\
\hline Helen Nadel & Siemens Canada - Speaker at sponsored symposium - Honorarium \\
\hline Oystein Olsen & Speaker for Guerbert Labratories and Bayer Schering Pharma \\
\hline John Racadio & $\begin{array}{l}\text { Philips Medical Systems Nederland B.V. - Attended Advisory Board Meeting and Speaker - } \\
\text { Travel Expenses }\end{array}$ \\
\hline Michael Riccabona & $\begin{array}{l}\text { GE/Kretz - Honoraria \& Consulting Fees \& Travel - Consultant, Speaking and Teaching } \\
\text { Toshiba - Honoraria \& Travel - Speaking \& Teaching }\end{array}$ \\
\hline Tim Roberts & Siemens Medical Solutions - Honoraria - Speaker \\
\hline & Prism - Stock Option - Consutlant/MAB \\
\hline Carol Rumack & Elsevier - Editor \& Author - Royalties from textbook \\
\hline Guy Sebag & EOS Imaging - Consulting Fee - Research/Consulting/Speaking \\
\hline & Guerbert - Consulting Fee - Research/Consulting/Speaking \\
\hline Marilyn Siegel & Siemens Medical - Travel Reimbursements - Speaking, Teaching. Advisory Committee \\
\hline Andrew Taylor & Siemes Medical Solutions - Research agreement - Academic PI \\
\hline Shreyas Vasanawala & GE Healthcare - Research Grant - Sub-PD/PI \\
\hline
\end{tabular}


The following faculty members have disclosed that they will discuss use of medical device or pharmaceutical that is classified by the Food and Drug Administration as investigational for the intended use:

Peter Brader

Patricia Burrows

Anne Marie Cahill

Timothy Cain

Brian Coley

Richard Fotter

Frederic Hoffer

Christian Kellenberger

Beth McCarville

Ali Shaibani

Andrew Taylor

Suzanne Verlhac

The following faculty members have disclosed that they will discuss or describe, in the educational content, use of medical device or pharmaceutical that is "off-label" e.g. a use not described on the products label:

Peter Brader

Dorothy Bulas

Patricia Burrows

Frandics Chan

Brian Coley

Jim Donaldson

Frederic Hoffer

Rajesh Krishnamurthy

Kelley Marshall

Beth McCarville

Michael Riccabona

Ali Shaibani

Andrew Taylor

\section{General information-European Society of Paediatric Radiology}

\section{Officers 2010-11}

President and General Secretary

Past President

1st Vice President

2nd Vice President

3rd Vice President

Treasurer

Counsellor for Northern Europe

Counsellor for Southern Europe

liaison officer with ESR/other institutions

ESPR Research Lead, ESPR delegate for

ESR Research Committee \& Secretary/

Coordinator for European Excellence

Network on Paediatric Radiology

Research

Pediatric Radiology Managing Editor
Catherine M. Owens (London, UK)

Jean-François Chateil (Bordeaux, France)

Maria Argyropoulou (Ioannina, Greece)

Eva Kis (Budapest, Hungary)

Rutger A.J. Nievelstein (Utrecht, Netherlands)

Catherine Adamsbaum (Paris, France)

Veronica Donoghue (Dublin, Ireland)

Paolo Tomà (Roma, Italy)

Freddy Avni (Brussels, Belgium)

Richard Fotter (Graz, Austria)

Guy Sebag (Paris, France) 
JESPeR delegate

Webmasters

Executive Assistant

Secretariat
Samuel Stafrace (Aberdeen, UK)

Rick Van Rijn (Amsterdam, Netherlands)

Jean-François Chateil (Bordeaux, France)

Amanda Dehaye (Paris, France)

Catherine M Owens

Department of Radiology

Great Ormond Street Hospital for Children, Great Ormond Street - London WC1N 3JH, UK

\section{Scientific committee IPR 2011}

Øystein E. Olsen (chair), Laurence Abernethy, Freddy Avni, Lorenzo Biassoni, Peter Brader, Jean-François Chateil, Marina Easty, Katharine Foster, Pilar Garcia-Peña, Catherine Garel, Luisa Lobo, Christian Kellenberger, Amaka Offiah, Lil-Sofie Ording-Müller, Annie Paterson, Michael Riccabona, Derek Roebuk, Karen Rosendahl, Andrea Rossi, Paolo Toma, Andrew Taylor, Paolo Toma, Andrew Watt

\section{Honorary members}

1964 John Caffey (USA)

1964 Lutz Schall (Germany)

1965 Sven R. Kjelberg (Sweden)

1965 Edward B. D. Neuhauser (USA)

1966 Jacques Lefebre (France)

1973 Hardy M. Geffert (Hungary)

1973 Ksawery Rowinsky (Poland)

1974 Frederic Silverman (USA)

1975 Ulf G. Rudhe (Sweden)

1979 John Kirkpatrick (USA)

1979 Arnold Lassrich (Germany)

1979 Jacques Sauvegrain (France)

1982 Clement Fauré (France)

1982 Andes Giedion (Switzerland)

1983 Eberhard Willich (Germany)

1984 Roy Astley (England)

1987 Jean Bennet (France)

1987 Ole Eklof (Sweden)

1987 Charles A. Gooding (USA)

1987 John Holt (USA)

1987 Andrew Poznanski (USA)

1987 D.C. Harwood-Nash (USA)

1987 Hooshang Taybi (USA)

1988 Herbert Kaufmann (Germany)

1989 Bryan Cremin (South Africa)

1989 Klaus D. Ebel (Germany)

1989 Helmut Fendel (Germany)

1989 Elizabeth Sweet (Scotland)

1990 Donald Kirks (USA)

1991 Alan Chrispin (England)

1991 Edmund Franken (USA)

1991 Daniel Nussle (Switzerland)

1991 Beverly Wood (USA)

1992 Walter Berdon (USA)

1993 Javier Lucaya (Spain)
1993 Wilhelm Holthusen (Germany)

1994 Noemie Perlmutter (Belgium)

1994 Hans Ringertz (Sweden)

1994 Donald Shaw (England)

1996 Robert Lebowitz (USA)

1996 Bela Lombay (Hungary)

1997 Yan Briand (France)

1997 Philip Small (England)

1997 N. Thorne Griscom (USA)

1998 Alan Daneman (Canada)

1998 Gabriel Kalifa (France)

1999 Michael Grunebaum (Israel)

1999 Paul Thomas (Ireland)

2000 Noel Blake (Ireland)

2000 Peter Kramer (Netherlands)

2000 Gunnar Stake (Norway)

2001 Janet Strife (USA)

2001 Robert Brasch (USA)

2001 Max Hassan (France)

2001 Yacob Bar-Ziv (Israel)

2002 Sven Laurin (Sweden)

2003 Aldo Pelizza (Italy)

2003 Giampiero Beluffi (Italy)

2003 Helen Carty (England)

2003 Bruce Parker (USA)

2004 Christine Hall (England)

2004 Andrzej Marcinski (Poland)

2005 Ulrich Willi (Switerland)

2005 Jean-Philippe Montagne (France

2005 Giuseppe Farielo (Italy)

2006 Francis Brunelle (France)

2006 Laurent Garel (Canada)

2006 Morteza Meradji (Netherlands)

2006 Alan E. Oestreich (USA)

2007 Marianne Spehl (Belgium) 
2007 Gabriel Benz-Bohm (Germany)

2007 Pedro Daltro (Brazil)

2007 Richard Fotter (Austria)

2008 Jose Fonseca-Santos (Portugal)

2008 Ingmar Gassner (Austria)

2008 Tom Slovis USA)

2008 Rita Teele (New Zealand)

2009 Reinhart Schumacher (Germany)

2009 Nicholas. Gourtsoyiannis (Greece)

2009 Ines Boechat (USA)

2009 Steve Chapman (United Kingdom)
2009 Jochen Troeger (German)

2009 Ernst Richter (Germany)2009

2010 Veronica Donoghue (Ireland)

2010 Freddy Avni (Belgium)

2010 François Diard (France)

2010 Paolo Toma (Italy)

\section{Gold medallists}

2007 Javier Lucaya (Spain)

2008 Gabriel Kalifa (France)

2010 Ulrich Willi (Switzerland)

\section{Jacques Lefebvre awards}

1977 Ringertz H. (Sweden)

1978 Garel L. (France)

1979 Brauner M. (France)

1980 Spehl-Robberech M. (Belgium)

1981 Garel L. (France)

1982 Couture A. (France)

1983 Brunelle F. (France)

1984 Veyrac C. (France)

1985 Avni F. (Belgium)

1986 Pariente D. (France)

1987 Sellier N. (France)

1988 Deeg K. H. (Germany)

1989 Winkler P. (Germany)

1990 Garel C. (France)

1991 Pracros J. P. (France)

1992 Hollman A. (UK)

1993 Chami M. (France)

1994 Adamsbaum C. (France)

1995 Sebag G. (France)

1996 Rohrschneider W. (Germany)

1997 Hertz-Pannier L. (France)

1998 Nicaise N. (Belgium)

1999 Rypens F. (Belgium)

2000 Ziereisen F. (Belgium)

2001 Lidegran M.K (Sweden)

2002 Cassart M. (Belgium)

2003 Boddaert N. (France)

2004 Jourdan C. (Germany)

2005 Kellenberger C.J. (Switzerland)

2006 Phalla O. (France)
The width of cranial sutures in neonates: an objective method of assessment.

Xanthogranulomatous pyelonephritis in children: 19 cases

Metrizamide myelography in infants with brain injury to the brachial plexus

Ultrasonic study of the pancreas in cystic fibrosis

The renal sinus: an important anatomical landmark in children

Ultrasonographic exploration of cerebral malformations

Percutaneous cholecystography in children

Ultrasound of normal and pathologic choroid plexus

Ultrasonic demonstration of abnormal and atypical gallbladder content in newborns

Biliary tract involvement in children with Langerhans cell Histiocytosis

Focal cortical dysplasia: a rare cause of epilepsy

Pulsed Doppler sonographic measurement of normal values for the flow velocities in cerebral arteries of healthy infants

Major pitfalls in the Doppler examination of cerebral vascular system

Laryngeal ultrasonographic study in infants and children. Pathological findings

Systemic study of superior mesenteric vessels in abdominal ultrasound

Colour Doppler imaging of the acute paediatric scrotum

Ultrasound contribution in the analysis of the newborn infant normal foot and club foot: preliminary study

Vermian agenesis without posterior fossa cyst

Magnetic resonance angiography of paediatric renal transplants with quantification of allograft blood flow

US, CT and MR imaging. Characteristics in nephroblastomatosis: evaluation of 23 Patients

Non-invasive preoperative motor mapping in children with brain functional MRI

Dynamic Gd-DTPA-enhanced T1W turbo field echo imaging: Interest in paediatric renal evaluation

Fetal lung volume estimation by MRI: normal values and potential use

Doppler assessment of pulsatility index (PI) of the uterine artery in girls around puberty

MRI and echocardiography in assessment of ventricular function in atrially corrected transposition of the great arteries

The assessment of fetal uronephropathies by MR imaging

18F-Fluoro-L-Dopa PET scan of focal forms of hyerinsulinism of infancy

US evaluation of intima-media thickness (IMT) and elastic properties distensibility, stiffness and incremental modulus of elasticity of the common carotid artery as a marker of early vascular damage in children with chronic renal failure and reference values.

Cardiovascular MRI for investigating Newborns and Infants with Congenital Heart Disease.

Detection of coronary complications after arterial switch operation for transposition of the great arteries: first experience with 65 -slice CT in children 
2007 Sporcq C. (Belgium)

2008 Damasio M. B. (Italy)

2009 McDonald K. (UK)

2010 Ording-Müller L.S. (Norway)

\section{Poster awards}

1994 Gomes H. (France)

1995 Schmit P. (France)

1997 Schmit P. (France)

1998 Brisse H. (France)

2000 Valle M. (Italy)

2001 Rohrschneider W. K (Germany)

2002 Owens C.M (UK)

2003 Schumacher R. (Germany)

2004 Mentzel H.-J. (Germany)

2005 Enriquez G (Spain)

2006 de Maupeou F. (France)

2007 Punwani S. (UK)

2008 Chateil J.-F. (France)

2009 Barez MG. (Spain)

2010 Brun M. (France)

\section{Young researcher awards}

2003 Brun M. (France)

2004 Barnacle A.B (UK)

2005 Raissiki M. (Greece)

2006 Sorge I. (Germany)

2007 Alison M. (France)

2008 Herrmann J (Germany)

2010 Arthurs O. (U.K.)

\section{President's awards}

2004 Kilian A.K. (Germany)

2005 Larke A. (Ireland)

2007 Duran C. (Spain)

2008 Calder A. (UK)

2009 Senocak E. (Turkey)

2010 Franchi-Abella S. (France)
Reappraisal of the sonographic characteristics of the fetal and newborn kidney: introducing the cortico-medullary ratio

Which is the best imaging modality to capture bone erosions in juvenile idiopathic arthritis?

DWI to assess chemotherapy response in solid tumors

Development of the wrist. Normal standards based on MRI for 6-15 year old

Neonatal hip sonography from anatomy to sonography

Imaging of cystic mesenchymal hamartomas of the liver. Review of 13 patients

Congenital hepatic vascular malformations in children

In utero MRI. Normal gyral development of the human brain

High-frequency ultrasound detection of the brachial plexus in newborns and infants

Static dynamic MR-urography - simultaneous morphological and functional evaluation of the urinary tract

The utility of MRI in the assessment of symptomatic adenoidal hypertrophy and rhinosinusitis in children. pre and post medical therapy

Sonographical anatomy of the anal sphincter complex (ASC) and levator ani muscle in neonates and infants

Comparison of whole body STIR MRI and ${ }^{99 \mathrm{~m}}$ Tc-methylene diphosphonate scintigraphy in the examination of children with suspected multifocal bone lesions

Prenatal assessment of lung hypoplasia in congenital diaphragmatic hernia: correlation between volumetric MRI and biometric ultrasound measurements

Whole body imaging in malignant bone tumours in children: preliminary results

Effects of reducing radiation dose on lung nodule detection

Imaging of acquired spinal cord lesions and spinal canal pathology in children

Spectrum of imaging findings in the brachial apparatus anomalies

Diffusion tension imaging in attention deficit disorders in children treated for posterior forsa tumours: preliminary results

Phonological Decoding in Dyslexic Children: Activation Pattern of FMRI

Image-guided percutaneous biopsy of soft tissue masses in children

Eye-lens Bismuth Shielding in Pediatric Head CT Examinations

Reduction of radiotherapy in children with early stages of Hodgkin's lymphoma, influenced by a new imaging and FDG-PET based strategy

In vivo targeting of macrophagic activity with MRI contrast agent (USPIO) in an experimental model of neonatal brain lesions

Capsular arterial collateralisation after paediatric liver transplantation

MR Voiding cystourethrography for vesico-ureteric reflux in unsedated infants

Prenatal magnetic resonance (MR) lung volumetry of congenital diaphragmatic hernia (CDH): comparison with the clinical outcome and the necessity of extracorporeal membrane oxygenation (ECMO)

MRI findings as an indication of underlying genetic lesions in congenital malformations of the brain

Voiding cystosonography for the study of the urethra

Computed tomography compared with ultrasound and chest radiography in children with pleural empyema

MRI and DWI findings in children with hemophagocytic lymphohistiocytosis: tendency for symmetricity

Congenital portosystemic shunt: complications and outcome after closure: about 19 pediatric cases 


\section{Past presidents and meeting sites}

1964 Jacques Lefebvre, Paris, France

1965 Ulf Rudhe, Stockholm. Sweden

1966 John Sutcliffe, London, England

1967 Herbert Kaufmann, Basel, Switzerland

1968 Arnold Lassrich, Hamburg, Germany

1969 Ksawery Rowinsky, Warsaw, Poland

1970 Guido Lannacone, Rome, Italy

1971 Gregers Rhomsen, Copenhagen, Denmark

1972 Jacques Sauvegrain, Paris, France

1973 Roy Astley, Birmingham, UK

1974 Per-Erik Heikel, Helsinki, Finland

1975 Klaus Knapp, Madrid, Spain

1976 Ole Eklof, Stockholm, Sweden

1977 Andreas Geidion, Lucerne, Switzerland

1978 Noemi Perlemutter-Cremer, Brussels, Belgium

1979 Klaus Dieter Ebel, Koln, Germany

1980 The Dutch Group of Paediatric Radiologists, The Hague, Netherlands

1981 Gunnar Stake, Oslo, Norway

1982 Antonin Rubin, Prague, Czechoslovakia

1983 Clement Fauré, Paris, France

1984 Gianfranco Vichi, Florence, Italy

1985 Elizabeth Sweet, Glasgow, Scotland

1986 Javier Lucaya, Barcelona, Spain

1987 Denis Lallemand (ESPR) and Derek Harwood-Nash (SPR) Toronto, Canada

1988 Daniel Nussle, Montreux, Switzerland

1989 Noel Blake, Dublin, Ireland

1990 Helmut Fendel, Munich, Germany

1991 Hans Ringertz (ESPR) and Donald Kirks (SPR), Stockholm, Sweden

1992 Bela Lombay, Budapest, Hungary

1993 Donald Shaw, London, UK

1994 Fred Avni, Brussels, Belgium

1995 Peter Kramer, Utrecht, Netherlands

1996 Paul Thomas (ESPR) and Kenneth Fellows (SPR), Boston, USA

1997 Ulrich Willi, Lugano, Switzerland

1998 Basilos Theodoropoulos, Rhodes, Greece

1999 Jacob Bar-Ziv and Gabriel Kalifa, Jerusalem, Israel
2000 Jose Fonseca Santos, Lisbon, Portugal

2001 Francis Brunelle (ESPR) and Janet Strife (SPR), Paris, France

2002 Tore Nordshus, Bergen, Norway

2003 Paolo Tomà, Genoa, Italy

2004 Jochen Troeger, Heidelberg, Germany

2005 Veronica Donoghue, Dublin, Ireland

2006 Richard Fotter (ESPR) and George Taylor (SPR), Montreal, Canada

2007 Goya Enriquez, Barcelona, Spain

2008 Stephen Chapman, Edinburgh, UK

2009 Mithat Haliloglu, Istanbul, Turkey

2010 Jean-François Chateil, Bordeaux, France

\section{Future meetings}

2012 Athens, Greece, 28 May-1 June

2013 Budapest, Hungary, 3-7 June

2014 Amsterdam, the Netherlands

\section{European Courses of Paediatric Radiology (ECPR)}

1992 F. Brunelle, Biarritz, France

1993 P. Tomà, Genoa, Italy

1994 G. Enriquez, Barcelona, Spain

1995 C. Raybaud, Marseille, France

1996 G. Benz-Bohm, Koln, Germany

1997 H. Carty, Liverpool, UK

1998 C. Adamsbaun, G. Sebag, Montpellier, France

1999 P. Tortori-Donati, Genoa, Italy

2000 R. Fotter, Graz, Austria

2001 S. Laurin, Lund, Sweden

2002 B. Lombay, Budapest, Hungary

2003 E. Martin-Fiori, T Huisman, Zurich, Switzerland

2004 T. Berrocal, Madrid, Spain

2005 M. Spehl, C. Christophe, Brussels, Belgium

2006 J.-N. Dacher, Rouen, France

2007 R. Schumacher, Mainz, Germany

2008 K. Chong, London, UK

2009 R. R. van Rijn, Amsterdam, Netherlands

2010 C. Fonda, Firenze, Italy

2011 I. Barber, Spain 


\section{ESPR 2011 Gold Medallist}

The ESPR gold medal is an exceptional award recently instituted to recognise a lifetime's work and outstanding achievements in paediatric radiology in Europe. This year's award will be presented to Professor Richard Fotter (Austria).

\section{Professor Dr. Richard Fotter, Austria}

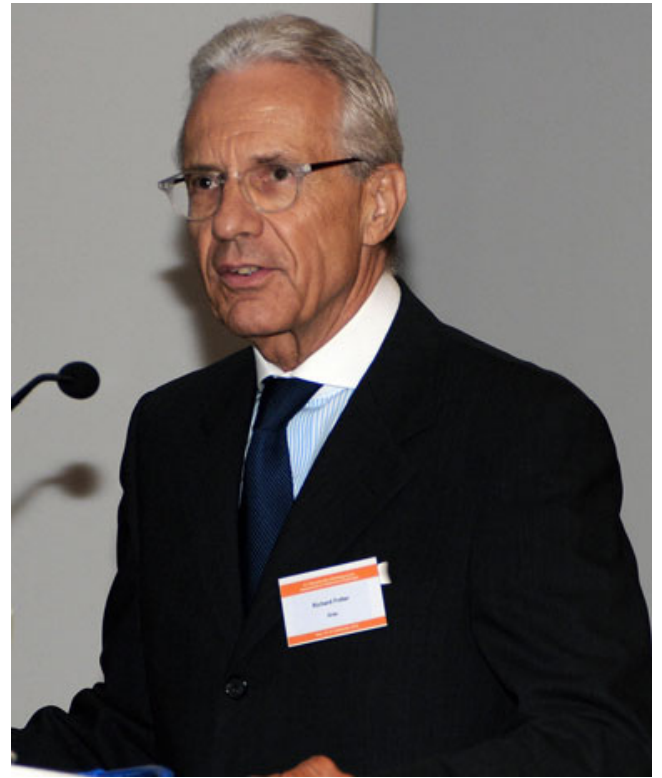

Richard Fotter graduated in medicine from the KarlFranzens-Universität, Graz, Austria, in 1973, and continued his training in pathology, internal medicine and paediatric surgery until 1976. He went on to train in radiology in Graz (1976-1980) and in paediatric radiology in Graz and Germany (1978-1982).

He became Assistant Professor in 1982, Associate Professor in 1987 and Full Professor in 1993.

He has been Professor and Chairman of the Department of Radiology, Graz, and Head of the Clinical Division of Paediatric Radiology from 1994 to date.

Prof. Fotter attended his first ESPR meeting in Florence in 1984, and established the Austrian Society of Pediatric Radiology in 1989, acting as Chairman 1989-2008.

He co-organised the Annual Meeting of the German Speaking Society of Paediatric Radiology (GPR) in Graz 1985, and was ECPR organiser in 2000, and a member of the Paediatric Radiology Subcommittee of the ECR in 2002, Paediatric Radiology Subcommittee Chairman at ECR in 2003 and Categorical Course Paediatric Radiology Organiser at ECR in 2004. Prof. Fotter also organised (with
Prof. Fred Avni) the congress "Reorientation and Future Trends in Paediatric Uroradiology" in Graz 2002. He coorganised the Annual Meetings of the Austrian Society of Pediatric Radiology in Salzburg and Graz from 1998 to 2011 and was ESPR President of the very successful IPRmeeting in Montreal 2006. He organised the 47th International Annual Meeting of the German Speaking Society of Paediatric Radiology (GPR) in Graz 2010.

Other roles Prof. Fotter has assumed include research lead for ESPR, and ESPR representative on the ESR Research Committee since 2006. He set up the European Excellence Network in Paediatric Radiology Research, which he has coordinated since 2007. He also helped set up ESPR task forces on CT-dose and molecular imaging/multi-modality imaging. He has been a research adviser at the Joanneum Research-Centre for Economic and Innovation Research 2005-2011 and editor, author and co-author of Paediatric Uroradiology (Springer Verlag, first edition 2008).

Richard Fotter is a member of the Skeletal Society, ESUR, ESR, RSNA, GPR, DRG and ÖRG, and corresponding member of the Austrian Society of Paediatric Surgery. He became Honorary Member of the ESPR in 2007, and an Honorary Member of the German Speaking Society of Paediatric Radiology (GPR) in 2010.

He has produced over 150 peer-reviewed publications and 50 book chapters, and has a particular interest in paediatric uro-radiology, paediatric skeletal radiology and CT-technique/CT-dose and concepts and strategies to improve paediatric radiology research at a European level. He is a member of the editorial boards of Pediatric Radiology, Der Radiologe, European Radiology, and of Encyclopedia of Diagnostic Imaging (2008).

Richard is happily married to Karin and has two daughters and a grandson, Ferdinand. His non-professional interests include travelling, sport (cycling, skiing), photography, his family and his much beloved dog, Leopold, a Cavalier King Charles Spaniel.

$\mathrm{He}$ is also a keen motorcyclist, and travels around Europe, particularly Italy, enjoying the spectacular beauty and culture of this country, which he and Karin love.

Richard Fotter's life has been dedicated to excellence within his chosen field of academic paediatric radiology, which he has pursued with tireless energy, enthusiasm and infectious zeal. His superb leadership skills are apparent in the Graz University Radiology department, where he has led one of the most outstanding units in Europe, focusing on the development of new technologies and their timely implementation into clinical practice, such as molecular imaging and developments of safe low-dose techniques for paediatric CT. His esteemed colleagues and superb equip- 
ment are a testament to his hard work. He is a true visionary and a wise statesman.

We applaud and thank him for his example and inspiration to us all, as a most deserving recipient of this ESPR gold medal, for a lifetime's work, dedication and outstanding achievements within Paediatric Radiology.

Catherine M. Owens

\section{ESPR 2011 Honorary Members}

\section{Dr. Rose De Bruyn (United Kingdom)}

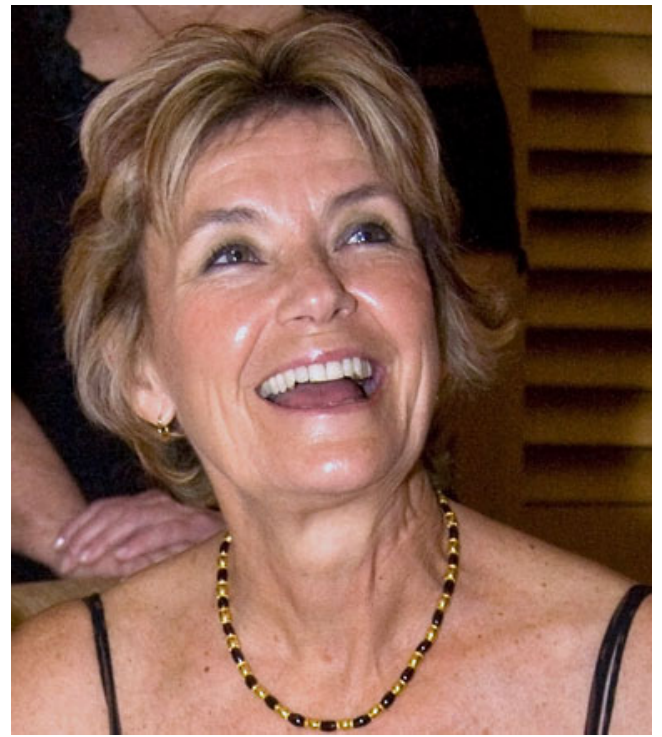

Dr. Rosalie De Bruyn was born in Johannesburg, South Africa, choosing medicine as her career, over ballet dancing (which was her other great talent and love). She spent her medical student elective with Ian Donald in Edinburgh, Scotland - one of the early pioneers of medical ultrasound, becoming inspired in this 'new' imaging technique.

Rose returned to South Africa and qualified in medicine from the University of the Witwatersrand in 1973 and (with her newly acquired husband Eric) she travelled through Europe in a camper van. Fortunately for us they decided to settle in the United Kingdom, where Rose trained in radiology at Westminster Hospital, London, under Dr. Jo Gleeson, an inspirational teacher. She was a popular resident and was awarded the Fellowship of the Royal College of Radiologists London in 1980.

Rose was appointed consultant radiologist and lead consultant in ultrasound in 1982 to Great Ormond Street Hospital for Children, London and attended her first ESPR meeting in Florence 1983.

She was a member of organising committee of the ESPR London 1993 with Dr. Donald Shaw as President, a member of the scientific committee at Euroson, Edinburgh in 2001, and editor of Ultrasound 2005-2008 (the journal of the British Medical Ultrasound Society).
Rose has 53 publications in peer-reviewed journals and has written 18 book chapters. She is primary author and editor of the very popular and much lauded textbook Paediatric Ultrasound-How, why and when (Elsevier, translated into French and Turkish).

She is a popular and regularly invited speaker at national and international meetings.

Under Rose's unassuming persona, is the lynch pin of selfless leadership, superb organisational skills and steely determination. Her role in the development of a world class radiology and ultrasound department at Great Ormond Street Hospital, London, remains as Rose herself, subtle, understated, but crucial to the heart of effective team working and accomplishment. With her charm and hard work she promoted and led the acceptance and full engagement of paediatric radiologists to the adult ultrasound world in the UK.

Her recent retirement from radiology has left a void which will be difficult to fill, as she is unique. However, Rose always maintains the best work life balance, so has her family and friends, and a very exciting retirement has been organised, planned and is now well under way.

Catherine M. Owens

\section{Dr. Goya Enriquez (Spain)}

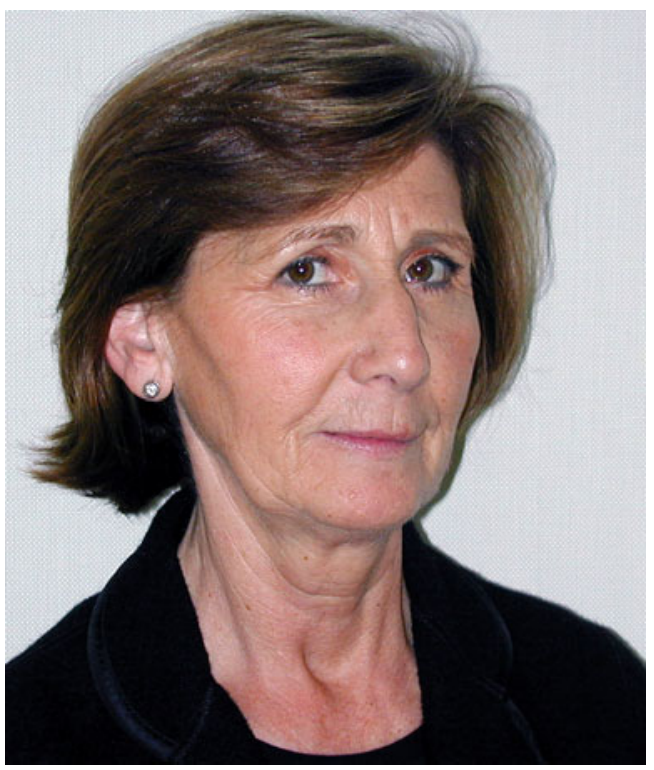

Dr. Goya Enriquez went to medical school at Salamanca University. She then specialised in paediatric radiology at The Children's Hospital, Vall d'Hebron, Barcelona under the mentorship of Dr. Javier Lucaya.

In the early 1980s, she set up the ultrasound unit, and ultrasound has since been her main priority and passion. She spent elective periods at the Hôpital Arnaud-de-Villeneuve in Montpellier, France, and at the Children's Hospital of Cincinnati, Ohio, furthering her training in ultrasound with 
Dr. Couture and Dr. Babcock, respectively. Since 2005, Dr. Enriquez has been head of the Paediatric Radiology department at the Children's Hospital, Vall d'Hebron.

Dr Enriquez attended her first ESPR meeting in Madrid, 1975. She was the scientific secretary of the annual European meeting on Paediatric Radiology, Barcelona in 1986 and chairman of the scientific committee for paediatric radiology of the ECR in 1993 and 1994. She organised the very successful ECPR meeting on Paediatric Chest in Barcelona, 1996, and was president of the ESPR and organiser of the annual meeting in Barcelona in 2007.

She has delivered more than 150 lectures at national and international congresses and written more than 90 peerreviewed publications and 9 book chapters. She has been a peer-reviewer of Eurorad for 10 years, and for AJR. Dr. Enriquez is also a research collaborator in several high-profile European projects.

Goya has an ability to do everything she does with style, sophistication and great attention to detail, and the results are outstanding. Despite all of her professional achievements, she is the centre of a very happy and successful family. Her husband Dr. Jose Nieto (a highly respected Paediatric nephrologist) and her daughter (a successful lawyer) and son (an ophthalmologist) benefit from her superb organisational skills and great sense of humour. Her non-professional interests include sports, and travelling with family and friends. Goya is a wonderful example of successful work life balance and a pioneering role model to women in medicine. We are proud and happy to have her as an officer and honorary member of ESPR!

Catherine M. Owens

\section{Dr. Cristian Garcia, MD (Chile)}

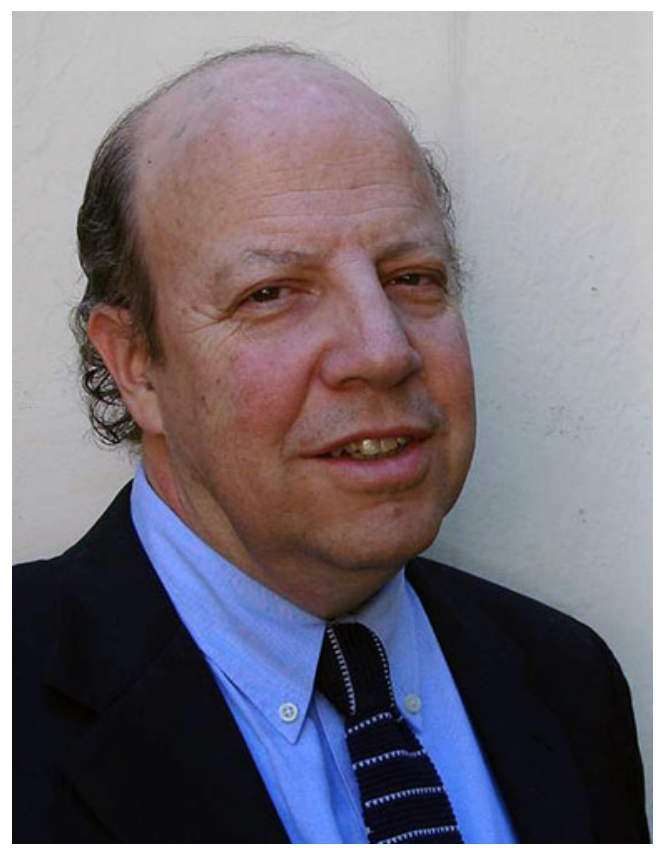

Dr. Cristian Garcia studied medicine at the Catholic University School of Medicine, Santiago, Chile, where he has remained. After his graduation in 1979 and a residency in diagnostic radiology, Dr. Garcia was appointed radiology programme director, radiology departmental chairman and professor of radiology and paediatrics (current post).

His post-graduate training included a fellowship in padiatric radiology at Yale University, School of Medicine, Connecticut, United States, a visiting fellowship in the Department of Radiology at the Hospital for Sick Children, Toronto, Canada and postgraduate diplomas in medical education and bioethics (Dr. Garcia's areas of special interest).

At the Catholic University School of Medicine, Dr. Garcia teaches undergraduate radiology, the history of medicine, and the philosophical basis for medicine. $\mathrm{He}$ also teaches postgraduate students: residents in radiology, paediatrics, paediatric nephrology, paediatric pulmonology, paediatric endocrinology, paediatric oncology and paediatric intensive care.

Dr. Garcia is a member of the Society for Paediatric Radiology (Honorary Member since 2009), the European Society for Paediatric Radiology, and the Latin American Society for Pediatric Radiology (SLARP; president 19981999 and 2006-2007, vice president 1997-1998, general secretary 2000-2003 and an honorary member since 2006 . He is a member of the Chilean Society of Radiology (vice president 1995-1996), the Chilean Society of Paediatrics, the Inter-American College of Radiology, and the Association of University Radiologists.

He has published 184 papers nationally, 35 internationally, and has written 18 book chapters. He has presented and exhibited his work world wide and is a much beloved guest on the international lecture circuit. His teaching and work have won him a number of awards. Dr. Garcia is on the editorial boards of Pediatría al Día, the Chilean Journal of Respiratory Diseases, and the Chilean Journal of Pediatrics. Cristian Garcia is an exceptional person who has dedicated his life to the pursuit and advancement of children's imaging. He is also a loving husband, father, and a witty and charming man. Alongside his passionate colleagues in SLARP, he is responsible for putting children's imaging in Chile and South America on the world map for us all to applaud.

Catherine M. Owens 


\section{Dr. Paul Kleinman, MD (USA)}

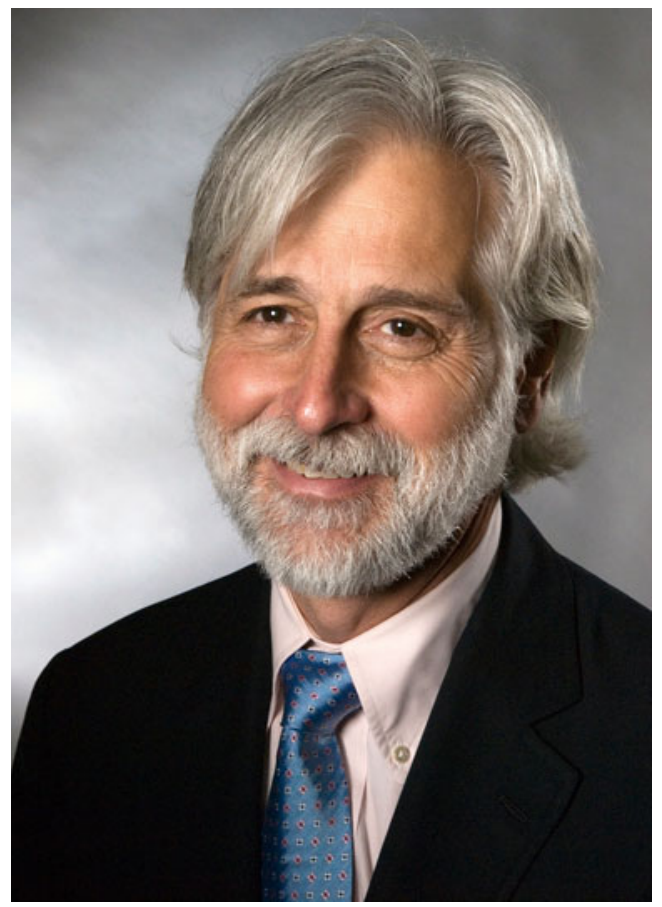

Paul Kleinman was born in upstate New York and thankfully ignored some of his somewhat deluded teachers who urged him (as a consequence of his self confessed unruly and rebellious nature) to avoid scholarly pursuits and simply enter the family business! True to spirit he proved them wrong, ignored their misguided advice and pursued a career in medicine. Whilst working as an x-ray assistant during college summers, he resolved that he did not want to become a radiologist. So he initially chose a career in academic paediatrics. However, his exposure to Dr. Jack O'Connor at Boston City Hospital, inspired him pursue paediatric radiology, following his residency in paediatric medicine.

The fact that this was the perfect choice has been validated by his happy and fulfilling 20-year tenure at the University of Massachusetts Medical Center, Worcester, Massachusetts. His passion for paediatric radiology, in particular imaging of child abuse, has been balanced with the many exquisite pleasures of New England life.

A sample of Paul's extensive academic appointments include: assistant, then associate clinical professor of radiology, Georgetown University School of Medicine, Washington, D.C. (1977), assistant professor of radiology and paediatrics, University of Massachusetts Medical School, Worcester, Massachusetts (1978-1980), professor of radiology and paediatrics, University of Massachusetts Medical School, Worcester, Massachusetts (1980-1987), professor of radiology and pediatrics and adjunct professor of radiology, University of Massachusetts Medical School,
Worcester, Massachusetts (1987-2002), and professor of radiology, Harvard Medical School, Boston, Massachusetts (2002). Examples of his hospital or affiliated institution appointments include staff radiologist, Department of Radiology, National Naval Medical Center, Bethesda, Maryland (1976-1978), director of paediatric radiology, Department of Radiology, University of Massachusetts Medical Center, Worcester, Massachusetts (1978-2001), and section chief, musculoskeletal imaging, Children's Hospital, Boston, Massachusetts (2000).

Paul Kleinman is an active member of many professional societies, including the Society for Pediatric Radiology. He became a member of the European Society of Paediatric Radiology in 1995. He has served on the editorial boards of Clinical Imaging (1990), Clinical Anatomy (1990-1995), Osteologiai Kozlemenyek (Hungary) (1993-2002), Child Abuse Newsletter (1994), Skeletal Radiology (1995-2005), and Pediatric Radiology, Head-Child Abuse Section (19952002), and been a manuscript reviewer for AJR, Archives of Adolescent and Pediatric Medicine, Child Abuse Quarterly Update, Journal of Intensive Care Medicine, Pediatric Radiology, and Skeletal Radiology.

Paul has received numerous awards and honours for his pioneering work, including the Caffey Award for Best Paper, (Society for Pediatric Radiology Boston, Massachusetts 1985), the Presidential Recognition Award (Society for Pediatric Radiology, 2000, and Honorary Membership Argentinean Radiologic Society (1993), the Hungarian Radiologic Society (1994) and Chicago Radiologic Society (1994).

A renowned public speaker, Paul has delivered six eponymous lectures in the USA, the most recent - the Lawrence A. Davis M.D. Memorial Lectureship, Imaging Child Abuse: Current Concepts and Controversies (Kosair Children's Hospital, Louisville, Kentucky 2003). He has been invited to speak on the national and international scientific circuit on 275 occasions. Dr. Kleinman has produced 96 peer-reviewed articles and three superb textbooks and is an examiner with the American Board of Radiology.

With his beloved wife, Patricia, he enjoys sailing and skiing, and both are great opera buffs, and are passionate about the writings of Marcel Proust, the South of France and haute cuisine. Paul and Patricia have two children and two grandchildren. Paul's move to Children's Hospital Boston 10 years ago came with hopes of winding down, but this goal has been deferred indefinitely... Paul has a legendary dry wit and is a charismatic and charming colleague with many anecdotes delivered that are too numerous to record. His courageous dedication to the controversial issues of evidence-base within imaging in child protection, and non-accidental injury have inspired us all, and we are proud to include him as an honorary member of the ESPR.

Catherine M. Owens 


\section{Dr. George Taylor, MD (USA)}

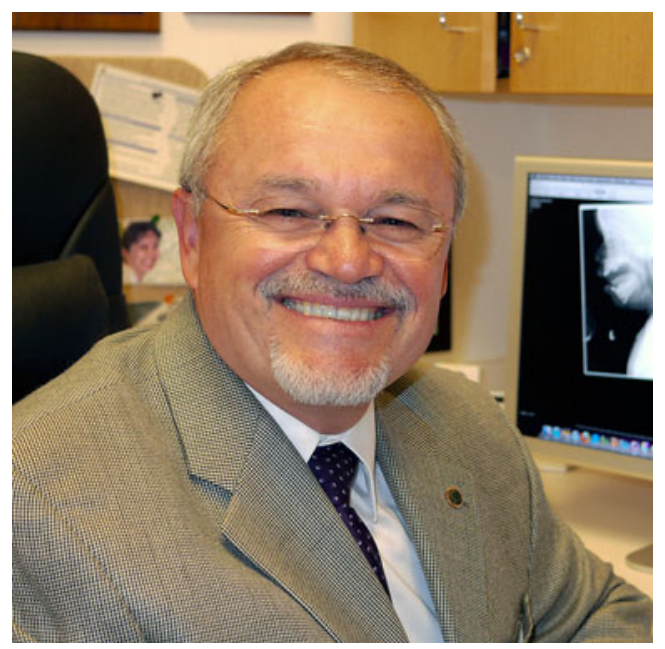

George Taylor has had an exemplary career in radiology as a clinician, scientist and world leader in his subspecialty of paediatric radiology. He graduated with a B.S. (zoology) from George Washington University in 1974, thence an MD (with distinction) from George Washington University School of Medicine in 1978. His post doctoral training included a residency in general paediatrics at the Johns Hopkins Medical Institutions, where he was inspired by imaging, and entered the institutions' residency program in diagnostic radiology. He undertook his fellowship in paediatric radiology at the Children's Hospital Medical Center, Harvard Medical School.

Professor Taylor's exhaustive list of academic appointments includes assistant, Department of Radiology, Harvard Medical School; assistant thence associate professor of radiology and child health and development, George Washington University School of Medicine; associate professor of radiology and paediatrics, The Johns Hopkins University School of Medicine; associate thence full professor of radiology (paediatric), Harvard Medical School; and John A. Kirkpatrick professor of radiology, Harvard Medical School. His hospital appointments have been at the most prestigious United States centres for health, including the Children's National Medical Center, Washington, DC; the Johns Hopkins Hospital, Baltimore, Maryland program in diagnostic medical sonography, the Johns Hopkins Hospital and Essex Community College, Baltimore, Maryland; associate staff, Department of Radiology, Children's Hospital, Boston, Massachusetts; consulting staff, Department of Radiology, Brigham \& Women's
Hospital, Boston, Massachusetts; consulting staff, Department of Radiology, Beth Israel Deaconess Medical Center, Boston, Massachusetts; and radiologist-in-chief, Department of Radiology, Children's Hospital, Boston, Massachusetts (until this year). Other professional positions and major visiting appointments have included consulting research radiologist, Children's Hospital National Medical Center, Washington, DC; consultant radiologist for the newborn vitamin A-project, Dana Center for Preventive Ophthalmology; the Wilmer Eye Institute; The Johns Hopkins School of Public Health; consultant radiologist for the National Institute of Child Health and Development (NICHD) project Impact of maternal lifestyle during pregnancy of acute neonatal events and long-term neuro developmental outcome of infants; consultant radiologist for the American Pediatric Surgical Association Outcomes \& Clinical Trials Center, Renal Injury Expert Panel.

Professor Taylor has been a member of the Society for Pediatric Radiology since 1985, serving in all its prestigious roles, from research committee chair to chairman of the board of directors (1994-1997), and president in 2005-2006. He has been a member of the European Society of Paediatric Radiology since 1991.

He is a superb didactic and much sought after lecturer on the world lecture circuit, which is enhance by his fluency in four languages. He has served on 11 of the most prestigious radiology editorial boards, including Radiology (Associate Editor) and the Journal of Ultrasound in Medicine.

Professor Taylor has the rare and desirable combination of great academic prowess, superb clinical skills and an ability to understand his subject so intimately that his teaching and lecturing talents have placed him at the summit of his profession. His love of imaging has clearly inspired his great talent as a photographer. His extensive collection of photographic images taken on his many travels is truly mesmeric, demonstrating his great skill.

George has balanced leadership, science and medicine with a happy and close family life, despite the recent tragic loss of his much beloved wife of many years, Lydia. Lydia was (in his own words) his best friend, coach, partner, lover and psychiatrist. She died after a long and very courageous battle with cancer, and George remains a loving father to his two children, for whom he is a solid and steadfast example of devotion and love.

We are privileged to include him as an honorary member of the ESPR.

Catherine M. Owens 


\section{General information - The Society for Pediatric Radiology}

\section{Mission statement}

The Society for Pediatric Radiology is dedicated to fostering excellence in pediatric health care through imaging and image-guided care.

\section{Officers, directors and committees 2010-11}

\section{Board of directors}

Neil D. Johnson, MBBS, Chair

Dorothy I. Bulas, MD, President

Donald P. Frush, MD, President-Elect

Sue C. Kaste, DO, 1st VP

Richard A. Barth, MD, 2nd VP

James S. Donaldson, MD, Secretary

Brent H. Adler, MD, Treasurer

Paul S. Babyn, MD

Taylor Chung, MD

Harris L. Cohen, MD

Heike E. Daldrup-Link, MD

Peter J. Strouse, MD

M. Ines Boechat, MD, FACR, ex officio

Christopher I. Cassady, MD, ex officio

Marilyn J. Goske, MD, ex officio

Marta Hernanz-Schulman, MD, ex officio

Thomas L. Slovis, MD, ex officio

Mary R.B. Wyers, MD, ex officio

\author{
Abstract review committee - papers \\ Dorothy I. Bulas, MD, Chair \\ Richard A. Barth, MD \\ Alan S. Brody, MD \\ Taylor Chung, MD \\ Brian D. Coley, MD \\ James S. Donaldson, MD \\ Josee Dubois, MD \\ Donald P. Frush, MD \\ Michael J. Gelfand, MD \\ Thierry A.G.M. Huisman, MD \\ Diego Jaramillo, MD MPH \\ Neil D. Johnson, MBBS \\ Sue C. Kaste, DO \\ Tal Laor, MD \\ Mary Beth McCarville, MD \\ Harriet J. Paltiel, MD \\ Tina Y. Poussaint, MD \\ Thomas L. Slovis, MD
}

\section{Abstract review committee - posters}

Lisa H. Lowe, MD, Chair

Brian D. Coley, MD
Maria S. Figarola, MD

Brenda C. Grabb, MD

Marta Hernanz-Schulman, MD

Neil D. Johnson, MBBS

Nadja Kadom, MD

J Herman Kan, MD

Geetika Khanna, MD

Beth M. Kline-Fath, MD

Joshua Q. Knowlton, MD

Edward Y. Lee, MD MPH

Kay L. North, DO

Daniel J. Podberesky, MD

Avrum N. Pollock, MD

Janet R. Reid, MD

Cynthia K. Rigsby, MD

Douglas C. Rivard, DO

Manrita K. Sidhu, MD

Peter J. Strouse, MD

\section{Bylaws}

Neil D. Johnson, MBBS, Chair

Dorothy I. Bulas, MD

Taylor Chung, MD

Harris L. Cohen, MD

\section{Cardiac imaging committee}

Rajesh Krishnamurthy, MD, Chair

Dianna M. E. Bardo, MD

Kerry A. Bron, MD

Lorna P. Browne, MBBS

S. Bruce Greenberg, MD

Jeffrey C. Hellinger, MD

Randolph K. Otto, MD

Andrada R. Popescu, MD

Cynthia K. Rigsby, MD

Laureen M. Sena, MD

Shreyas S. Vasanawala, MD, PhD

\section{Child abuse committee}

Jeannette M. Perez-Rossello, MD, Chair

Stephen L. Done, MD

Vesna M. Kriss, MD

Tal Laor, MD

Kenneth L. Mendelson, MD

Daniel M. Schwartz, MD

Sabah Servaes, MD

Terry J. Vaccaro, MD

Matthew R. Wanner, MD

Ingrid Holm, MD, ex officio

Carole Jenny, MD, ex officio

Paul K. Kleinman, MD, ex officio

Joelle Moreno, ex officio 


\section{Clinical practices steering committee}

Sue C. Kaste, DO, Chair

Christopher I. Cassady, MD

Judy A. Estroff, MD

Lynn A. Fordham, MD

J. Damien Grattan-Smith, MBBS

Blaise V. Jones, MD

Rajesh Krishnamurthy, MD

Edward Y. Lee, MD MPH

Marguerite T. Parisi, MD MS

Jeannette M. Perez-Rossello, MD

Daniel J. Podberesky, MD

Dennis W.W. Shaw, MD

Michael J. Temple, MD

Sjirk J. Westra, MD

\section{Community hospital-based pediatric radiologists}

Debra J. Pennington, MD, Chair

Amaya Ormazabal, MD Vice Chair

Christopher E. Dory, MD

Maria B. Mata, MD

Maria-Gisela Mercado-Deane, MD

Linnea J. Priest, MD

Michael D. Rubin, MD

\section{CT committee}

Sjirk J. Westra, MD, Chair

Jonathan R. Dillman, MD

Donald P. Frush, MD

Edward Y. Lee, MD MPH

Sabah Servaes, MD

Alexander J. Towbin, MD

\section{Diagnostics committee}

Daniel J. Podberesky, MD, Chair

Karen M. Ayotte, MD

Karen Blumberg, MD

Soni C. Chawla, MD

Marcus M. Kessler, MD

Leann E. Linam, MD

Jeffrey S. Prince, MD

Eva I. Rubio, MD

Linda P. Thomas, MD

Anthony I. Zarka, DO

\section{Fellowship directors}

Jane E. Benson, MD, Chair

Fetal imaging committee

Christopher I. Cassady, MD, Chair

Stephen D. Brown, MD

Dorothy I. Bulas, MD

Maria A. Calvo-Garcia, MD
Lucia Carpineta, MD CM

Lisa R. Delaney, MD

Judy A. Estroff, MD

Hollie A. Jackson, MD

Beth M. Kline-Fath, MD

Ashley J. Robinson, MBChB

\section{Finance committee}

Brent H. Adler, MD, Chair

Richard A. Barth, MD

Dorothy I. Bulas, MD

Molly E. Dempsey-Robertson, MD

Donald P. Frush, MD

Sue C. Kaste, DO

Randheer Shailam, MD

\section{Honors}

Marilyn J. Goske, MD, Chair

M. Ines Boechat, MD FACR

Marta Hernanz-Schulman, MD, FACR

\section{Informatics}

Alexander J. Towbin, MD, Chair

Robert P. Guillerman, MD

Neil D. Johnson, MBBS

Janet R. Reid, MD

Keith S. White, MD

International outreach task force

M. Ines Boechat, MD FACR, Chair

Dorothy I. Bulas, MD

Ronald A. Cohen, MD

James S. Donaldson, MD

Charles A. Gooding, MD

Neil D. Johnson, MBBS

Stuart A. Royal, MS, MD

Interventional radiology committee

Michael J. Temple, MD, Chair

G. Peter Feola, MD

Marc S. Keller, MD

Els Nijs, MD

John M. Racadio, MD

Ashley J. Robinson, MBChB

Dennis W.W. Shaw, MD

Manrita K. Sidhu, MD

Nghia (Jack) Vo, MD

Judiciary committee

Richard B. Gunderman, MD, Chair

Stephen D. Brown, MD

Stuart A. Royal, MS, MD

Charles D. Williams, MD 


\section{MR committee}

J. Damien Grattan-Smith, MBBS, Chair

Sudha A. Anupindi, MD

Lauren W. Averill, MD

Kassa Darge, MD

Kathleen H. Emery, MD

Sabiha P. Karakas, MD

Marcus M. Kessler, MD

Hee-Kyung Kim, MD

Prakash M. Masand, MD

Sheila G. Moore, MD FACR

Neil Vachhani, MD

Shreyas S. Vasanawala, MD PhD

Neuroradiology committee

Blaise V. Jones, MD, Chair

Laura L. Hayes, MD

Thierry A.G.M. Huisman, MD

Nadja Kadom, MD

Ashok Panigrahy, MD

Gaurav Saigal, MBBS

Unni K. Udayasanakar, MD

\section{Newborn imaging committee}

Judy A. Estroff, MD, Chair

Dorothy I. Bulas, MD

Teresa Chapman, MD, MA

Ashok Panigrahy, MD

Richard Parad, MD

Eva I. Rubio, MD

Teresa Victoria, MD

\section{Nominating committee}

Neil D. Johnson, MBBS, Chair

Michael J. Callahan, MD

Steven J. Kraus, MD, MS

Beverley Newman, MD, FACR

Susan Palasis, MD

Avrum N. Pollock, MD

Cynthia K. Rigsby, MD

\section{Nuclear medicine committee}

Marguerite T. Parisi, MD, MS, Chair

Lisa J. States, MD Vice Chair

Larry A. Binkovitz, MD

Ruth Lim, MD

Gerald A. Mandell, MD

Helen R. Nadel, MD, FRCPC

Marla BK Sammer, MD

Susan E. Sharp, MD

Stephanie E. Spottswood, MD, MSPH

Pranav K. Vyas, MD

Sally S. Wildman, DO

J. Brad Wyly, MD
Physician resources committee

Ellen C. Benya, MD, Chair

Rebecca L. Hulett-Bowling, MD

Vesna M. Kriss, MD

Sosamma T. Methratta, MD

Sarah S. Milla, MD

Eva I. Rubio, MD

Publications committee

Ashok Panigrahy, MD, Chair

Johan G. Blickman, MD

Jonathan R. Dillman, MD

James S. Donaldson, MD

Charles M. Glasier, MD

Alexander J. Towbin, MD

Brian D. Coley, MD, ex officio

Neil D. Johnson, MBBS, ex officio

Cynthia K. Rigsby, MD, ex officio

Thomas L. Slovis, MD, ex officio

Peter J. Strouse, MD, ex officio

\section{Representatives}

Sara J. Abramson-Squire, MD, FACR - ACR

Kimberly E. Applegate, MD MS - ACR Council

Steering Committee

Dorothy I. Bulas, MD - ARR

Christopher I. Cassady, MD - AAP

Brian D. Coley, MD - AIUM

Kate A. Feinstein, MD FACR - ACR

Donald P. Frush, MD - ABR

Blaise V. Jones, MD - ASPNR

Carlos J. Sivit, MD - ASER

Richard B. Towbin, MD - ASPNR

SPR research and education foundation

Donald P. Frush, MD, President

Dorothy I. Bulas, MD, Vice President

James S. Donaldson, MD, Secretary

Brent H. Adler, MD, Treasurer

Lisa H. Lowe, MD

William H. McAlister, MD

Ashok Panigrahy, MD

Stuart A. Royal, MS, MD

Beverly P. Wood, MD, MS

\section{Safety committee}

Dennis W.W. Shaw, MD, Chair

Sudha A. Anupindi, MD

Lane F. Donnelly, MD

Donald P. Frush, MD

Marilyn J. Goske, MD

David B. Larson, MD

Robert C. Orth, MD PhD,

Thomas L. Slovis, MD, ex officio 


\section{Structured report committee}

James S. Meyer, MD, Chair

Kimberly E. Applegate, MD, MS

Michael P. D'Alessandro, MD

Robert P. Guillerman, MD

Susan D. John, MD

Neil D. Johnson, MBBS

Ann M. Johnson, MD

Edward Weinberger, MD

\section{Thoracic imaging committee}

Edward Y. Lee, MD MPH, Chair

Alan S. Brody, MD

Robert P. Guillerman, MD

Jeffrey C. Hellinger, MD

Frederick R. Long, MD

Beverley Newman, MD FACR

Sjirk J. Westra, MD

\section{Ultrasound committee}

Lynn A. Fordham, MD, Chair

Richard D. Bellah, MD

Jeanne S. Chow, MD

Jamie L. Coleman, MD

Judy A. Estroff, MD

Boaz Karmazyn, MD

Leann E. Linam, MD

Martha M. Munden, MD

Els Nijs, MD

Sara M. O'Hara, MD

Henrietta K. Rosenberg, MD

Cicero T. Silva, MD

Dayna M. Weinert, MD

Website editorial committee

Mary R.B. Wyers, MD, Chair

Benjamin H. Taragin, MD

\section{Workforce task force}

Lisa H. Lowe, MD, Chair

Dorothy I. Bulas, MD

Donald P. Frush, MD

Robert L. Lorenzo, MD

Philip L. Lund, MD

Kenneth L. Mendelson, MD

Rafael Rivera, MD

Eva I. Rubio, MD

Manrita K. Sidhu, MD

Sonia L. Wright, MD

\section{Gold medallists}

1988 Frederic N. Silverman, MD

1989 John L. Gwinn, MD
1990 John F. Holt, MD

1991 John A. Kirkpatrick, Jr., MD

1991 Bernard J. Reilly, MB, FRCP

1992 Edward B. Singleton, MD

1993 Hooshang Taybi, MD

1994 Walter E. Berdon, MD

1994 J. Scott Dunbar, MD

1995 Guido Currarino, MD

1995 Derek C. HarwoodNash, MD, DSc

1996 Andrew K. Poznanski, MD

1996 Beverly P. Wood, MD

1997 N. Thorne Griscom, MD

1997 John F. O'Connor, MD

1998 William H. McAlister, MD

1999 E. Anthony Franken, MD

2000 Eric L. Effmann, MD

2001 Giulio J. D'Angio, MD

2002 David H. Baker, MD

2003 Brinton B. Gay, Jr., MD

2003 William H. Northway, Jr., MD

2004 Diane S. Babcock, MD

2004 Virgil R. Condon, MD

2005 Jerald P. Kuhn, MD

2005 Thomas L. Slovis, MD

2006 Robert L. Lebowitz, MD

2006 John C. Leonidas, MD

2007 Leonard E. Swischuk, MD

2008 Barry D. Fletcher, MD

2009 Charles A. Gooding, MD

2010 Janet L. Strife, MD

2011 Carol M. Rumack, MD, FACR

\section{Pioneer honourees}

1990 John Caffey, MD

1991 M.H. Wittenborg, MD

1992 Edward B. Singleton, MD

1993 Frederic N. Silverman, MD

1994 John P. Dorst, MD

1995 E.B.D. Neuhauser, MD

1996 Edmund A. Franken, MD

1996 Kazimierz Kozlowski, MD

1996 M. Arnold Lassrich, MD

1997 Arnold Shkolnik, MD

1998 Heidi B. Patriquin, MD

1998 William H. Northway, Jr., MD

2000 Jerald P. Kuhn, MD

2001 Diane S. Babcock

2002 Fred E. Avni, MD, PhD

2003 Walter E. Berdon, MD

2004 G.B. Clifton Harris, MD

2005 Rita L. Teele, MD

2006 Robert L. Lebowitz, MD 
2007 Carol M. Rumack, MD

2008 Paul S. Babyn, MD

2009 Kenneth E. Fellows, MD

2010 David K. Yousefzadeh, MD

2011 Massoud Majd, MD

\section{Presidential recognition awards}

1999 David C. Kushner, MD

2000 Paul K. Kleinman, MD

2001 Neil Johnson, MD

2001 Christopher Johnson

2002 Jennifer K. Boylan

2002 Thomas L. Slovis, MD

2003 Danielle K.B. Boal, MD

2003 Marta Hernanz-Schulman, MD

2004 Kenneth L. Mendelson, MD

2005 Taylor Chung, MD

2005 J. A. Gordon Culham, MD

2005 Shi-Joon Yoo, MD

2006 L. Christopher Foley, MD

2007 Donald P. Frush, MD

2008 Mary K. Martel, PhD

2008 Connie L. Mitchell, MA, RT(R)(CT)

2008 Harvey L. Neiman, MD

2009 Karen S. Schmitt

2010 Richard A. Barth, MD

2011 Kimberly E. Applegate, MD, MS, FACR

2011 Keith J. Strauss, MS, FACR

\section{Honorary members}

1985 Jacques Sauvegrain, MD

1987 Bryan J. Cremin, MD

1987 Ole A. Eklof, MD

1987 Clement C. Faure, MD

1987 Andres Giedion, MD

1987 Denis Lallemand, MD

1987 Arnold Lassrich, MD

1987 Ulf G. Rudhe, MD

1998 Frederic N. Silverman, MD

1989 John L. Gwinn, MD

1990 John F. Holt, MD

1990 Richard G. Lester, MD

1991 Gabriel L. Kalifa, MD

1991 Javier Lucaya, MD

1991 John P. Masel, MD

1991 Noemi PerlmutterCremer, MD

1991 Hans G. Ringertz, MD

1991 John A. Kirkpatrick, Jr., MD

1991 Bernard J. Reilly, MB, FRCP(C)

1992 Edward B. Singleton, MD
1992 Donald R. Kirks, MD

1992 Beverly P. Wood, MD

1993 Hooshang Taybi, MD

1992/94 Walter E. Berdon, MD

1994 Marie A. Capitanio, MD

1994 Edmund A. Franken, Jr., MD

1994 John C. Leonidas, MD

1994 William H. McAlister, MD

1994 Andrew K. Poznanski, MD

1994 J. Scott Dunbar, MD

1995 David H. Baker, MD

1992/95 Derek C. HarwoodNash, MD, DSc

1995 N. Thorne Griscom, MD

1995 Guido Currarino, MD

1996 Francis O. Brunelle, MD

1996 Lloyd L. Morris, MD

1996 Heidi B. Patriquin, MD

1997 John F. O'Connor, MD

1996 Theodore E. Keats, MD

1998 Rita L. Teele, MD

1998 H. Ted Harcke, MD

1999 J. Bruce Beckwith, MD

2000 Joseph Volpe, MD

2001 Ulrich V. Willi, MD

2001 Henrique M. Lederman, MD

2001 Mutsuhisa Fujioka, MD

2002 Eric J. Hall, DSc, FACR, FRCR

2002 Walter Huda, PhD

2003 Michael R. Harrison, MD

2004 Lee F. Rogers, MD

2005 Carden Johnston, MD, FAAP, FRCP

2006 Alan B. Retik, MD

2007 Robert R. Hattery, MD

2008 Professor Hassen A. Gharbi

2009 Dolores Bustelo, MD

2009 Pedro A. Daltro, MD

2009 Cristian Garcia, MD

2009 Antônio Soares de Souza, MD

2010 Stephen Chapman, MD

2011 Catherine M. Owens, MBBS

2011 Madan M. Rehani, PhD

\section{Singleton-Taybi awards}

2006 Corning Benton, Jr., MD

2007 Michael P. D'Alessandro, MD

2007 Janet R. Reid, MD

2008 Dorothy I. Bulas, MD

2009 Lane F. Donnelly, MD

2010 Wilbur L. Smith, Jr., MD

2011 Ralph S. Lachman, MD, FACR 


\section{John A. Kirkpatrick young investigator awards}

This award is given to the author of the best paper presented by a resident or fellow at the SPR meeting. Beginning in 1995, the award became known as the John A. Kirkpatrick Young Investigator Award.

1993 Philippe K. Lang, MD

1993 Stephanie P. Ryan, MD

1994 Sara O’Hara, MD

1995 Philipp K. Lang, MD

1996 Fergus V. Coakley, MB, FRCR

1997 Ronald A. Alberico, MD

1998 Laura J. Varich, MD

1999 A. E. Ensley, BS

1999 R.W. Sze, MD

2000 S. H. Schneider, MD

2001 Valerie L. Ward, MD

2002 Ricardo Faingold, MD

2003 Andrea Doria, MD

2004 Nina M. Menezes, PhD

2005 Lena Naffaa, MD

2006 Courtney A. Coursey, MD

2007 Ashley J. Robinson, MBChB

2008 Hee Kyung Kim, MD

2009 Conor Bogue, MD

2010 Albert Hsiao, MD, PhD

\section{Berdon award - best basic science paper}

2010 Goo HW. Initial experience of dual energy lung perfusion CT using a dual source CT system in children. September, p 1536

\section{Berdon award - best clinical research paper}

2010 Raissaki M, Perisinakis K, Damilakis J, Gourtsoyiannis N. Eye-lens bismuth shielding in pediatric head CT: artifact evaluation and reduction. November, p 1748

For a list of recipients before 2010, please visit the SPR website.

\section{The SPR Research and Education Foundation Awards}

The SPR Research and Education Foundation is dedicated to promoting research and scholarship in pediatric radiology. The SPR Board of Directors has supported research through grants since 1990. The Foundation was established in 1994 with an initial donation from the Society's reserves.

\section{The Jach O. Haller award for excellence in teaching}

2005 Alan Daneman, MD

2006 William R. Cranley, MD and John F. O’Connor, MD
2007 Cindy R. Miller, MD

2008 Sara J. Abramson-Squire, MD

2009 Michael A. DiPietro, MD

2010 George A. Taylor, MD

2011 Paul K. Kleinman, MD

\section{The Heidi Patriquin international fellowship}

2005 Luy Lyda, MD, Angkor Hospital for Children, Siem Reap, Cambodia

2006 Hakima Al-Hashimi, MD Salmaniya Medical Complex, Manama, Bahrain

2006 Pannee Visrutaratna, MD, Chiang Mai University, Chiang Mai,Thailand

2006 Juana Maria Vallejo, MD, Clinica del Country, Bogota, Colombia

2007 Nathan David P. Concepcion, MD, St. Luke's Medical Center, Quezon City, Philippines

2008 Rolando Reyna Lopez, MD, Hospital Santo Tomas, Panama City, Panama

2009 Ahmed Mussa Jusabani, MD, Kilimanjaro Christian Medical Centre, Moshi Town, Tanzania

2010 Omolola Mojisola Atalabi, MD, College of Medicine, University of Ibadan, Nigeria

2011 Kushaljit Singh Sodhi, MD, Post Graduate Institute of Medical Education \& Research, Chandigarh, India

Caffey award for best basic science research paper

2002 Understanding the Functional Angiogenic Process in an Antigen-Induced Arthritis Model: Correlative BOLD MR Imaging (fMRI) of the Stages of Synovitis along the Time Course of the Disease. Doria AS, Babyn PS, Crawley A, Noseworthy M, Pritzker K, Salter RB, et al.

2003 A Novel Method for Non-Viral Gene Therapy: Transcatheter Hydrodynamic Delivery Using Isolated Liver as a Depot Organ in a Rabbit Model. Baskin K, Eastman SJ; Scheule RK; Hodges BL; Chu Qiuming; Towbin RB

2004 Site-Specific Induction of Lymphatic Malformations in a Rat Model for Image-Guided Therapy. Short, R, Shiels, W, Sferra T, Nicol K, Schofield M, Wiet G

2005 Quantitative Measurement of Microbubble Ultrasound Contrast Agent Flow to Assess the Efficacy of Angiogenesis Inhibitors In Vivo. McCarville B, Streck C, Li CS, Davidoff A

$2006{ }^{64} \mathrm{Cu}$-Immuno-PET Imaging of Neuroblastoma with Bioengineered Anti-GD2 Antibodies. Voss SD, Smith SV, DiBartolo NM, McIntosh LJ, Cyr EM, Bonab AA, et. al

2007 MR Imaging of Adenocarcinomas with FolateReceptor Targeted Contrast Agents. Daldrup-Link HE, Wang ZJ, Meier R, Corot C 
2008 Evaluation of Quality Assurance Quality Control Phantom for Digital Neonatal Chest Projection Imaging. Don S.

2009 Faster Pediatric MRI Via Compressed Sensing. Vasanawala S, Alley M, Barth R, Hargreaves B, Pauly J, Lustig M

2010 Clinical Evaluation of Readout-Segmented-EPI for Diffusion-Weighted Imaging - Roland Bammer, $\mathrm{PhD}$, Stanford University, Palo Alto, CA, Samantha J Holdsworth, PhD; Stefan Skare, PhD; Kristen Yeom, MD; Patrick D Barnes, MD; High-Resolution Motion-Corrected Diffusion-Tensor Imaging (DTI) in Infants - Stefan T Skare, PhD, Stanford University, Stanford, CA; Samantha J Holdsworth, $\mathrm{PhD}$; Kirsten Yeom, MD; Patrick D Barnes, MD; Roland Bammer, PhD; 3D SAP-EPI in MotionCorrected Fast Susceptibility Weighted Imaging (SWI) - Roland Bammer, PhD, Stanford University, Palo Alto, CA, Samantha J Holdsworth, PhD; Stefan Skare, PhD; Kristen Yeom, MD; Patrick D Barnes, MD; T1-Weighted 3D SAP-EPI for Use in Pediatric Imaging - Roland Bammer, PhD, Stanford University, Palo Alto, CA, Samantha J Holdsworth, $\mathrm{PhD}$; Stefan Skare, PhD; Kristen Yeom, MD; Patrick D Barnes, MD

\section{Caffey award for best clinical reseach or educational paper}

2002 MR Imaging of Kidneys: Functional Evaluation Using F-15 Perfusion Imaging. Grattan-Smith D, Jones RA; Little S, Perez M, Kirsch A

2003 Differential Regurgitation in Branch Pulmonary Arteries after TOF Repair. Yoo SJ, Kang IS, Redington A, Benson LN, Macgowan CK, Valsangiacomo ER

2004 Feasibility of a Free-Breathing SSFP Sequence for Dynamic Cardiac Imaging in Pediatric Patients. Krishnamurthy R, Muthupillai R, Vick G, Su J, Kovalchin J, Chung T

2005 Evaluation of High Resolution Cervical Spine CT in 529 Cases of Pediatric Trauma: Value Versus Radiation Exposure. Shiran D, Jimenez R, Altman D, DuBose M, Lorenzo R

2006 Alterations in Regional $\mathrm{O}_{2}$ Saturation $\left(\mathrm{StO}_{2}\right)$ and Capillary Blood Volume $(\mathrm{HbT})$ with Brain Injuries and ECMO. Grant PE, Themelis G, Arvin K, Thaker S, Krishnamoorthy KK, Franceschini MA

2007 Evaluation of Single Functioning Kidneys Using MR Urography. Grattan-Smith D, Jones R, Little S, Kirsch A, Alazraki A

2008 Evaluating the Effects of Childhood Lead Exposure with Proton MR Spectroscopy \& Diffusion Tensor Imaging Neuroradiology. Cecil KM
2009 Improving Patient Safety: Effects of a Safety Program on Performance and Culture in a Department of Radiology at a Children's Hospital. Donnelly L, Dickerson J, Goodfriend M, Muething S

2010 Juvenile Osteochondritis Dissecans (JOCD): Is It a Growth Disturbance of the Secondary Physis of the Epiphysis? Tal Laor, MD, Cincinnati Children's Hospital Medical Center, Cincinnati, OH, Eric J Wall, MD; Andrew M Zbojniewicz, MD

\section{Caffey award for posters}

2003 Assessing the Use of Magnetic Resonance Imaging in Determining the Age of Closure of Growth Plates. Rajwani T, Huang EM, Secretan C, Bhargava R, Lambert R, Bagnall $\mathrm{K}$

2004 Outstanding Basic Science Research Poster - Imaging of the Diaphragm in Neonates and Young Infants with Special Emphasis on Diaphragmatic Motion. Epelman $M$, Navarro $O$, Miller $S$

2004 Outstanding Clinical Research Poster - The Spectrum of Renal Cystic Disease in Children. Restrepo R, Ranson $M$, Sookman J, Jacobson E, Daneman A, Fontalvo L

2005 3D MRI and CT in the Evaluation of Congenital Anomalies of the Aortic Arch. Dehkharghani S, Olson K, Richardson R

2006 Diffusion Weighted imagin in Pediatric Neuroradiology: A Primer Sagar P, Grant PE

2006 Imaging of Suprarenal Fossa in Children: Radiological Approach and Clinico-Pathological Correlation. Kukreja K, Restrepo R, D'Almeida M

2007 Neuroimaging of Nonaccidental Trauma: Pitfalls and Controversies. Lowe L, Obaldo RE, Fickenscher KA, Walsh I,

2008 Estimation of Cumulative Effective Doses from Diagnostic and Interventional Radiological Examinations in Pediatric Oncology Patients.Thomas KE, Ahmed BA, Shroff P, Connolly B, Chong AL, Gordon C

2009 Scientific: MRI Findings in the Term Infant with Neonatal Seizures. An Etiologic Approach. Rebollo Polo M, Hurteau-Miller J, Laffan E, Tabban H, Naser H, Koujok K

2009 Educational: MR Urography: Functional Analysis Made Simple! Khrichenko D, Darge K

2009 Case Report: Multi-Modality Imaging Manifestations of the Meckel's Diverticulum in Pediatric Patients. Kotecha MK, Bellah RD, Pena AH, Mattei P

2010 Scientific: Dual Phase Intravenous Contrast Injection in Pediatric Body CT Erika Mann, MD, Hospital for Sick Children,Toronto, ON, CA, Amin Alzahrani; Nancy Padfield; Liane Farrell; Guila BenDavid; Karen Thomas, MD 
2010 Educational: Hemangiomas Revisited: The Useful, the Unusual and the New Ricardo Restrepo, MD, Miami Children's Hospital, Miami, FL, Rajaneeshankar Palani, MD; Umamahesh Matapathi, MD; Nolan Altman, MD; Luisa Cervantes, MD; Ana-Margarita Duarte, MD; Ibrahim Amjad, MD

2010 Case report: MRI of Congenital Urethroperineal Fistula Maryam Ghadimi Mahani, MD, University of Michigan Health System, C.S. Mott Children's Hospital, Ann Arbor, MI, Jonathan R Dillman, MD; Deepa Pai, MD; John M Park, MD; Michael A DiPietro, MD; Maria F Ladino Torres, MD

For a list of Caffey award papers and posters prior to 2003, please visit the SPR website.

\section{Previous Neuhauser lectures}

1995 Frances S. Collins, MD, PhD, Washington, DC "The Human Genome Project and the Future of Medicine"

1996 M. Judah Folkman, MD, Boston, Massachusetts. Clinical Applications of Angiogenesis Research

1997 S. Steven Potter, PhD, Cincinnati, Ohio "Homeobox Genes and Pattern Formation (Master Genes)"

1998 Roy A. Filly, MD, San Francisco, California "Fetal Thoracic Surgery"

1999 Harold A Richman, PhD "Child Abuse: From a Radiologist's Discovery to a Major Issue of Public Policy. What Have We Wrought?"

2000 William D. Lyman, PhD, Detroit, Michigan "Prenatal Molecular Diagnosis and Fetal Therapy"

2001 Jerry R. Dwek, MD, Columbus, Ohio "Médecins Sans Frontiéres/The Doctors Without Borders Experience - Afghanistan"

2002 Eric J. Hall, DSc, FACR, FRCR, New York, New York "Lessons We Have Learned From Our Children: Cancer Risks From Diagnostic Radiology"

2003 Jeffrey A. Towbin, MD, Houston, Texas "Molecular Cardiology: Laboratory to bedside"

2004 Bruce R. Rosen, MD, PhD, Boston, Massachusetts "New Advances in MRI: A Guide for the Practicing Pediatric Radiologist"

2005 Bruce R. Korf, MD, PhD, Birmingham, Alabama "Pathobiology and Management of NF1 in the 'Genomic Era'",

2006 Richard M.J. Bohmer, MD, MPH "Evolution, Innovation and the Changing Nature of Healthcare Delivery"

2007 Nogah Haramati, MD "21st Century Radiology: Growth and Development of Our Workflows and Processes"

2008 Emanuel Kanal, MD, FACR, FISMRM, AANG "MR Technology: Where Are We, Where Are We Going”?
2009 Roberta G. Williams, MD “Cardiology and Radiology: Partners in Producing Healthy Adults with Congenital Heart Disease"

2010 Regina E. Herzlinger "The Economic Basis of Change in Healthcare"

For a list of Neuhauser Lecturers prior to 1995, please visit the SPR website.

\section{Past presidents}

1958-59 Edward B. Neuhauser, MD*

1959-60 Frederic N. Silverman, MD*

1960-61 John F. Holt, MD*

1961-62 Arthur S. Tucker, MD*

1962-63 John W. Hope, MD*

1963-64 R. Parker Allen, MD*

1964-65 Edward B. Singleton, MD

1965-66 J. Scott Dunbar, MD*

1966-67 Harvey White, MD*

1967-68 M.H. Wittenborg, MD*

1968-69 David H. Baker, MD

1969-70 John A. Kirkpatrick, Jr., MD*

1970-71 Norman M. Glazer, MD*

1971-72 Bertram R. Girdany, MD

1972-73 Donald H. Altman, MD

1973-74 Hooshang Taybi, MD*

1974-75 John L. Gwinn, MD*

1975-76 Lawrence A. Davis, MD*

1976-77 Marie A. Capitanio, MD

1977-78 John P. Dorst, MD*

1978-79 Bernard J. Reilly, MB, FRCP (C)

1979-80 Walter E. Berdon, MD

1980-81 Andrew K. Poznanski, MD

1981-82 N. Thorne Griscom, MD

1982-83 Virgil R. Condon, MD

1983-84 Jerald P. Kuhn, MD

1984-85 Lionel W. Young, MD

1985-86 John C. Leonidas, MD*

1986-87 Derek C. HarwoodNash, MD, DSc*

IPR 1987 Denis Lallemand, MD (ESPR)

1987-88 Beverly P. Wood, MD

1988-89 John F. O’Connor, MD

1989-90 E.A. Franken, Jr., MD

1990-91 Donald R. Kirks, MD

IPR 1991 Hans G. Ringertz, MD, PhD (ESPR)

1991-92 William H. McAlister, MD

1992-93 M. B. Ozonoff, MD

1993-94 Joanna J. Seibert, MD

1994-95 Eric L. Effmann, MD

1995-96 Kenneth E. Fellows, MD

IPR 1996 Paul S. Thomas, MD (ESPR)

1996-97 Diane S. Babcock, MD 
1997-98 Charles A. Gooding, MD

1998-99 Robert L. Lebowitz, MD

1999-00 Thomas L. Slovis, MD

2000-01 Janet L. Strife, MD

IPR 2001 Francis Brunelle, MD (ESPR)

2001-02 Bruce R. Parker, MD

2002-03 Richard B. Towbin, MD

2003-04 David C. Kushner, MD

2004-05 Stuart A. Royal, MD

2005-06 George A. Taylor, MD

IPR 2006 Richard Fotter, MD (ESPR)

2007 Marilyn J. Goske, MD

2008 Marta Hernanz-Schulman, MD, FACR

2009 M. Ines Boechat, MD, FACR

2010 Neil D. Johnson, MBBS

*Deceased

\section{Previous SPR meeting sites}

1991/IPR 1991 Stockholm, Sweden

1992 Orlando, Florida

1993 Seattle, Washington

1994 Colorado Springs, Colorado

1995 Washington, D.C.

1996/IPR 1996 Boston, Massachusetts

1997 St. Louis, Missouri

1998 Tucson, Arizona

1999 Vancouver, British Columbia

2000 Naples, Florida

2001/IPR 2001 Paris, France

2002 Philadelphia, Pennsylvania

2003 San Francisco, California

2004 Savannah, Georgia

2005 New Orleans, Louisiana

2006/IPR 2006 Montréal, Quebec, Canada

2007 Miami, Florida

2008 Scottsdale, Arizona

2009 Carlsbad, California

2010 Boston, Massachusetts

\section{Future SPR meetings}

2012 April 16-20 San Francisco, California

2013 May 14-18 San Antonio, Texas

\section{SPR 2011 gold medallist}

The Gold Medal of The Society for Pediatric Radiology is our most distinguished honor. The SPR Medal is awarded to pediatric radiologists who have contributed greatly to the SPR and our subspecialty of pediatric radiology as a scientist, teacher, personal mentor and leader.

\section{Dr. Carol Rumack, MD}

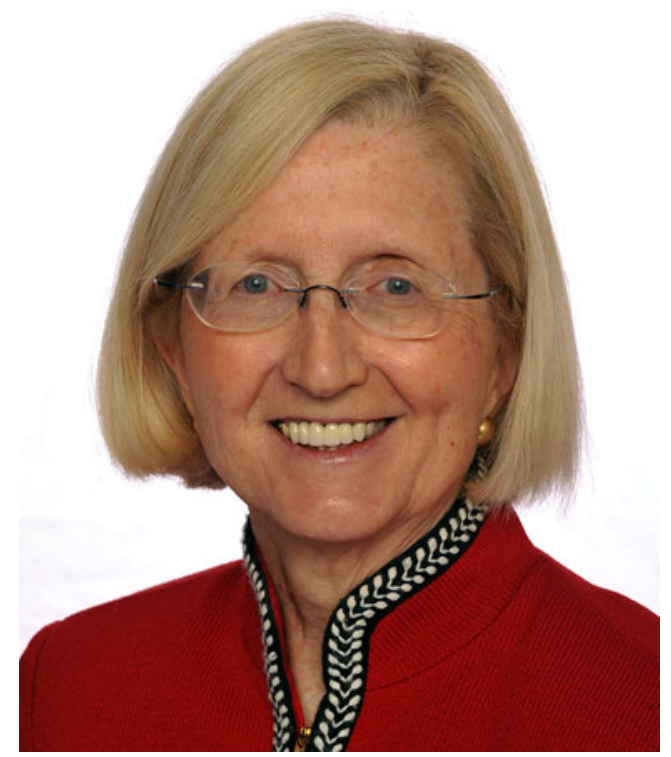

The 2011 SPR Gold Medal is awarded to Dr. Carol Rumack who is most deserving of this long overdue recognition. Her distinguished career has been characterized by seminal scientific research contributions, a deeply committed lifetime of academic leadership, wide ranging accomplishments in medical education and mentoring, and a sterling international reputation.

Dr. Rumack considers that her career defining greatest contribution to the science of radiology is the understanding of intracranial hemorrhage (ICH) in premature infants. Her first presentation on this was at the ARRS, in Boston, in 1977, and, thus began many years studying the incidence, timing, and outcome of ICH, which previously, was thought to be a rare event until she began to see the problem clearly on computed tomography. In 1977, when she began her career at the University of Colorado at Denver General Hospital, she used CT to study premature infants from the entire city. She found that $\mathrm{ICH}$ was a common event, occurring in $55 \%$ of premature infants under 32 weeks gestation, rather than the only $5 \%$ when it was studied at autopsy. Two different journals rejected this first paper on the topic because they did not believe that this new data from CT could be correct compared to the "known" data from autopsy. In 1981, Dr. Rumack presented a compelling award winning paper to the SPR, one of the first papers on ultrasound of ICH. Her team studied each premature newborn every $8 \mathrm{~h}$ for a week after birth and, thus, she was able to determine when these events occurred in real time. She feels that this was her best research and it is widely accepted to be a seminal contribution.

Segueing from research to education, Dr. Rumack believes that her textbook, Diagnostic Ultrasound, which she co-edits 
is her greatest contribution to clinical radiology. It has 100 contributors who are leading experts in ultrasound diagnosis, it is used worldwide, and is now in its fourth edition.

Dr. Rumack is a strongly optimistic, founding president of the American Association of Women Radiologists (AAWR) and she considers this to be another of her best contributions to medicine and, in particular, to women in medicine. The AAWR made women feel welcome in a male dominated environment. That's not an experience many women had 40 years ago. Next year will be the thirtieth anniversary of this strong and positive organization.

At the University of Colorado, Carol has multilayered responsibilities as an Associate Dean for Graduate Medical Education, leading her institution to excellence on 5 year accreditation reviews and creating many innovative projects. She now serves on the Board of ACGME at a national level. As the Woman's Liason Officer in medicine and science, she has led the University of Colorado, Denver School of Medicine to nominate women to leadership training positions at the AAMC.

On a national level, Carol has served as president and twice elected Chancellor of the American College of Radiology, Board of Governors of the AIUM, and Board of Directors of the ACGME. She is a Fellow of the ACR, has served on the SPR Board of Directors, Fellow of the SRU, and AFIP Distinguished Scientist. She has received the Alice Ettinger Award and the Marie Curie Award from the AAWR, the 2009 ARRS Gold Medal, and the SPR Pioneer Award. Internationally, Carol is an Honorary Member of the Academy of Medicine of Singapore, Honorary Member of the Australian Society for Pediatric Imaging, and Honorary Member of the Venezuelan Association of Medicine.

Dr. Rumack went into medicine, following her mother and father who were both family doctors and her role models from an early age. Her mother, Dr Ruth, was just one of two women who graduated from the University of Pittsburgh's Medical School. She practiced medicine for 64 years and delivered 3200 babies. Carol's father, Dr. Ray, served as Medical Director of the Bettis Atomic Power Laboratory for 35 years and he oversaw the safety of the engineers and workers who built the first nuclear submarine engine for the USS Nautilus. One of his inventions, radiation safety badges, is still used today. Carol went to the University of Chicago where she met her husband, Barry, and followed him to the University of Wisconsin for medical school. Carol had her radiology residency and pediatric radiology fellowship at the University of Colorado. This was followed by her appointment as Instructor in 1976, Assistant Professor in 1978, Associate Professor of Radiology and Pediatrics in 1982, and Professor in 1990. Her husband, Barry, is Professor Emeritus of the University of Colorado School of Medicine and Director Emeritus of the Rocky Mountain Poison and Drug Center. Carol and Barry live in
Denver. Their daughter Becky Allen and husband, Will, are both lawyers who have two daughters. Their son Marc, who is a pilot, lives in Phoenix and is married to Beth, a neonatal nurse practitioner and they have three children. Carol and Barry, who are a passionately devoted couple, love to hike in their free time. They walk about five miles, 3 days a week and on weekends they hike in the mountains or snowshoe near their cabin in the Colorado Rocky Mountains.

Carol believes that Pediatric Radiology has a great future and that the "Image Gently" campaign has given the SPR visibility and credibility. To her, this movement is critical to the best care of children, protecting them from excessive radiation, and assuring them that they receive the most appropriate studies.

In summary, because of a lifetime of extraordinary achievement in pediatric radiology, the SPR proudly awards its 2011 Gold Medal to Dr. Carol Rumack.

Charles A. Gooding, MD, FACR, FRCR

\section{SPR 2011 pioneer honoree}

Pioneer Honorees were first acknowledged in 1990 as a means to honor certain physicians who made special contributions to the early development of our specialty.

\section{Massoud Majd, MD}

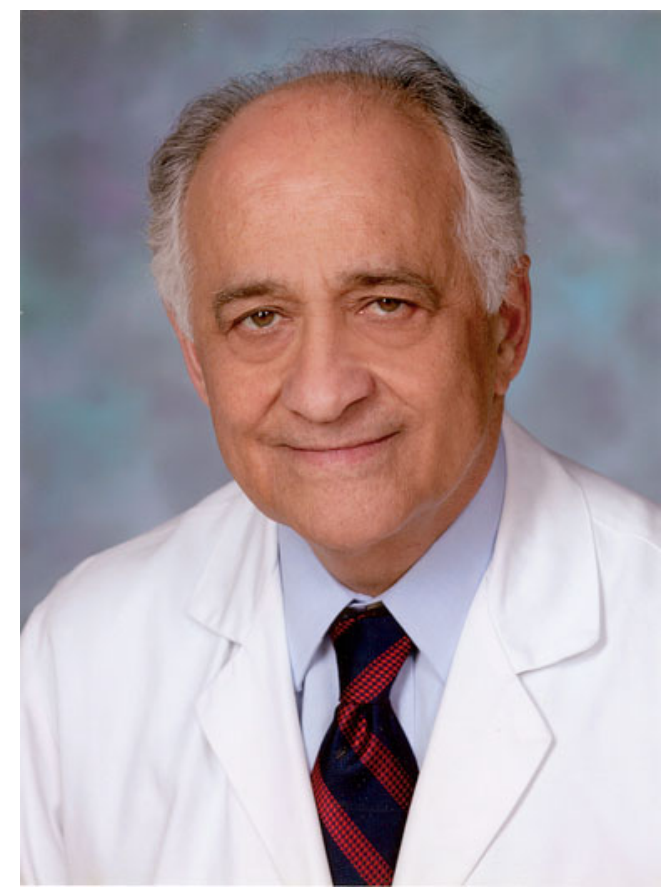

Massoud Majd embodies the definition of a "pioneer". He has quietly and humbly made original important contributions to the field of pediatric nuclear medicine breaking new ground in biliary, skeletal and renal imaging. 
Massoud Majd's life began on July 23, 1935 in the old city of Yazd in central Iran. He was the great grandson of a theological scholar and son of a landowner. His father grew up in the city of Torbat, in northeast Iran, attended a Russian school and was planning to study medicine in St. Petersburg. However, his plans were foiled by the Bolshevik Revolution in 1917. While his real ambition was to become a physicist, Massoud fulfilled his father's dreams by attending Tehran University school of Medicine, from which he graduated in 1960. His interest in pediatrics was evident early on. He spent 8 of 12 months of his internship at the Hospitals of the University of Tehran in Pediatrics and Pediatric Surgery and wrote his final medical thesis on clubfeet.

Massoud came to the United States in July, 1961, and did another year of rotating internship in Buffalo, New York at the Deaconess and Children's Hospitals. He then moved on to a radiology residency program at Georgetown University Hospital in Washington, D.C. from 1962 to 1966. During his residency, he rotated through Children's National Medical Center for pediatric radiology. Dr. Majd's interest in the field grew under the tutelage of the brilliant pediatrician/pediatric radiologist, Dr. Joseph Lopresti.

Massoud returned to Iran in 1966 and worked mainly in adult radiology at Pahlavi University in Shiraz for 2 years. In June, 1968, he married Fereshteh H.S. Javadi, a law school graduate whose work for the government included serving as a liaison to the United States Peace Corps. Shortly afterwards, upon returning to Shiraz from their honeymoon, Massoud found a letter and a telegram waiting for him from Dr. Lopresti asking him to join the pediatric radiology staff at Children's Hospital. Massoud accepted the offer and the newlyweds returned to Washington in August, 1968.

Pediatric nuclear medicine at that time was in its infancy with a few innovative leaders including Dr. Larry Samuels in Columbus, Dr. Melvin Tefft in Boston and Dr. James Conway in Chicago. Initially, Dr. Majd covered all areas of pediatric radiology. Recognizing the importance of nuclear medicine studies in pediatrics, he was successful in establishing the section of Nuclear Medicine at CNMC in January 1969. He developed a close working relationship with several CNMC pediatric surgeons, urologists and pathologists. With rapid growth of nuclear medicine studies, pediatric nuclear medicine became the primary area of his clinical and research activities leading to many outstanding contributions.

A major innovation in the evaluation of neonatal jaundice occurred in 1981 when Dr. Majd described the use of phenobarbital-enhanced Tc99m-IDA hepatobiliary scintig- raphy. He elegantly demonstrated the enhanced specificity of the Tc99m-IDAhepatobiliary scintigraphy in the diagnosis of extrahepatic biliary atresia by pre-treating with phenobarbital.

Massoud's keen observation of the effect of ACE-inhibitors on kidney function in 1982 inspired him to investigate the effect of captopril on the sensitivity of renal scintigraphy for detection of renal artery stenosis in hypertensive children. He found administration of captopril before renography caused reversible deterioration of renal function only in the kidneys with renal artery stenosis and presented his innovative concept at the 1983 SNM meeting. His presentation was included as one of the Henry Wagner Highlights of the meeting and the era of captopril renography was launched.

Massoud's contributions to genitourinary imaging also include optimizing diuresis renography in the management of neonates with hydronephrosis, comparing direct and indirect radionuclide cystography, and assessment of acute pyelonephritis and renal scarring.

Dr. Majd spent several years in basic research on pyelonephritis working with various imaging techniques in piglets. Using intra-arterial injection of microspheres Massoud was the first to demonstrate that focal ischemia occurs early in the areas of the kidney affected with acute pyelonephritis. His studies documented the sensitivity of DMSA scan for the diagnosis of acute pyelonephritis as well as the relative accuracy of CT, MRI, Power Doppler and DMSA SPECT.

Dr. Majd was promoted to Professor of Radiology and Pediatrics at the George Washington University School of Medicine in 1979. Nationally he has been active in multiple ACR committees particularly the guidelines and standards committee and became a fellow in 1984. Massoud was one of the founding members of the Pediatric Nuclear Medicine Club of the Society of Nuclear Medicine and also served as President. When the club formally became a Council, he served on its board of directors. Massoud also served as a member and chair of the pediatric nuclear medicine committee of the SPR.

Dr. Majd has spoken at innumerable courses nationally and internationally and has been an invited visiting professor at 24 institutions. He has presented over 40 abstracts, published over 80 peer reviewed manuscripts and authored 10 book chapters.

We are not the first to honor Massoud for his wonderful work. His numerous awards include honorary membership to the Urology Section of the American Academy of Pediatrics in recognition of his outstanding contributions to the urologic care of children. He was recipient of the Harry Miller Teaching excellence award in urology from George Washington University. $\mathrm{He}$ is a Fellow of the American College of Nuclear Physicians and was awarded 
the Presidential Distinguished Service award in 2003 by the Society of Nuclear Medicine. In 2009 the Majd-Gilday Pediatirc Young Investigator award was established by the Pediatric Imaging Council of the SNM in honor of Dr. Majd and Dr. David Gilday.

Massoud has been a dedicated teacher, physician, and mentor. He is blessed with a wonderful family including his wife, Fereshteh, who is an avid painter, their daughter Katayoon, who is a public interest lawyer, their son Kurosh, who is also a radiologist, their daughter-in-law Alison, and two grandchildren, Zack and Ella.

The SPR is thrilled to bestow the 2011 Pioneer award on Dr. Massoud Majd for his many contributions to the field of pediatric imaging.

Dorothy I. Bulas, MD and Eglal Shalaby-Rana, MD

\section{SPR 2011 presidential recognition awards}

The Society bestows presidential recognition award on members or other individuals whose energy and creativity have made a significant impact on the work of the society and its service to its members.

\section{Kimberly E. Applegate, MD, MS, FAAP, FACR}

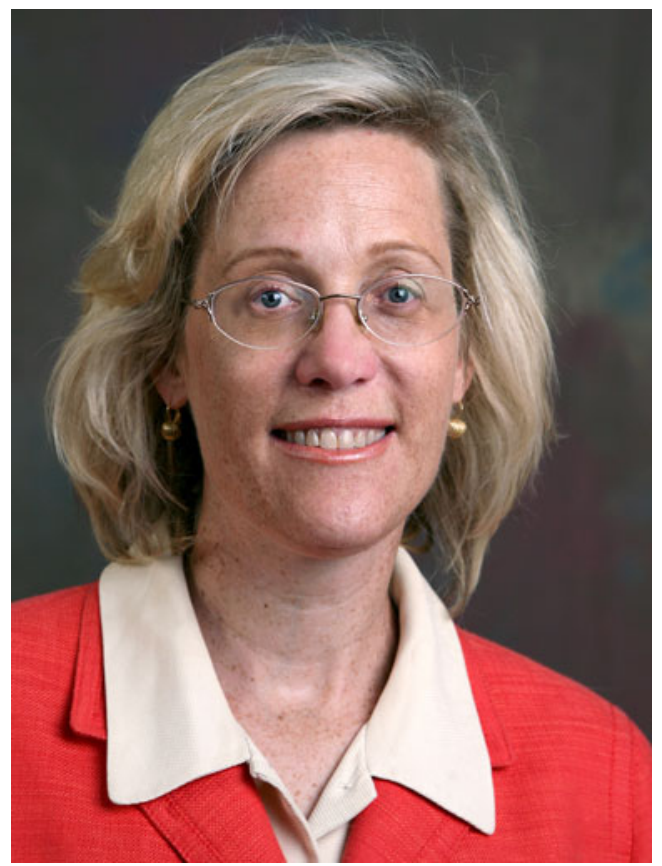

The 2011 SPR presidential recognition award is given to Dr. Kimberly Applegate who has been one of the most active and influential forces in pediatric radiology. She has been a leader in many radiology organizations and has elevated the influence of pediatric radiology throughout this work. She is full of ideas, enthusiasm, warmth, and support for colleagues and learners and her commitment has engaged many others in service to organizations.
Dr. Applegate was born and raised in Sacramento, California. Her father was a solo family practitioner and her role model who took her on house calls and was loved by his patients. Her mother grew up on a cattle ranch which the family returned to on weekends to enjoy and do farm work. She received her Bachelor of Science from the University of California, Berkley in Chemistry, and her MD from George Washington University in Washington, DC and her Masters in Epidemiology and Biostatistics from Case Western Reserve University in Ohio. She was a radiology resident and Chief Resident at Dartmouth-Hitchcock Medical Center and a Pediatric Radiology Fellow at Boston Children's Hospital. During this time she was recognized for her research interests by being invited to the first annual Resident Introduction to Research Program at RSNA.

In 1997, Dr. Applegate began her academic career at the Cleveland Clinic Center of the Ohio State University and soon moved to Case Western University Hospital and Rainbow Babies \& Children's Hospital in Cleveland. Then in 2001, she joined the faculty at Indiana University at Riley's Children's Hospital. In 2009, she was recruited to Emory University Medical School in Atlanta, Georgia as Vice Chair of Quality and Safety. Throughout her career, she has been very fortunate to have the constant support from her husband, Dr. George Parker, and their three sons. As recognition of her expertise and leadership she was elected a member of the SPR Board of Directors from 2005 to 2008. As an expert in evidence-based imaging, she was the clear choice to be course director for the 2009 SPR post-graduate course on evidence-based imaging. In the Society for Pediatric Radiology, she has been Chair of the Membership and the Safety committees, Chair of the annual SPR meeting Scientific Poster Review and created the SPR Collaborative program with Pediatric Radiology Nurses. She has served on committees for Child abuse, Fetal Imaging and Diagnostics. She has been on the Bylaws Committee, the Finance Committee and Physician resources. For the SPR Corporate Support Committee, she raised more than $\$ 60,000$ in 1 year by developing educational relationships with Bayer and other corporations.

Dr. Applegate was one of the key Steering Committee members who developed the highly acclaimed Image Gently Campaign and worked on the development of their parent and CT education modules. She is now Chair of the International Image Gently Outreach Working Group which has succeeded by major alliance building with international radiology and medical physics organizations and the World Health Organization.

Dr. Applegate has served as a pediatric radiology expert on the Editorial Boards of Pediatric Radiology, Academic Radiology, AJR Integrative Imaging, Journal of the American College of Radiology, and Radiology. She has been an outstanding leader as the President of the Association for University Radiologists, the Radiology Alliance for Health Services 
Research, the Indiana Radiological Society, and the American Association for Women in Radiology.

Dr. Applegate has represented pediatric radiology with outstanding leadership in the American College of Radiology on the Council Steering Committee, now as Vice Chair of all ACR Guidelines and Standards, and Chair of the ACR Pediatric Commission Safety Committee. She was honored by election to the National Council for Radiation Protection (one of two pediatric radiologists elected to this government sponsored body). She has worked closely with the American Board of Radiology.

Her work on raising awareness of Radiation Protection throughout all of radiology includes the ACR Blue Ribbon Panel's publication of the 2007 JACR White Paper on Radiation Dose: in Medicine. She has published over 100 peer reviewed papers, 18 book chapters and has been a visiting professor 21 times and an invited faculty at over 150 regional, national and international meetings. Recognizing a knowledge gap in understanding evidence and appropriate use of imaging, she co-edited the first book on Evidence-Based Practice of Imaging in Children in 2010. Dr. Kimberly Applegate is truly an outstanding example of leadership in pediatric radiology and a deserving recipient of the SPR 2011 Presidential Award.

Carol M. Rumack, MD

\section{Keith J. Strauss, MS, FACR}

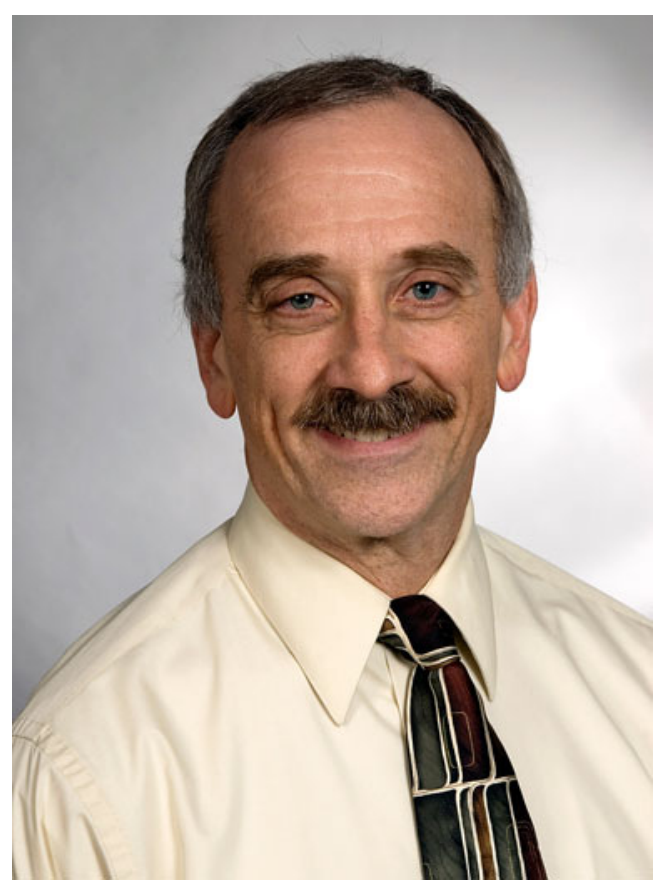

The 2011 Presidential Award from the Society for Pediatric Radiology could not be bestowed upon a more deserving recipient than Keith Jerel Strauss, MSc, Director of
Radiology Physics and Engineering, Department of Radiology Children's Hospital of Boston and Associate in Radiology at Harvard Medical School.

I first met Keith during the planning of the SPR ALARA concept in pediatric intervention and fluoroscopic imaging in 2006 for which he and I were co-program directors. I quickly learned of Keith's superb skills and expertise in the physics of diagnostic imaging and even more so, of his commitment to minimizing exposure to ionizing radiation in pediatrics. Prior to this interaction, I had no inkling as to the expanse of his involvement in these initiatives.

Keith received his Bachelor of Arts degree in physics from Manchester College, Indiana in 1974 and went on to receive his Masters in Science in Radiological Physics from the University of Chicago in 1977. From 1976 to 1984, Keith served in multiple capacities at Michael Reece Hospital and Medical Center in Chicago. In 1984, he migrated to Children's Hospital of Boston where he became the Director of Radiology Physics and Engineering, a position he holds today. I venture to say that it is in this capacity that Keith has made the greatest impact on the physics of diagnostic imaging. To his credit, he has revolutionized techniques in pediatric imaging and influenced the industrial partners toward minimizing exposure to ionizing radiation in children. As you will see below, this influence has expanded beyond pediatrics in the United States; the impact of his efforts are now felt worldwide and have expanded into the adult patient population as well. From 1978 to the present, Keith Strauss has served in innumerable capacities as a consultant radiological physicist. He has served on national and international committees from 1983 to the present, not the least of which is as a board examiner of medical physics for the American Board of Radiology. He is a member of numerous professional societies including Sigma Pi Sigma, the national honor society of physics.

It is particularly noteworthy that Keith contributes countless hours volunteering on multiple imaging task forces for the American Academy of Physics and Medicine (AAPM), commits his expertise to the education of trainees and established physicians, serves on numerous ACR committees on standards and accreditation of equipment and medical imaging techniques, and has served as program director of AAPM sponsored annual training courses across the country.

Most applicable to the current honor is that Keith has been involved with the Society for Pediatric Radiology as a member in general, a member of multiple committees, and co-director of multiple pediatric radiology ALARA conferences. His involvement with the Alliance for Radiation Safety in Pediatric Imaging and with the Image Gently Campaign has been critical to the growing initiatives toward improving medical imaging while minimizing 
exposure to ionizing radiation. The optimized pediatric CT protocols whose development Keith spearheaded have been downloaded over 20,000 times. He helped organize the Image Gently CT Vendor Summit in 2008, which brought together major CT manufacturers, radiologists, physicists and technologists with the purpose to create dose-index of radiation exposure appropriate for children. In the words of Dr. Marilyn Goske: "Keith Strauss has been the qualified medical imaging physicist (he likes this complete term) for the Alliance for Radiation Safety in Pediatric Imaging and through his tireless work has taught the entire pediatric radiology community much about radiation protection for children. He is unselfish about sharing that knowledge and using any work he creates to improve the care of children. He has a unique ability to take complex imaging physics and distill the information to the critical essence of what must be taught. He is able to keep his writing and teaching focused and practical so the learner does not become overwhelmed with technical knowledge, but walks away with scientifically sound yet useful information. There are few within the medical community with this gift. In addition, he is simply a great guy, with a superb sense of humor, who has made a lot of work... a lot of fun!"

Receiving honors is not new to Keith Strauss. His strong national reputation is recognized by Fellowship designation in both the American Association of Physicists in Medicine and the American College of Radiology (ACR). In the last 50 years, only 10 medical physicists with a Masters degree have been honored by both organizations. He has also been recognized by the National Conference of Radiation Control Program Director, the American Association of Physicists in Medicine, the American College of Radiology, and now the Society for Pediatric Radiology.

Keith is a well-respected renowned lecturer-locally, regionally, nationally and internationally. In the words of Dr. George Taylor: "Keith is a very effective educator and highly sought-after speaker. His lectures are clear and well organized, and always well-attended. The fact that his talks are well-attended is high praise, given the cod liver oil-like reputation that physics has as a topic among trainees!"

His numerous publications contribute profoundly to the education of healthcare providers and trainees as well as to establishing standards for controlling exposure to ionizing radiation from medical imaging.

Importantly, Keith's life is shared with his wonderful wife Roberta "Bobbie", a retired elementary school teacher who now works as an office manager at their church, where Keith also serves in a leadership position and volunteers numerous hours. His life is further rounded by being a loyal Chicago Bears football fan, biking, boating on Lake Archer, and enjoying strategy games. Keith and Bobbie have a son Andy (mathematically inclined like his father) and a daughter Erin (dedicated to the care of children as a pediatric nurse at Boston Children's).
In short, it is with profound thanks, great pride and pleasure that the Presidential Award from the Society for Pediatric Radiology is presented to Mr. Keith Strauss - an invaluable member of our Society as a teacher, innovator, medical physicist and friend who has had a marked and sustained impact on the safe imaging of children throughout the world.

Sue C. Kaste, DO

\section{SPR honorary members}

The Society extends Honorary membership to individuals who have made outstanding contributions to the care of children.

\section{Catherine M. Owens, BSc, MBBS, MRCP, FRCR}

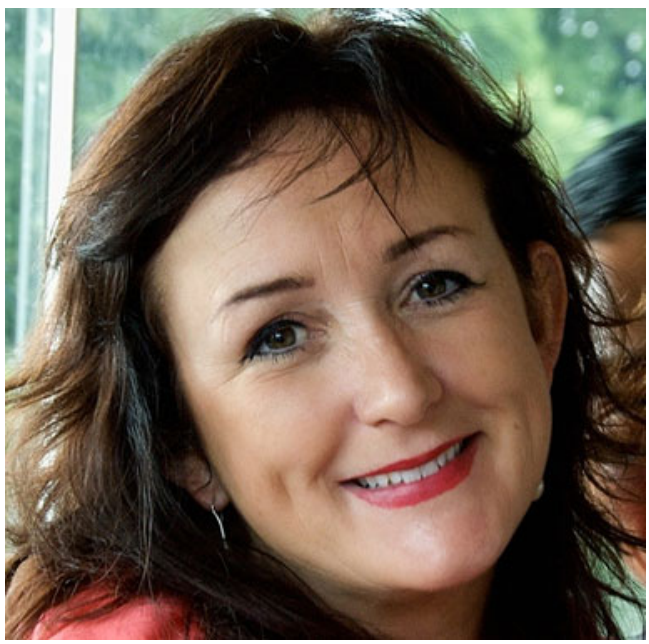

Dr. Catherine Owens received an honors degree as Bachelor of Science in Pharmacology in 1982 and then her medical degree from St Bartholomew's Hospital Medical School at the University of London in 1984. Dr. Owens became a Member of the Royal College of Physicians in 1987 and a Fellow of the Royal College of Radiologists in 1992. She completed her Pediatric Radiology Fellowship at the Sick Children's Hospital in Toronto in 1994.

Dr. Owens was then appointed Consultant Pediatric Radiologist at St Mary's Hospital where she worked until 1999. Dr. Owens began working part time at Great Ormond Street Hospital, one of the largest children's hospitals in Europe, in 1996 becoming a full time Consultant Pediatric Radiologist there in 1999 and remaining there today. She has a joint academic appointment as Reader at University College London. Dr. Owens served as Director of the Department of Radiology from 2000 to 2006. In the last 6 years, serving as CT unit lead, she has added clinical and research personnel, a dual source CT scanner, and two state-of-the-art MRI scanners to what has become the largest and most comprehensive imaging service for children in the UK. 
Dr. Owens has been an active researcher throughout her career. A review of her early publications provides insight into her later research career. In 1993 Dr. Owens was a coauthor on a paper entitled "Detection of pneumothorax with lateral shoot-through digital radiography." This manuscript shows her interest in diseases of the chest and in new technology, which have continued to this day. The senior author on this manuscript can only be described as one of the best in the business. To this foundation of a focused area of interest, use of the latest technology, and working with superbly qualified colleagues, Dr. Owens has added impressive skills as a researcher, team leader, and mentor. Her efforts have resulted in an impressive $\mathrm{CV}$, grant funding of several million pounds, and currently mentoring three Ph.D. students in the areas of CT and MRI.

In constant demand as a speaker and invited professor, Dr. Owens is a gifted teacher. She is one of the Core Faculty Teachers of the Royal College of Radiologists. Add to this, major roles in the national and international radiology community. A short summary includes: Editorial boards of 7 journals, Sub editor of European Radiology, Clinical Vice President of the UK Radiology Congress, the largest UK general radiology meeting (2008); lead program organizer of Pediatric Radiology for the European Congress of Radiology in 2009; ESPR representative to the Image Gently Campaign, Co founder and lead of the ESPR task force in CT, Treasurer of the ESPR since 2003 and General Secretary since 2007, and of course this year's IPR President.

On a personal note, Cathy may say, "chest is best", but her heart is first and foremost with her family: Her husband Paul (of 25 years) and her children, Charles (19) Delphine (14) and Eloise (12). It has been suggested that while her family greatly appreciates her abilities as a domestic goddess, they are sometimes less pleased that her beloved dog Lara has first call on her affections.

The few who actually read these biographies will know that they are written to serve two purposes. The first is to demonstrate, often through a list of professional accomplishments, that the Honoree deserves to be honored. The second is to introduce, often with a humorous anecdote, the Honoree to the members of the Society. I am sure that the recitation above has demonstrated that Dr. Owens is abundantly deserving of Honorary Membership in the SPR. For the second purpose, this text will clearly fail. It is not possible to introduce Dr. Owens through the written word. To meet Cathy, you must meet her face to face.

This is the only way to experience her energy, wit, and nononsense attitude. One of her friends and mentors wrote that "conversations with Cathy are a bit like breathing ozone, one comes away unaccountably energized". For all this, you are more likely to come away knowing that you have met someone who shares true friendliness and infectious warmth, and who has a vibrancy that comes from fully enjoying life. Please do make an effort to meet our new Honorary Member. You won't be disappointed.

Alan S. Brody, MD

\section{Madan M. Rehani, Ph.D.}

"Before you do anything, stop and recall the face of the poorest most helpless destitute person you have seen and ask yourself, 'Is what I am about to do going to help him?" Mahatma Gandhi

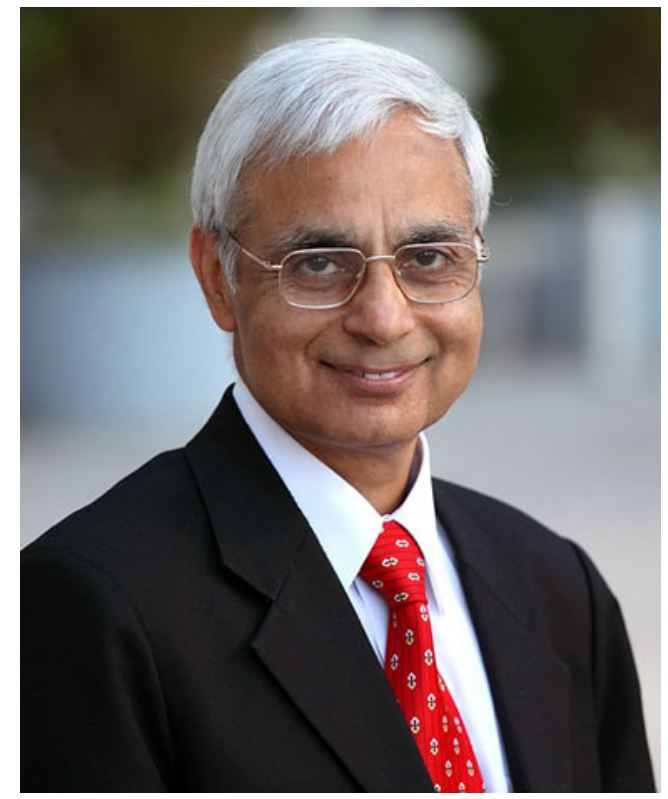

Dr. Madan Rehani is the Radiation Safety Specialist in Radiation Protection of Patients Unit at the International Atomic Energy Agency (IAEA), a United Nations organization. When I first met him just over a year ago in December 2009, his humble manner and quiet demeanor masked the many professional accomplishments he has accumulated as an internationally recognized medical imaging physicist. We honor him for his relentless work on radiation protection worldwide and the true impact he is making for children in this area of patient safety. The driving force in his career is his passion to "to assess patient safety in radiological examinations and work towards making the particular patient or child safer". He pursues this goal with singular vision until there is documentation of improvement on a local level.

Dr. Rehani was born in 1950 at Panipat, India and received his $\mathrm{PhD}$ in Medical Physics at the All India Institute of Medical Sciences in New Delhi India in 1976 after receiving a Masters of Science degree in physics at Kurukshetra University in India. If you have had the wonderful opportunity to hear him teach, you would know that teaching is a passion for him. His first position was as a faculty at the Post Graduate Institute of Medical Education and Research in Chandigarh, India. By 1988, he became Additional Professor and Head of the Medical Physics Unit in the Cancer Hospital of the All India Institute of 
Medical Sciences (AIIMS) in New Delhi, then Professor in 2000 and Head of the Collaborating Centre of the World Health Organization (WHO) on Imaging Technology and Radiation Protection which he established in 1997 . He has been a member of the International Commission on Radiological Protection (ICRP) since 1997 and has been Chair of two Task Groups that resulted in Annals of ICRP Publications 87 and 102 on "Managing Patient Dose in Computed Tomography".

In his position at the IAEA, he has the responsibility for developing and directing multi-national projects on medical radiation protection, education and training and quality assurance activities in a large part of the world.... and what a job he has done! He has used this position of high visibility to work co-operatively to empower local medical professionals to acquire skills on patient dose management and to act locally to achieve change on behalf of patients, in particular children. Seeing him in action is an example of the powers of persuasion... complimenting, cajoling, and applying constructive criticism to allow medical professionals who may have limited resources to act responsibly. He and his agency provide free access to education materials (many of which he has created or organized) and scientific expertise to make real changes in regard to radiation protection worldwide.

In recognition of these accomplishments, he has been awarded the Harold Johns Medal by the IOMP in 2009, and the most prestigious award of India in the nuclear sciences, the Homi Bhabha Memorial Oration by the Society of Nuclear Medicine in India in 1999 and the Dr. K.M. Rai Oration by Indian Radiological and Imaging Association in 2001. He has edited 5 books, contributed over 26 book chapters, has been responsible for about a dozen publications of the IAEA, and has published over 70 papers in peer reviewed journals.

He embraces change and the power of technology to educate and was quick to recognize the power of the internet to teach and reach the world. With this in mind, he established the IAEA's website on radiation protection of patients (http://rpop. iaea.org). This site has over 0.8 million hits per month. He has used the internet to establish networks of medical professionals on radiation protection for children covering 45 countries! His responsibilities include establishing training programs for interventional cardiologists and other non-radiologists who perform medical imaging. This led to the Asian network of cardiologists in radiation protection who have lowered and optimized radiation dose for patients as a direct result of his scientific work and activism. Recent work has led to assessing use of medical imaging in many far-flung countries in an attempt to promote standardization of practice and appropriate use through the world particularly in children.

His lovely family include a pedodontist wife, Usha, (another connection with children) and two daughters-one Bhavya is a fourth-year radiology resident and another Navya, a computer science graduate from Stanford who works in Goldman Sachs in New York. His many travels across the world leave little time to sleep, but he uses the spiritual practices of meditation and yoga to provide nourishment to the body and soul as well as support from his accomplished family.

It is most appropriate to give him Honorary Membership of the Society for Pediatric Radiology at this International meeting in London. Children throughout the world are benefitting from his passion and activism in promoting radiation protection for children and thoughtful use of our amazing medical imaging technologies. He truly is one of those rare individuals who, by his work and beliefs, has made the world better for children. With his love for Gandhi, I will finish with another quote of Mahatma Gandhi, "whatever you do will be insignificant, but it is very important that you do it."

Congratulations, Madan and thank you!

Marilyn J. Goske, MD

\section{SPR 2011 Singleton-Taybi award}

The Singleton-Taybi Award is given in honor of Edward Singleton and Hooshang Taybi, in recognition of their personal commitment to the educational goals of the SPR. Initiated in 2006, the Award is presented annually to a senior member of the SPR whose professional lifetime dedication to the education of medical students, residents, fellows, and colleagues has brought honor to him/her and to the discipline of pediatric radiology.

\section{Ralph S. Lachman, MD}

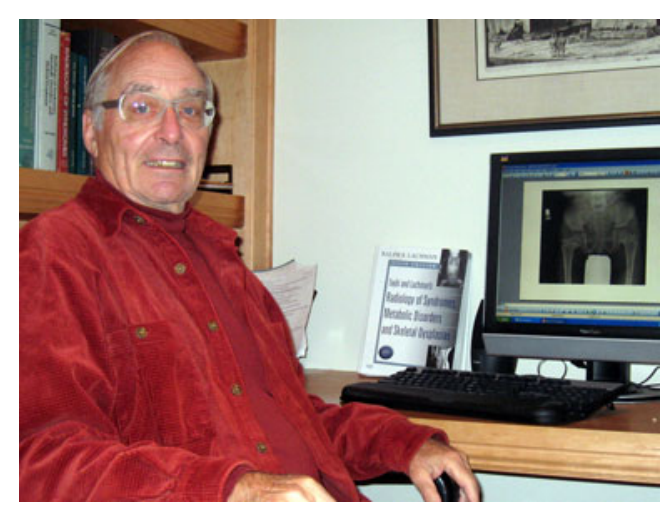

When I was asked to write a note on Dr. Ralph Lachman, recipient of the Taybi Singleton Award, I was flattered and challenged. The facts were frightening:

- Forty years in research on skeletal dysplasia

- Editor of the Taybi book of syndromes

- Author of the Skeletal Dysplasia chapter in Caffey

I decided to let Dr. Lachman speak in his own words. Ralph Lachman was born in 1935 in Wuppertal-Elberfeld, Germany. He and his parents escaped the Nazi persecution via Holland, arriving in America in 1939. The next 20 odd years of his life were spent in Philadelphia, Pennsylvania. He graduated from Central High School and completed a Bachelor of Arts 
degree from Temple University. He became the first non-black medical student to attend Meharry Medical College in Nashville, Tennessee. During his time at Meharry he was involved in the sit-ins that led to the integration of the downtown "public areas" of Nashville. Graduating from Meharry in 1961 he married Rose, the young lady who turned out to be not only the love of his life, but his best friend over the next 50 years. Today they are not only the parents of two lovely daughters but three amazing grandchildren.

Dr. Lachman served his internship and two residencies in New York City. He first completed his Pediatric Residency at the Mount Sinai Hospital and served in the US Army as base pediatrician for 2 years in Bad Kreuznach, Germany at the Field Hospital. Returning to the "States", his next residency began in his climb to become a Pediatric Radiologist. The next 4 years were occupied with a Diagnostic Radiology Residency at the New Mount Sinai Hospital \& School of Medicine. This was followed by a 2 year Pediatric Radiology fellowship at Harvard's, Boston Children's Hospital.

He is boarded in both Diagnostic Radiology \& Pediatrics. He is also "Subspecialty boarded" [CAQ] in Pediatric radiology for which he was one of the original candidates. He is one of the few or perhaps only "Genetic Radiologists" in the world.

Now he and his family were off to California arriving at what was the "Harbor Hospital" already known by the Harvard medical students as "A great place to train". He became the first Pediatric Radiologist at Harbor- UCLA Medical Center, joining the faculty of medicine at UCLA. Another fateful event occurred in 1970, the simultaneous arrival of Dr. Lachman and a pediatric geneticist, Dr. David L. Rimoin. Dr. Rimoin was to become his co-investigator for the next 40 years, but even more so, his good friend. They both realized that they had common interests in Syndromes, the evolving field of Genetics and especially in the radiological oriented area of Skeletal Dysplasias. The commonality of interests led to the evolution of the International Skeletal Dysplasia Registry originally housed at Harbor-UCLA Medical Center within the "barracks". Later it has moved to Cedars-Sinai Medical Center in Los Angeles.

Dr. Lachman has published over 250 research papers in peer reviewed journals. He has authored several books and book chapters. Recently he solely completed the 5 th edition of Taybi and Lachman's Radiology of Syndromes, Metabolic Disorders and Skeletal Dysplasias that has recently been released. He is a member if a large number of Societies some of which he has been an office holder and even a founder. He is an Associate Editor for the American Journal of Medical Genetics and for many years served on the editorial board of Pediatric Radiology.

Dr. Lachman's primary research has always been focused on the definition and diagnosis of the skeletal dysplasias, and more recently on the genetics and molecular basis of these disorders. With Dr. David L. Rimoin and the group he has described many new syndromes and skeletal dysplasias and has helped to define the molecular biology of disorders.

Dr. Lachman has been on the UCLA faculty for the last 40 years. He has been a professor Emeritus since 1999. Recently he has been appointed Visiting Scholar and then Clinical Professor at Stanford University where he still teaches, gives conferences and infrequently reads out ICU studies. At present, he continues to actively consult for the International Skeletal Dysplasia Registry combined clinic at Kaiser-Permanente and Children's Hospital MC Oakland and at Packer Children's Hospital, Stanford University. He has served many years as Medical Advisor for the LPA [Little People of America].

Walter E. Berdon, MD

Postscript: Dr. Ralph Lachman was in the right place at the right time. David Rimoin came to develop Genetics in the area in/around Los Angeles; he needed and found a Radiologist to work with, Ralph Lachman. Dr. Lachman was later also to be a colleague of Dr. Hooshang Taybi, author of the Syndrome Book. Lachman is now its editor. Dr. Lachman's legacy is immense. He developed the joining and integrating of Pediatric Radiology and Genetics.

\section{Lefebvre and Neuhauser lecturer}

\section{Sanjiv Sam Gambhir, MD, PhD}

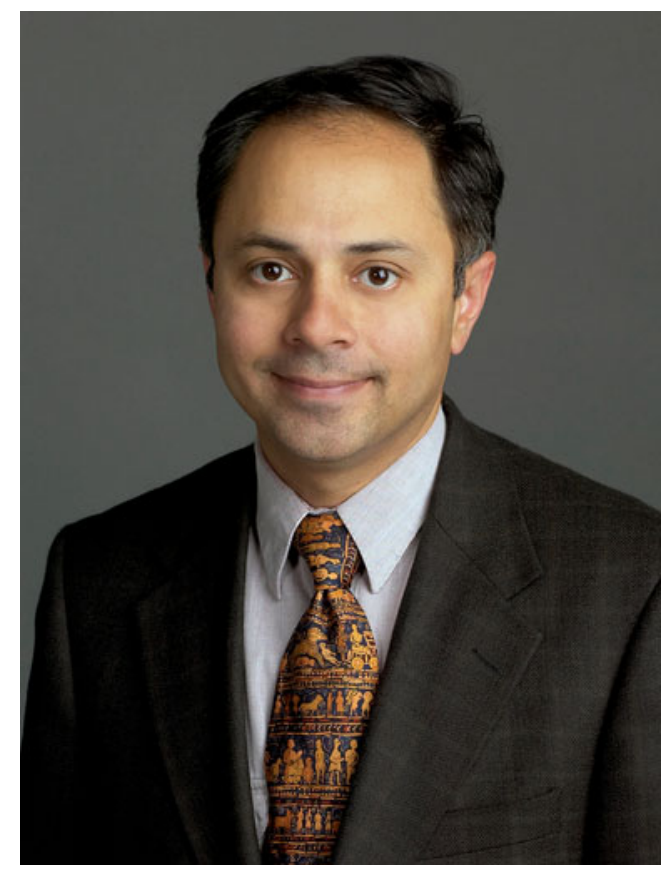

Sanjiv Sam Gambhir is Professor of Radiology, Bioengineering, and Materials Science at Stanford University USA and Director of the Molecular Imaging Program at Stanford. He also is the head of Nuclear Medicine and a member of the multidisciplinary Bio X program. At only 48 years of age, Prof. 
Gambhir has already published over 375 research articles, edited 3 books, and received over $\$ 90$ million in extramural funding as Principal Investigator. He serves as Associate Editor of many journals, including Radiology, Journal of Nuclear Medicine and Science Translational Medicine. In addition to this he has 30 granted/pending patents. He serves as an advisor to 10 imaging and biotechnology companies and has cofounded 3 imaging companies. Prof. Gambhir is also Principal of the Canary Center at Stanford for Cancer Early Detection and in this role he develops strategies for early cancer detection, shifting imaging from the current emphasis on late stage disease towards earlier disease detection, via in vitro diagnostics combined with molecular imaging.

Prof. Gambhir has extensive experience with clinical FDGPET having developed many of the original management algorithms for cancer patients, including cost-effectiveness models that led to FDG-PET reimbursement by Medicare in the United States. He runs a translational science laboratory that focuses on multimodality molecular imaging, with new probe development for positron emission tomography (PET) and optical imaging. The methods developed by Prof. Gambhir and his team to image gene expression in living subjects, (including humans), have been translated into clinical trials for cancer gene/cell therapies. He led the development of strategies for studying basic molecular biological events such as imaging protein-protein interactions at cellular level.

In recognition of his stellar career Prof. Gambhir has been awarded numerous prestigious awards including:

the Academy of Molecular Imaging Basic Scientist Award (2004), the Society of Molecular Imaging Achievement Award (2004), the Distinguished Clinical Scientist Award from the Doris Duke Charitable Foundation (2004),

the Hounsfield Medal from Imperial College London (2006), $t$ the Aebersold Award from the Society of Nuclear Medicine (2006), the Tesla Medal from the Royal College Of Radiologists (UK2008), and the Outstanding Researcher Award from the Radiological Society of Northern America (2009).

Sam Gambhir is one of 35 members of the National Cancer Institute (NCI) Scientific Advisory Board and was co-host of the Nobel Symposium on Molecular Imaging in Stockholm in 2007.

He was elected in 2008 as a member of the Institute of Medicine (IOM) of the US National Academies. In addition to all of his accomplishments, Sam Gambhir is a highly passionate educator and mentor for the 175 strong faculty of post doctorial fellows, residents, graduate students, and staff, who are fortunate enough to work with him at Stanford.

Sam Gambhir is truly a brilliant physician scientist, whose ideas advance the field of molecular imaging on multiple fronts.

Catherine Owens, Richard Barth, Peter Brader
Lecture handouts are posted on the SPR website at www. pedrad.org on the Meetings page.

\section{Social events}

One of the highlights of the IPR meetings is the social programme which accompanies it. Most evenings there are planned social events culminating in the gala dinner.

\section{Welcome reception}

The welcome reception is included for all delegates registered to attend on Friday. This event will be an ideal way to meet up with colleagues, make new acquaintances and find common interests.

Date: Friday 27 May

Time: 18.00-20.00

Location: St. Mary's Hospital, Praed Street, London, W2 $1 \mathrm{NY}$

\section{jSPR/jESPeR evening}

A night on town for our young delegates. Tickets are available to purchase. They are not included with the registration fee.

Date: Saturday 28 May

Time: 21.00 - Midnight

Location: Sway Club, 61-65 Great Queen Street, London, WC2B 5BZ

Distance from congress hotel: 2.9 miles.

Transport: either a taxi journey or by London Underground to Holborn station (Central and Piccadilly lines), or Covent Garden station (Piccadilly line). Sway Club is a short walk from either.

\section{Baroque concert}

Included for all delegates registered to attend on Sunday.

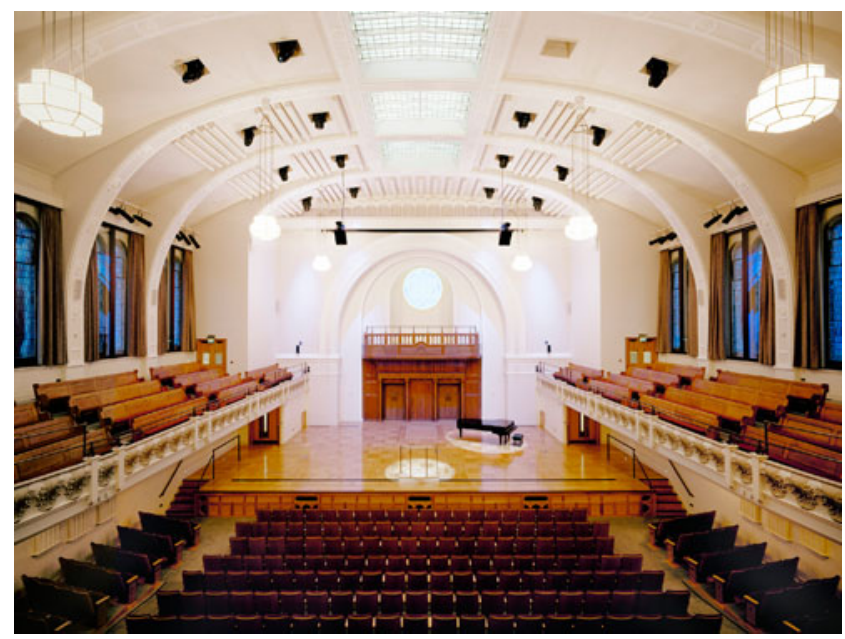

London's newest concert hall in the heart of Chelsea offers a wonderfully rich acoustic environment for one of the UK's 
leading baroque ensembles. The Cadogan Hall is a recently refurbished 900-seat concert hall on Sloan Terrace in Chelsea. Previously, the building was the First Church of Christ, Scientist, completed in 1907 to designs by the architect Robert Fellowes Chisholm. By 1996, the congregations had diminished dramatically and the building fell into disuse. Cadogan Estates, the property company owned by Earl Cadogan, whose ancestors have been the main landowners in Chelsea since the 18th century, purchased the building in 2000. It is grade 2-listed. Date: Sunday 29 May

Time: 19:00-20:30

Location: Cadogan Hall, 5 Slone Terrace, South Kensington, London, SW1X 9DQ

Distance from Hilton Hotel: 2.7 miles.

Transport: either a taxi journey or by London Underground to Slone Square station (District and Circle lines), from which Cadogan Hall is a 2-minute walk.

\section{Gala dinner}

Tickets are available to all delegates for purchase. They are not included with the registration fee.

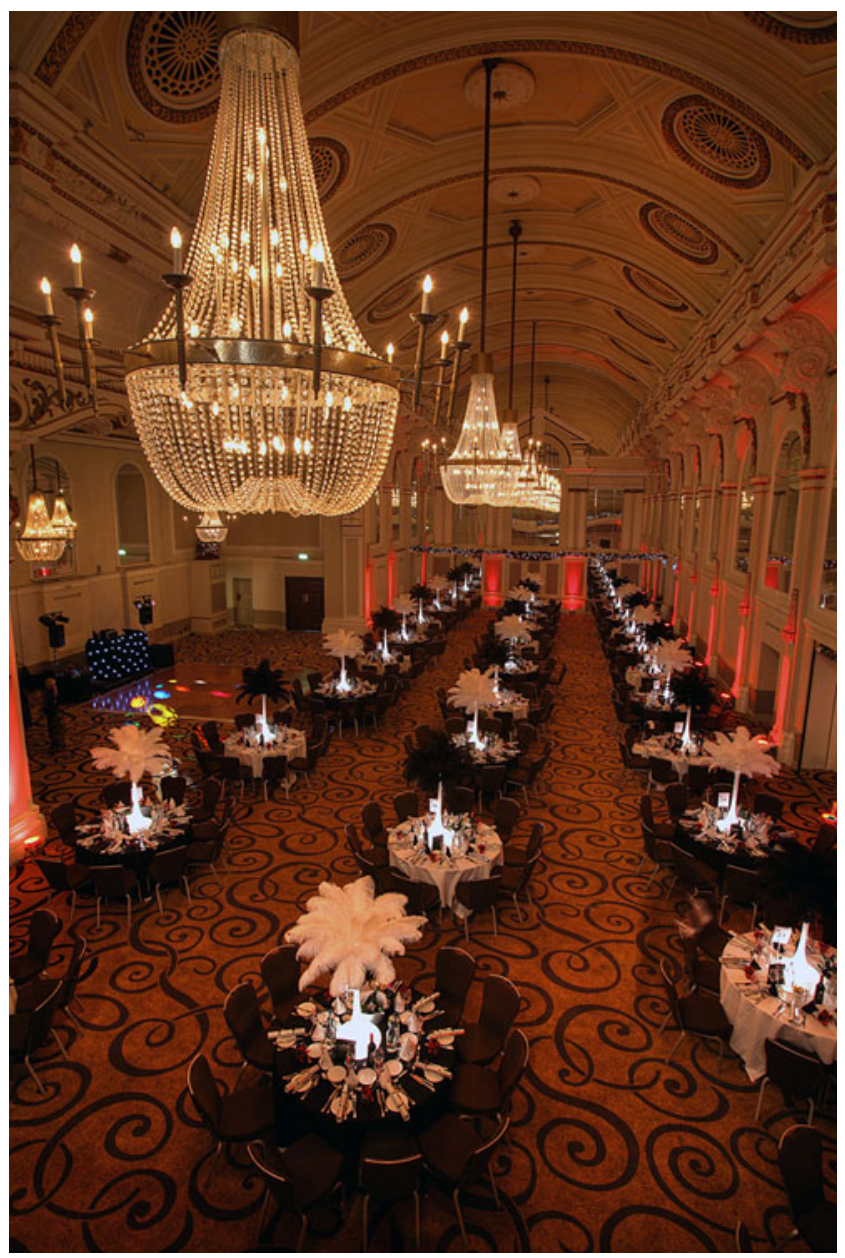

The Grand Connaught Rooms is one of the most superior and inspirational banqueting venues in Central London, offering a unique space that is a perfect location for the IPR gala dinner. The iconic Grand Hall, one of London's largest and most impressive event venues make the Grand Connaught Rooms the ultimate dinner venue in London.

Date: Tuesday 31 May

Time: 19:30 - Midnight

Location: Grand Connaught Rooms, 61-65 Great Queen Street, London, WC2B 5DA

Distance from Hilton Hotel: 2.9 miles. Transport: either a taxi journey or by London Underground to Convent Garden station (Piccadilly line) or Holborn station (Central and Piccadilly lines), from which the Grand Connaught Rooms is a short walk. 


\section{IPR 2011 - Programme}

Detailed programmes for the scientific sessions and task force meeting can be found in separate sections (Subject to change). All rooms are at Metropole Hilton Hotel unless specified otherwise

DAY 1 - FRIDAY 27 MAY 2011

\begin{tabular}{|c|c|c|c|}
\hline \multicolumn{2}{|r|}{$\begin{array}{c}\text { King } 1 \\
\text { Ultrasound summit }\end{array}$} & \multicolumn{2}{|r|}{$\begin{array}{c}\text { King } 2 \\
\text { Radiation Safety Summit }\end{array}$} \\
\hline $13: 30-15: 40$ & $\begin{array}{l}\text { Moderators: } \\
\text { Mike Riccabona ESPR } \\
\text { Brian Coley SPR } \\
\text { Honorary moderators: } \\
\text { Rose De Bruyn ESPR } \\
\text { Carol Rumack SPR }\end{array}$ & $13: 30-15: 35$ & $\begin{array}{l}\text { Moderators: } \\
\text { Marilyn Goske SPR } \\
\text { Richard Fotter ESPR } \\
\text { Honorary Moderators: } \\
\text { Paul Shrimpton HPA } \\
\text { Professor Willi Kalender }\end{array}$ \\
\hline $13: 30-13: 35$ & Introduction: Riccabona/Coley & $13: 30-13: 35$ & Introduction: Fotter/Goske \\
\hline $13: 35-13: 55$ & $\begin{array}{l}\text { Updates in neurosonography: } \\
\text { Corrine Veyrac }\end{array}$ & $13: 35-14: 00$ & $\begin{array}{l}\text { Quo vadis CT? } \\
\text { Professor Willi Kalender (Erlangen } \\
\text { University) }\end{array}$ \\
\hline $14: 00-14: 20$ & $\begin{array}{l}\text { Updates in neonatal Gl ultrasound: } \\
\text { Alan Daneman SPR }\end{array}$ & $14: 00-14: 25$ & $\begin{array}{l}\text { CT dosimetry - why do we need it and } \\
\text { what do we want to know? Paul } \\
\text { Shrimpton HPA }\end{array}$ \\
\hline $14: 20-14: 40$ & $\begin{array}{l}\text { Transcranial doppler - Paediatric } \\
\text { applications: } \\
\text { Suzanne Verhlac }\end{array}$ & $14: 25-14: 45$ & $\begin{array}{l}\text { Nuclear medicine and PET/CT - } \\
\text { justification and optimization: } \\
\text { Helen Nadel SPR }\end{array}$ \\
\hline $14: 40-15: 00$ & $\begin{array}{l}\text { Ultrasound of the paediatric chest: } \\
\text { Goya Enriquez ESPR }\end{array}$ & $14: 50-15: 05$ & $\begin{array}{l}\text { Interventional radiology: } \\
\text { /fluoroscopy/digital radiology: } \\
\text { Derek Roebuck ESPR }\end{array}$ \\
\hline $15: 00-15: 20$ & $\begin{array}{l}\text { Updates in paediatric renal sonography: } \\
\text { Freddy Avni ESPR }\end{array}$ & $15: 05-15: 25$ & $\begin{array}{l}\text { Update on the new patient dose index: } \\
\text { Keith Strauss SPR }\end{array}$ \\
\hline $15: 20-15: 35$ & $\begin{array}{l}\text { Contrast agents: Paediatric applications } \\
\text { Beth McCarville SPR }\end{array}$ & & \\
\hline $15: 40-16: 00$ & Coffee & & \\
\hline $16: 00-16: 20$ & $\begin{array}{l}\text { Updates in paediatric bowel sonography: } \\
\text { Kassa Darge SPR }\end{array}$ & $15: 50-16: 20$ & $\begin{array}{l}\text { CT protocols, the balance between dose } \\
\text { and quality - Fit for purpose } \\
\text { Richard Fotter ESPR }\end{array}$ \\
\hline $16: 20-16: 40$ & $\begin{array}{l}\text { Neonatal spine - how to do it: } \\
\text { Harriet Paltiel SPR }\end{array}$ & $16: 20-16: 40$ & $\begin{array}{l}\text { Oncology protocols - How can we do } \\
\text { better? } \\
\text { Sue Kaste SPR }\end{array}$ \\
\hline $16: 45-17: 05$ & $\begin{array}{l}\text { Updates in paediatric 3D/4D ultrasound: } \\
\text { Michael Riccabona ESPR }\end{array}$ & $16: 40-17: 10$ & $\begin{array}{l}\text { International outreach } \\
\text { Marilyn Goske SPR } \\
\text { Maria del Rosario Perez WHO } \\
\text { Madan Rehani IAEA }\end{array}$ \\
\hline $17: 05-17: 40$ & $\begin{array}{l}\text { Musculoskeletal ultrasound - new } \\
\text { paediatric applications } \\
\text { Carlo Martinoli }\end{array}$ & $17: 15-18: 00$ & $\begin{array}{l}\text { IPR Debate: } \\
\text { Should we consent patients for } \\
\text { radiation? }\end{array}$ \\
\hline $17: 40-18: 00$ & $\begin{array}{l}\text { The future of paediatric ultrasound } \\
\text { Brian Coley SPR } \\
\text { QA }\end{array}$ & & $\begin{array}{l}\text { Judge: Willi Kalender and Paul Shrimpton } \\
\text { Panel: Marilyn Goske, Richard Fotter, } \\
\text { Maria del Rosario Perez WHO } \\
\text { Madan Rehani IAEA } \\
\text { Yes: Rutger Jan Nievelstein ESPR } \\
\text { No: Don Frush SPR }\end{array}$ \\
\hline
\end{tabular}


Juvenile Idiopathic Arthritis Symposium, Hilton A/B

Moderators: Moderators Clarissa Pilkington, Karen Rosendahl ESPR

14:00 - 16:00

$14: 00$

$14: 20$

$14: 40$

$15: 00$

$15: 20$

$15: 40$
Recent advances in the treatment of JIA - the role of imaging Imaging in JIA - what can we learn from the OMERACT group? The OMERACT RA MRI scoring (RAMRIS) system.

Ultrasound in the diagnosis of JIA - description of a simplified wrist score and technological advances on data quantification related to the introduction of isotropic-voxel volumetric systems New research that might inform a novel MRI scoring system for disease activity in children

A novel scoring system for JIA based on MRI and XR - not exactly straightforward

Discussion - steps forward
Clarissa Pilkington

Speaker TBC

Carlo Martinoli

Lil-Sofie Ording-Müller ESPR

Karen Rosendahl ESPR

Task Force Programme

\begin{tabular}{|l|l|l|l|}
\hline Date & Time & Topic & Location \\
\hline Saturday 28 May & $14: 00-16: 00$ & Child Abuse Task Force & Hilton A / B \\
\hline Saturday 28 May & $16: 00-18: 00$ & Uro-radiology Task Force & Hilton A / B \\
\hline Sunday 29 May & $14: 00-16: 00$ & Dysplasia of the Hip Task Force & Hilton A / B \\
Sunday 29 May & $16: 00-18: 00$ & CT Dose Task Force & Hilton A / B
\end{tabular}

DAY 2 - SATURDAY 28 MAY 2011

Sunrise Sessions

\begin{tabular}{|c|c|}
\hline $\begin{array}{l}\text { Kings } \\
7: 00-8: 15\end{array}$ & $\begin{array}{l}\text { MRI Musculoskeletal } \\
\text { Moderators: Paul Babyn SPR and losif Mendikovsky } \\
\text { What the Radiologist needs to know. Practical principles of image optimisation: Part } 1 \text { signal to } \\
\text { image, pulse sequences: Øystein Olsen ESPR, Diego Jaramillo SPR } \\
\text { New dev in the evaluation of paediatric bone marrow and cartilage: Michael Ditchfield AOSPR } \\
\text { MR of knee: the old and the new: Jerry Dwek SPR }\end{array}$ \\
\hline $\begin{array}{l}\text { Cockburn Lecture } \\
\text { Theatre, St. } \\
\text { Mary's Hospital } \\
\text { 7:00-8:15 }\end{array}$ & $\begin{array}{l}\text { Neuroradiology - Advanced techniques } \\
\text { Moderators: Francis Brunelle ESPR and Ashok Panigrahy SPR } \\
\text { New frontiers for paediatric radiological imaging: Tim Roberts } \\
\text { ASL Perfusion Imaging in Paediatrics: Arastoo Vossough ASPNR } \\
\text { Perfusion DTI DSI: Ellen Grant SPR }\end{array}$ \\
\hline $\begin{array}{l}\text { Hilton B } \\
7: 00-8: 15\end{array}$ & $\begin{array}{l}\text { Foetal Chest } \\
\text { Moderators: Magali Saguintaah and Richard Barth SPR } \\
\text { Foetal evaluation of Congenital diaphragmatic hernias: Francoise Rypens SPR } \\
\text { Foetal Lung Masses: Guillaume Gorincour } \\
\text { Advances in Foetal Cardiac MRI: Shreyas Vasanawala SPR }\end{array}$ \\
\hline $\begin{array}{l}\text { Bannister } \\
\text { Lecture Theatre, } \\
\text { St. Mary's } \\
\text { Hospital } \\
\text { 7:00-8:15 }\end{array}$ & $\begin{array}{l}\text { Advanced Cardiac Imaging I } \\
\text { Moderators: Taylor Chung SPR and Christian Kellenberger ESPR } \\
\text { Assessment of TGA: Rajesh Krishnamurthy SPR } \\
\text { Assessment of Coronary Arteries: Hyun Woo Goo AOSPR } \\
\text { Assessment of single ventricle: Laureen Sena SPR }\end{array}$ \\
\hline $\begin{array}{l}\text { Hilton A } \\
7: 00-8: 15\end{array}$ & $\begin{array}{l}\text { Chest - Advanced Imaging } \\
\text { Moderators: Beverly Newman SPR and Charlotte De Lange ESPR } \\
\text { Practical MR scanning of the lung: Wolfgang Hirsch } \\
\text { Practical child imaging and interpretation of lung disease: Alan Brody SPR }\end{array}$ \\
\hline $\begin{array}{l}\text { Clinical } \\
\text { Lecture Theatre, } \\
\text { St. Mary's } \\
\text { Hospital } \\
\text { 7:00-8:15 }\end{array}$ & $\begin{array}{l}\text { Interventional Radiology updates } \\
\text { Moderators: Graham Wilkinson ESPR and Tim Cain AOSPR } \\
\text { Thrombolysis: Anne Marie Cahill SPR } \\
\text { Musculoskeletal interventions: Neil Johnson SPR } \\
\text { Urological interventions: Jim Donaldson SPR }\end{array}$ \\
\hline
\end{tabular}


DAY 2 - SATURDAY 28 MAY 2011

Main Programme (King 1 and King 2)

\section{Opening Ceremony}

\begin{tabular}{|c|c|}
\hline 08:20 & $\begin{array}{l}\text { Catherine M. Owens ESPR } \\
\text { Dorothy I. Bulas SPR }\end{array}$ \\
\hline $08: 30-08: 45$ & The future of children's' healthcare; a global issue: Professor Sir Cyril Chantler \\
\hline $08: 45-09: 45$ & $\begin{array}{l}\text { Jacques Lefebvre/Neuhauser Lecture: } \\
\text { Molecular imaging: Professor Sam Gambhir }\end{array}$ \\
\hline \multicolumn{2}{|c|}{ Course Session - Doctors in the Dock } \\
\hline 09:45-11:00 & Moderators: Paul Kleinman SPR and Christine Hall ESPR \\
\hline 09:50-10:10 & The medico legal system and radiologist - culpability/responsibility: Professor Peter Armstrong \\
\hline $10: 10-10: 30$ & A lifetime's perspective: Professor Sir Alan Craft \\
\hline $10: 30-10: 50$ & The judge's judgement: Justice Peter Kelly \\
\hline $10: 50-11: 00$ & Q\&A \\
\hline $11: 00-11: 20$ & Coffee Break \\
\hline
\end{tabular}

11:20 - 13:00 Moderators: Professor Andrew M. Taylor and Catherine M. Owens ESPR

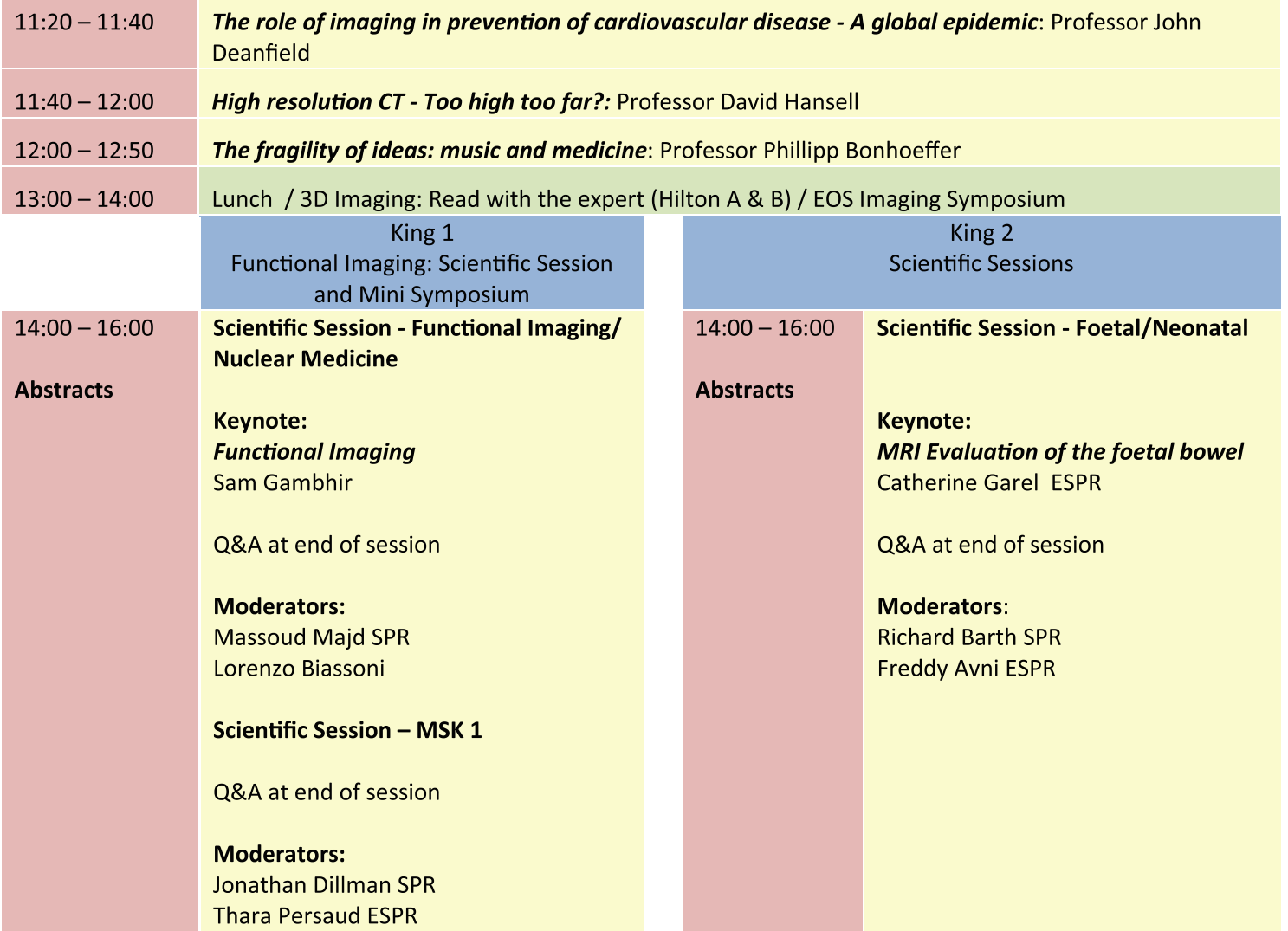




\begin{tabular}{|c|c|c|c|}
\hline $16: 00-16: 20$ & \multicolumn{3}{|l|}{ Coffee } \\
\hline $16: 20-18: 00$ & Mini Symposium Functional Imaging & $16: 20-18: 00$ & Scientific Session - Cardiac \\
\hline $16: 20-16: 45$ & $\begin{array}{l}\text { Molecular imaging in paediatrics: Peter } \\
\text { Brader ESPR } \\
\text { Building the paediatric radiology } \\
\text { department of the future: Raymond Sze } \\
\text { SPR }\end{array}$ & Abstracts & $\begin{array}{l}\text { Keynote: } \\
\text { Use of cardiac imaging to influence } \\
\text { new treatments in congenital heart } \\
\text { disease. } \\
\text { Andrew Taylor }\end{array}$ \\
\hline $17: 10-17: 35$ & $\begin{array}{l}\text { Imaging brain connectivity in the } \\
\text { developing brain in health and disease: } \\
\text { Chris Clark }\end{array}$ & & $\begin{array}{l}\text { Q\&A at end of session } \\
\text { Moderators } \\
\text { Zhu Ming AOSPR } \\
\text { Phalla Ou }\end{array}$ \\
\hline $17: 35-18: 00$ & $\begin{array}{l}\text { Magnetoencephalography Erin } \\
\text { Schwartz SPR } \\
\text { Moderators: } \\
\text { Pek Lan Khong AOSPR } \\
\text { Marina Easty ESPR }\end{array}$ & & \\
\hline $18: 00-19: 00$ & \multicolumn{3}{|c|}{$\begin{array}{l}\text { JESPeR/jSPR lecture } \\
\text { Unique radiographic and sonographic features of the neonatal abdomen } \\
\text { Professor Alan Daneman, Toronto Sick Children's Hospital }\end{array}$} \\
\hline $21: 00-0: 00$ & \multicolumn{3}{|c|}{ jSPR/jESPeR evening: Sway Club, 61-65 Great Queen Street, London, WC2B 5BZ } \\
\hline
\end{tabular}

DAY 3 - SUNDAY 29 MAY 2011

Sunrise Sessions

\begin{tabular}{|c|c|}
\hline $\begin{array}{l}\text { Kings } \\
7: 00-8: 15\end{array}$ & $\begin{array}{l}\text { MRI Abdomen } \\
\text { Moderators: Paolo Toma ESPR and Sheila Moore SPR } \\
\text { Practical principles of image optimisation: Part } 2 \text { motion elimination: } \varnothing y \text { stein Olsen ESPR, Diego } \\
\text { Jaramillo SPR } \\
\text { The growing role of MR in abdominal emergencies: Paul Humphries ESPR } \\
\text { MR enterography in Children: Kassa Darge SPR }\end{array}$ \\
\hline $\begin{array}{l}\text { Cockburn Lecture } \\
\text { Theatre, St. } \\
\text { Mary's Hospital } \\
7: 00-8: 15\end{array}$ & $\begin{array}{l}\text { Neuroradiology - The acutely ill child } \\
\text { Moderators: Gilbert Vezina ASPNR and Lesley Macpherson ESPR } \\
\text { Vascular Emergencies: Kling Chong ESPR } \\
\text { Updates in paediatric spine imaging: Pia Sundgren } \\
\text { New onset seizures: Charles Raybaud ASPNR }\end{array}$ \\
\hline $\begin{array}{l}\text { Hilton B } \\
7: 00-8: 15\end{array}$ & $\begin{array}{l}\text { Foetal Abdomen } \\
\text { Moderators: Freddy Avni ESPR and Beth Kline-Fath SPR } \\
\text { Foetal GI evaluation: Erika Rubesova SPR } \\
\text { Foetal Abdominal masses: Beth Kline-Fath SPR } \\
\text { Advances in foetal urologic MR evaluation: Kathia Chaumoitre }\end{array}$ \\
\hline $\begin{array}{l}\text { Bannister } \\
\text { Lecture Theatre, } \\
\text { St. Mary's } \\
\text { Hospital } \\
7: 00-8: 15\end{array}$ & $\begin{array}{l}\text { Advanced Cardiac Imaging II } \\
\text { Moderators: Andrew Taylor and Ron Cohen SPR } \\
\text { MR flow and ventricular volume: Shi- Joon Yoo SPR } \\
\text { Assessment of aortic disease: Oliver Tann } \\
\text { Assessment of TOF: Christian Kellenberger ESPR }\end{array}$ \\
\hline $\begin{array}{l}\text { Hilton A } \\
7: 00-8: 15\end{array}$ & $\begin{array}{l}\text { Nuclear Medicine - Image Fusion } \\
\text { Moderators: Ted Treves SPR and Diego de Palma EANM } \\
\text { SPECT/CT : Helen Nadel SPR } \\
\text { PET/MRI Body fusion: Thomas Pfluger EANM } \\
\text { Neuro PET/MRI SPECT/MRI fusion: Lise Borgwardt EANM }\end{array}$ \\
\hline $\begin{array}{l}\text { Clinical } \\
\text { Lecture Theatre, } \\
\text { St. Mary's } \\
\text { Hospital } \\
7: 00-8: 15\end{array}$ & $\begin{array}{l}\text { Interventional Radiology - Vascular } \\
\text { Moderators: Ricardo Restrepo SPR and Danièle Pariente ESPR } \\
\text { Hepatic vascular procedures: Danièle Pariente ESPR } \\
\text { High flow vascular malformations: Josée Dubois SPR/Patricia Burrows SPR } \\
\text { Low flow vascular malformations Philip John SPR }\end{array}$ \\
\hline
\end{tabular}


DAY 3 - SUNDAY 29 MAY 2011

Main Programme

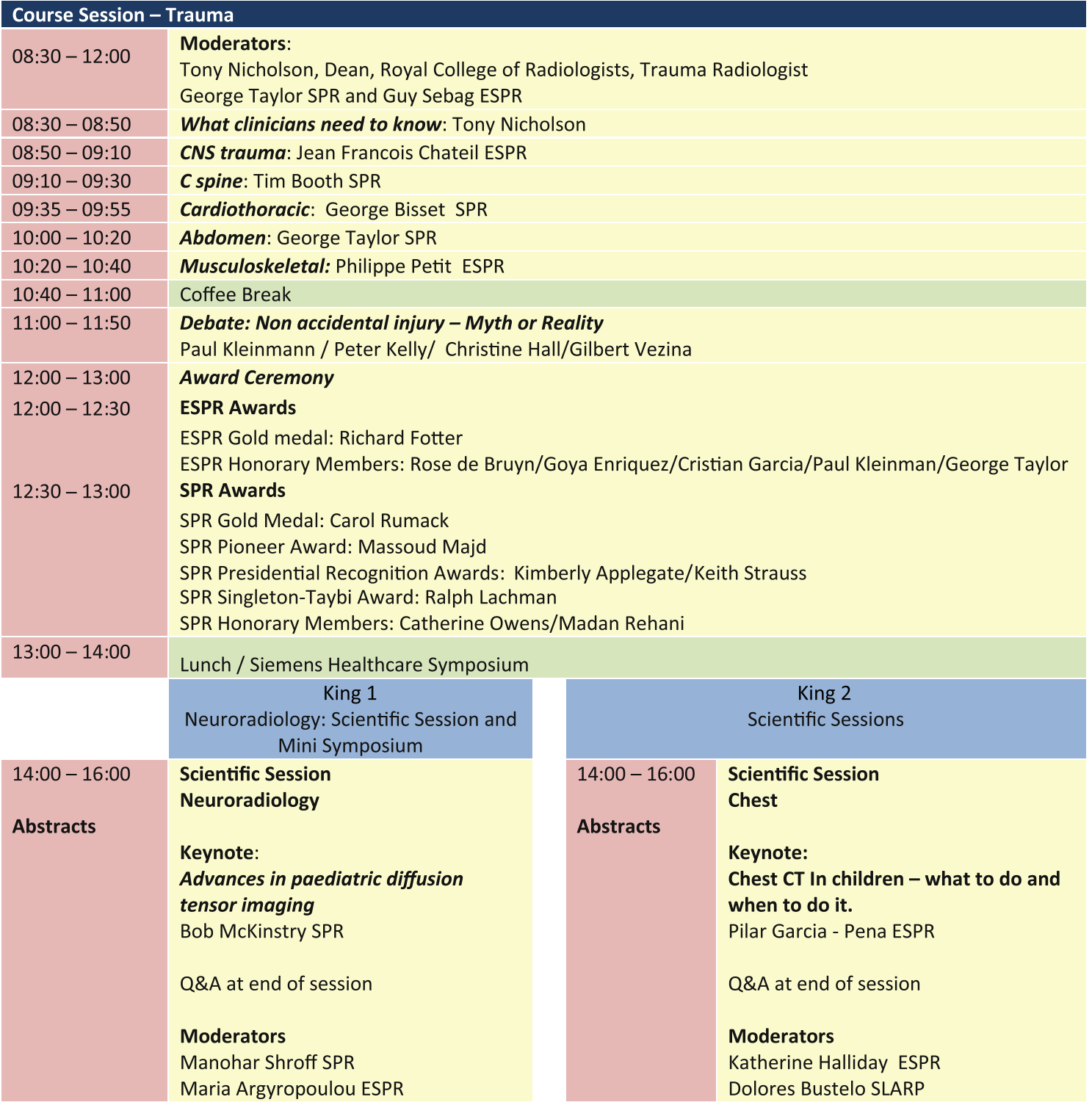




\begin{tabular}{|c|c|c|c|}
\hline $16: 00-16: 20$ & Coffee & & \\
\hline $\begin{array}{l}16: 20-18: 00 \\
\text { Abstracts }\end{array}$ & $\begin{array}{l}\text { Scientific session } \\
\text { Neuroradiology/ NAI } \\
\text { Keynote: } \\
\text { Evidence based Imaging of } \\
\text { headaches in children } \\
\text { Santiago Medina SPR } \\
\text { Q\&A at end of session } \\
\text { Moderators: } \\
\text { Richard Robertson SPR } \\
\text { Catherine Adamsbaum ESPR } \\
\text { Scientific session } \\
\text { Non-accidental injury } \\
\text { Q\&A at end of session } \\
\text { Moderators: } \\
\text { David Yousefzadeh SPR } \\
\text { Andrew Rickett ESPR }\end{array}$ & $\begin{array}{l}16: 20-18: 00 \\
\text { Abstracts }\end{array}$ & $\begin{array}{l}\text { Scientific Session } \\
\text { Genitourinary } \\
\text { Keynote } \\
\text { UTI workup - top down or down up? } \\
\text { Lil-Sophie Ording Muller ESPR } \\
\text { Q\&A at end of session } \\
\text { Moderators } \\
\text { David Stringer AOSPR } \\
\text { Paolo Toma ESPR }\end{array}$ \\
\hline
\end{tabular}

DAY 4 - MONDAY 30 MAY 2011

Sunrise Sessions

\begin{tabular}{|c|c|}
\hline $\begin{array}{l}\text { Kings } \\
7: 00-8: 15\end{array}$ & $\begin{array}{l}\text { MRI Retroperitoneal } \\
\text { Moderators: Jonathan Dillman SPR and Philippe Petit ESPR } \\
\text { Practical principles of image optimisation: Part } 3 \text { motion elimination: Øystein Olsen ESPR, Diego } \\
\text { Jaramillo SPR } \\
\text { Hydronephrosis: Damien Grattan-Smith SPR }\end{array}$ \\
\hline $\begin{array}{l}\text { Cockburn Lecture } \\
\text { Theatre, St. } \\
\text { Mary's Hospital } \\
7: 00-8: 15\end{array}$ & $\begin{array}{l}\text { Foetal Neuroradiology } \\
\text { Moderators: Thierry Huisman SPR and Nadine Girard } \\
\text { Foetal Ventriculomegaly Diagnostic challenges: Thierry Huisman SPR } \\
\text { Advances in foetal CNS MR imaging: Nadine Girard } \\
\text { Quantitative MRI measurements of human foetal brain development in utero: Chen Hoffmann }\end{array}$ \\
\hline $\begin{array}{l}\text { Hilton B } \\
7: 00-8: 15\end{array}$ & $\begin{array}{l}\text { MRI Musculoskeletal Sports } \\
\text { Moderators: Herman Kan SPR, Guy Sebag ESPR and Ignasi Barber ESPR } \\
\text { Injuries of the upper extremity: Kelley Marshall SPR } \\
\text { Injuries of the hip: Amaka Offiah ESPR } \\
\text { Injuries of the foot and ankle: Peter Strouse SPR }\end{array}$ \\
\hline $\begin{array}{l}\text { Bannister } \\
\text { Lecture Theatre, } \\
\text { St. Mary's } \\
\text { Hospital } \\
7: 00-8: 15\end{array}$ & $\begin{array}{l}\text { Chest Radiographs, what you need to know } \\
\text { Moderators: Ron Cohen SPR and Ingmar Gassner ESPR } \\
\text { Chest: manifestations of systemic diseases: Paul Guillerman SPR } \\
\text { The CXR what you really need to know in } 2011 \text { : Bob Cleveland SPR }\end{array}$ \\
\hline $\begin{array}{l}\text { Hilton A } \\
7: 00-8: 15\end{array}$ & $\begin{array}{l}\text { Nuclear Medicine - Therapeutic Response Monitoring } \\
\text { Moderators: Pranav Vyas SPR and Lorenzo Biassoni } \\
\text { Lymphomas: Beth McCarville SPR } \\
\text { MSK Tumors: Christian Franzius EANM } \\
\text { Neuroblastoma: Susan Sharp SPR }\end{array}$ \\
\hline $\begin{array}{l}\text { Clinical } \\
\text { Lecture Theatre, } \\
\text { St. Mary's } \\
\text { Hospital } \\
7: 00-8: 15\end{array}$ & $\begin{array}{l}\text { Interventional Radiology - Surgery or Radiology? } \\
\text { Moderators: Derek Roebuck ESPR and Torre Andrews SIR } \\
\text { Introduction: Torre Andrews SIR } \\
\text { A surgeon's perspective Martin Elliott } \\
\text { Integrating IR into the OR environment: John Racadio SPR }\end{array}$ \\
\hline
\end{tabular}


DAY 4 - MONDAY 30 MAY 2011

Main Programme (King 1 and King 2)

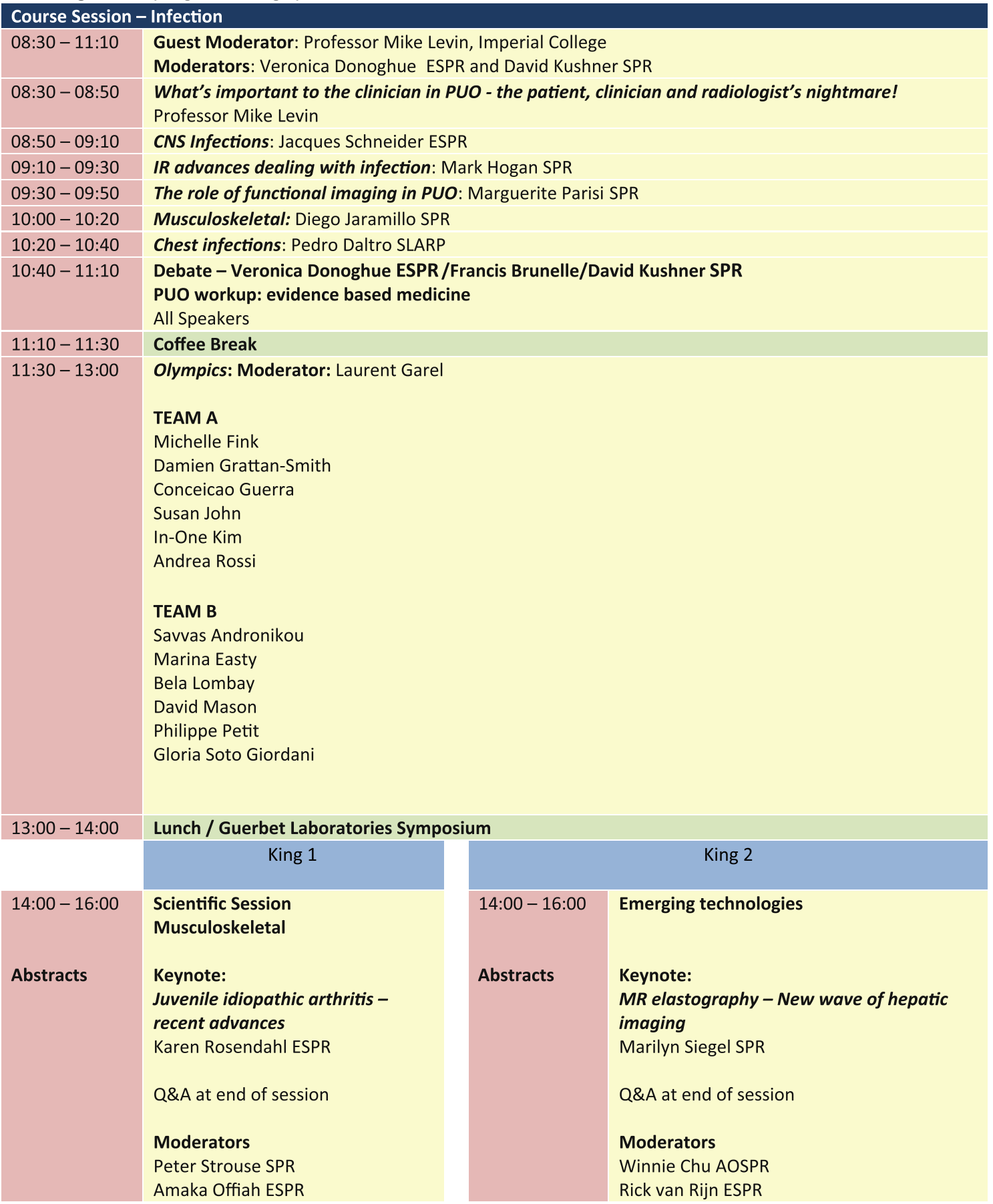




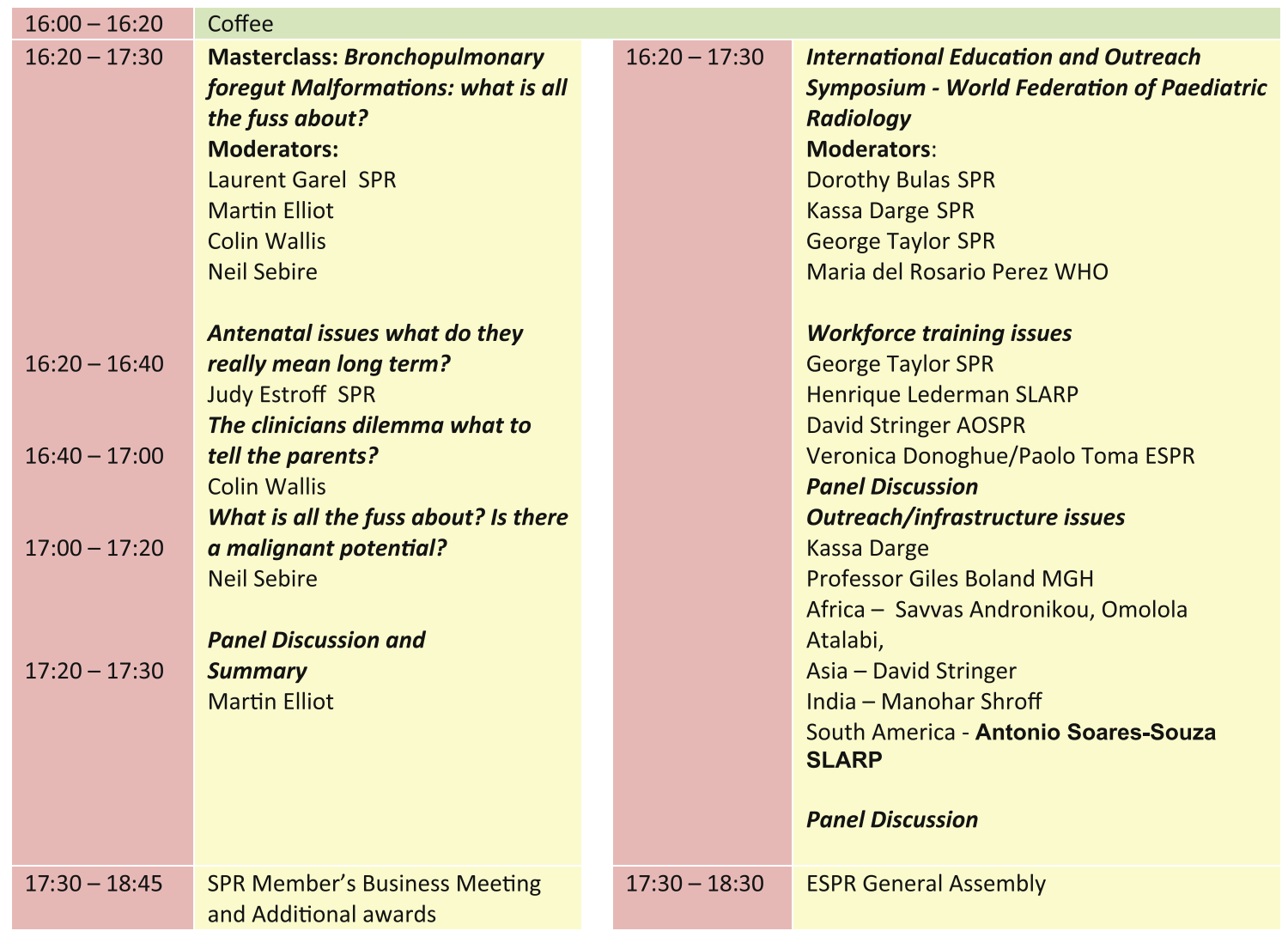

DAY 4 - MONDAY 30 MAY 2011

Paediatric Nuclear Medicine - Dose Reduction Symposium, Hilton A/B

This symposium is organized by the paediatric nuclear medicine community to review current options and discuss future goals regarding the optimization of paediatric nuclear medicine studies.

All are welcome to participate.

Moderators: Marguerite Parisi SPR and Diego de Palma EANM

$14: 00-17: 00$

14:00 CT in PET/CT, SPECT/CT

14:25 Resolution recovery (2D - SPECT)

14:45 Administered activity

15:00 Administered activity EANM

15:20 Modifying protocols to reduce administered activity

$15: 40$

$16: 00-17: 00$
F-8-fluoride bone PET needs CT?

$Q \& A$ and Discussion
Michael Gelfand SPR

Frederic Fahey

Ted Treves SPR

Diego De Palma EANM

Roberto Accorsi

Frederick Grant 
DAY 5 - TUESDAY 31 MAY 2011

Sunrise Sessions

\begin{tabular}{|c|c|}
\hline $\begin{array}{l}\text { Kings } \\
7: 00-8: 15\end{array}$ & $\begin{array}{l}\text { MRI Cardiac updates for the paediatric radiologist } \\
\text { Moderators: Hyun Woo Goo AOSPR and Taylor Chung SPR } \\
\text { Sequential analysis: Andrew Cook } \\
\text { CT / MRI which to use when: Frandics Chan SPR } \\
\text { 3D imaging of the heart: Gerald Greil }\end{array}$ \\
\hline $\begin{array}{l}\text { Cockburn Lecture } \\
\text { Theatre, St. } \\
\text { Mary's Hospital } \\
\text { 7:00-8:15 }\end{array}$ & $\begin{array}{l}\text { Neuroradiology neonatal imaging updates } \\
\text { Moderators: Dr. Pek Lan Khong AOSPR and Maria Argyropolou ESPR } \\
\text { Pre and postnatal brain development: Charles Raybaud SPR } \\
\text { Advances in MR imaging: Increased insight into the neonatal brain : Elida Vazquez ESPR } \\
\text { Hypoxic ischemic encephalopathy: Ashok Panigrahy }\end{array}$ \\
\hline $\begin{array}{l}\text { Hilton B } \\
7: 00-8: 15\end{array}$ & $\begin{array}{l}\text { Foetal and Neonatal Skeletal Dysplasia updates } \\
\text { Moderators: Amaka Offiah ESPR and Ella Onikul AOSPR } \\
\text { Foetal Skeletal dysplasia: Rita Teele SPR } \\
\text { Neonatal presentation of skeletal dysplasias: Christine Hall } \\
\text { Where are we now \& where do we go in the future regarding the diagnosis of skeletal dysplasia: } \\
\text { Ralph Lachman SPR }\end{array}$ \\
\hline $\begin{array}{l}\text { Bannister } \\
\text { Lecture Theatre, } \\
\text { St. Mary's } \\
\text { Hospital } \\
7: 00-8: 15\end{array}$ & $\begin{array}{l}\text { Paediatric Advanced Imaging and Informatics: State of the Art } \\
\text { Visualization from the Fetus to the Adolescent } \\
\text { 3D Structural Preserving Noise Reduction for Cardiovascular MRI and CT - Workstation } \\
\text { Algorithms for Improved Image Quality and Radiation Safety: Jeffrey Hellinger SPR } \\
\text { Skeletal Dysplasias, Disorders, and Trauma: 2D and 3D Imaging Techniques for enhanced } \\
\text { interpretation and workflow efficiency: Teressa Victoria SPR } \\
\text { Volume Rendering, MinIP, and MIP for the Airways and Lung: What, How, and Why: } \\
\text { Alister Calder and Carol Young ESPR } \\
\text { Diffusion Tensor Imaging Post-processing Techniques and CNS Applications: Andrea Rossi ESPR } \\
\text { Dynamic Functional and Virtual Anatomic GI and GU Workstation Applications: } \\
\text { Monica Epelman SPR" }\end{array}$ \\
\hline $\begin{array}{l}\text { Hilton A } \\
7: 00-8: 15\end{array}$ & $\begin{array}{l}\text { Chest emergencies and airways } \\
\text { Moderators: Lynn Anthony SPR and Claudio Fonda ESPR } \\
\text { Chest emergencies: Katharine Foster ESPR } \\
\text { The airways; all you need to know in } 30 \text { mins: Ed Lee SPR }\end{array}$ \\
\hline $\begin{array}{l}\text { Clinical } \\
\text { Lecture Theatre, } \\
\text { St. Mary's } \\
\text { Hospital } \\
\text { 7:00-8:15 }\end{array}$ & $\begin{array}{l}\text { Information Technology Dilemmas - Ask the experts } \\
\text { Moderator: Neil Johnson SPR } \\
\text { Panel: } \\
\text { Alex Towbin SPR } \\
\text { Ed Weinberger SPR } \\
\text { Jean-Francois Chateil ESPR } \\
\text { Erich Sorantin ESPR }\end{array}$ \\
\hline
\end{tabular}

DAY 5 - TUESDAY 31 MAY 2011

Main Programme (King 1 and King 2)

\begin{tabular}{|c|c|}
\hline $08: 30-13: 00$ & $\begin{array}{l}\text { Moderators - Øystein Olsen ESPR, Sue Kaste SPR } \\
\text { Guest moderator: Professor Kathy Pritchard-Jones }\end{array}$ \\
\hline $08: 30-9: 40$ & Wilms' tumour in children with predisposing conditions - how to detect, and how to follow? \\
\hline 08:30 & Clinicial and biological perspective: Professor Kathy Pritchard-Jones \\
\hline 08:50 & MRI - new techniques and critical appraisal: Damien Gratton Smith SPR \\
\hline 09:10 & PET - new techniques and critical appraisal: Dr. Peter Brader ESPR \\
\hline 09:30 & Discussion \\
\hline $09: 40-12: 10$ & The future of oncological imaging \\
\hline 09:40 & Advances in oncological PET imaging: Michael Gelfand SPR \\
\hline 10:00 & Advances in local, regional and whole-body staging Hyun Woo Goo AOSPR \\
\hline $10: 20$ & Interventional radiology - what will be on offer for children with cancer in future? Fred Hoffer SPR \\
\hline $10: 40-11: 00$ & Coffee Break \\
\hline $11: 00$ & New treatments and new imaging techniques - where are we going? Stephan Voss SPR \\
\hline $11: 20$ & Histopathology and imaging - are the boundaries blurring? Professor Neil Sebire \\
\hline $11: 40$ & Advances in CNS tumour imaging: Andrea Rossi ESPR \\
\hline $12: 00-12: 10$ & Discussion \\
\hline
\end{tabular}




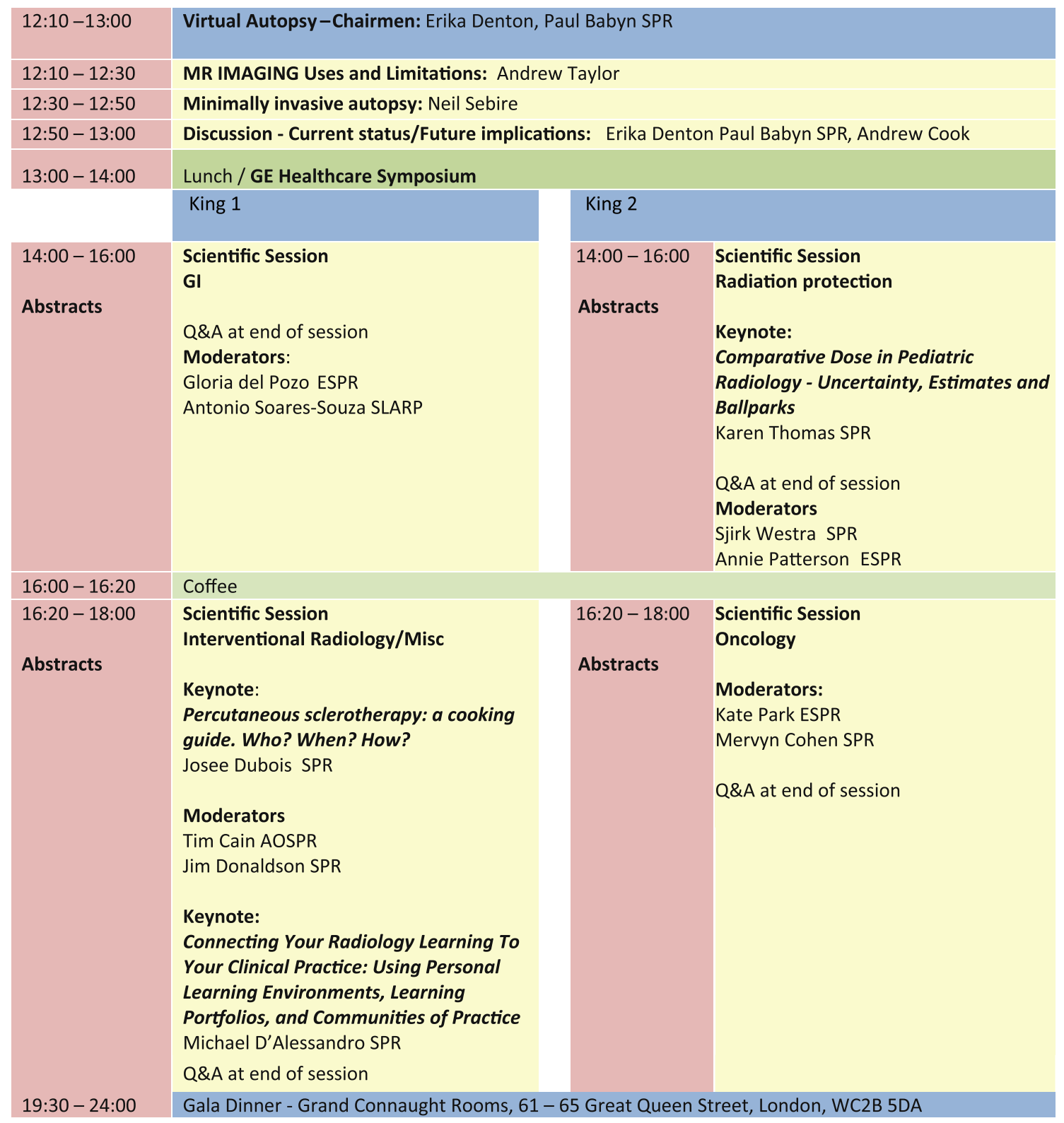


Mini-symposium and public session: ESPR paediatric uroradiology task force (120 $\mathrm{min})$

Joint ESPR task force and ESUR paediatric work group

Chaired by M. Riccabona and F. Avni

\section{Content and description}

This ESPR uroradiology task force mini-symposium aims at presenting and discussing new essential problems in paediatric GU imaging to complete and supplement existing recommendations of the group. The results of the public discussion after the individual presentations on imaging in paediatric cystic renal disease and imaging in childhood renal transplantation, will be integrated into the proposals. These will then again be presented and discussed at the annual ESUR meeting by the ESUR paediatric work group for discussion before being finalised and published. All existing recommendations as well as the new proposals can be found at the poster area for information. Every comment is welcome.

A special focus of this session is the use of US contrast media (US-CM) in children. To promote the licensing of US-CM for use in children, an extensive meta-analysis and data from a Europe-wide questionnaire will be presented to back-up existing recommendations on indications and (at present off-license) use for paediatric contrast-enhanced US. These data and the result of the discussion will then be brought forward to the official bodies asking them to consider registering US-CM for paediatric applications, as a joint effort of ESPR, ESUR, GPR and EFSUMB.

1) How to image and classify paediatric cystic kidney disease - an update (Avni/Riccabona; $10+5 \mathrm{~min}$ )

Objectives:

- Which imaging modality to use when for assessing suspected cystic renal disease in infancy and childhood

- How to classify cystic renal disease based on new theoretical insights and their respective imaging appearance

- To learn about the natural course of paediatric cystic renal disease

- To list the implications of new and accordingly adapted imaging based classification of cystic kidney disease on modern therapeutic approaches

2) Imaging in children with renal transplant (Damasio/ Ordning-Müller/Riccabona/ Willi; $10+5 \mathrm{~min}$ )

Objectives:

- Try to harmonise imaging in childhood renal transplant

- Propose a minimum standardised imaging algorithm and protocol for the various stages and queries during and following childhood renal transplant

- To learn about the basic needs and problems in renal transplantation and their implication for required imaging
- To discuss efficient use of imaging, not only to reduce costs, but also to minimise invasiveness

- To define pre-transplant imaging in recipient and donor, peri-operative imaging during and briefly after transplantation, as well as follow-up imaging (including the value of US, CE-US, MRI, nuclear medicine, and image-guided interventional procedures)

3) Paediatric US contrast media (US-CM)

Objective:

- Try to define and analyse the present stage of use of US$\mathrm{CM}$ in children

- To propose indications for off-license US-CM applications in childhood

- To summarise what we know about the use and safety of US-CM applications in childhood

- To present the results from an ESPR survey on the use of US-CM in Europe with its safety implications

- To discuss what can and should be done by the task force and the ESPR to promote and push for paediatric registration of US-CM

Contents:

a) How to promote and apply CE-(V)US in children considerations on present state (Avni; $7+5 \mathrm{~min}$ )

b) Meta-analysis of CE-VUS applications based on a literature research (Papadopoulou/Darge; $10+5 \mathrm{~min}$ )

c) Current use of CE-US beyond Europe, particularly in the United States (Darge; 3 min)

d) General consideration concerning indications for and applications of SonoVue ${ }^{\circledR}$ and CE-US applications in children - present state (Claudon; $10+5 \mathrm{~min}$ )

e) Safety aspects of SonoVue ${ }^{\circledR}$ and US contrast media in childhood - results of an ESPR survey and questionnaire (Riccabona; $10+5 \mathrm{~min}$ )

Panel discussion with public contribution:

ESPR statement on the use of SonoVue ${ }^{\circledR}$ (and other US contrast media) in children

Panel: Avni, Claudon, Darge, Papadopoulou, Riccabona $(10+10 \mathrm{~min})$

\section{The developmental dysplasia of the hip task force} Chaired by K. Rosendahl, P. Tomà

14.00-14.10 Hip screening - status Europe. Short summary of the presentations in Bordeaux 2010. (Prof. Paolo Toma) 14.10-14.40 New research that might inform screening policies. From the Dutch (Ass.prof. Magda Boere-Boonekamp) and Norwegian/British (PhD-fellow Dr Lene Bjerke Laborie) research groups.

14.40-15.00 Screening for DDH - from a clinical perspective. (Ms Deborah Eastwood, paediatric orthopaedic surgeon) 
15.00-15.20 Recommendations on hip screening from the DDH task force working group. (Prof. Karen Rosendahl)

15.20-15.40 Training, accreditation/competency assessment, report forms etc. (Dr Rosemary Arthur)

15.40-16.00 Discussion - steps forward

\section{The CT-dose task force (90 mins)}

Chaired by Richard Fotter, Catherine M Owens

1) Introduction - CT phantom studies - resources and costs (R. Fotter, 15 mins)

2) "Fit for purpose" (C. Owens, 15 mins)

3) Optimising the $\mathrm{CT}$ imaging chain for paediatric use - from scout view to automatic exposure control (E. Sorantin, 15 mins) 4) Iterative reconstruction in multidetector-CT - another step forward in dose reduction (R. J. Nievelstein, 15 mins) 5) An EENPR multi-centre trial: can WB-MRI replace CT and/or PET/CT in diagnosis and follow up of paediatric malignant lymphoma? (R. J. Nievelstein, 15 mins)

6) Discussion (15 mins)

\section{The child abuse task force (90 mins)}

Chaired by R. Van Rijn

Objective: Child abuse is a universal, and unfortunately sometimes underestimated, socio-medical problem. Paediatric radiologists not only play a vital role in the primary detection of physical child abuse but also in the differential diagnostic process. The aim of this task force is to come to a harmonisation of the imaging approach throughout Europe, create social bonds between paediatric radiologists involved in this field, and to support international cooperation in research projects.

1) Introduction: Aim of the task force (R. van Rijn)

2) Guidelines, rationale and adherence (A. Offiah)

3) Experiences from the USA, the role of a societies task force (J. Perez-Rossello)

4) Vitamin D deficiency - myth or reality, a position statement (A. Offiah, J. Perez-Rosello, R. van Rijn) 


\section{Scientific sessions}

Questions and discussion will be conducted per session, or per block of presentations at the moderators' discretion. Exact timing is therefore not provided. If reserve presentations are 'activated', they will be inserted into the order of the other presentations based on their topic.

Author name in italic, indicates presenting author.

\section{Functional (FU) Saturday 14:00-15:00}

\section{Room 1}

Moderators: Massoud Majd, Lorenzo Biassoni

Keynote: Sam Gambhir, Functional Imaging

6 presentations

FU-1

Effectiveness of Pre-Medication and Pre-Warming for Suppression of FDG Uptake in Brown Adipose Tissue

Michael Gelfand, Jessica Huang, Susan Sharp

FU-2

Differentiation of the normal thymus from mediastinal lymphoma on Pediatric PET-CTs

Heike Daldrup-Link, Rakhee Gawande, Aman Khurana, Randy Hawkins

FU-3

PET with Selective CT at Follow-Up in Pediatric and Adolescent Patients with Lymphoma

Michael Gelfand, Jessica Huang, Susan Sharp

FU-4

MRI vs. PET/CT for detection of focal splenic lesions in paediatric and adolescent lymphoma at initial staging

Shonit Punwani, King Kenneth Cheung, Nicholas Skipper, Alan Bainbridge, Stuart Taylor, Ashley Groves, Sharon Hain, Simona Ben-Haim, Ananth Shankar, Paul Humphries

\section{FU-5}

PET/CT and MRI Capability of Detection of Early Soft Tissue Inflammatory Changes in Knees of a BloodInduced Arthropathy Rabbit Model

Afsaneh Amirabadi, Amer Shammas, Elka Miller, Anguo Zhong, Ruth Weiss, Tammy Rayner, Rahim Moineddin, Harpal Gahunia, Marianne Rogers, Roland Jong, Andrea Doria

FU-6

Clinical Experience with Lower Dose FDG Pediatric Brain PET-CT

Jeffrey Miller, Gerald Mandell, Richard Towbin, John Curran

FU-R1

PET-CT in Pediatric Rhabdomyosarcoma
Beth McCarville, Matt Krasin, Sheri Spunt, Catherine Billups, Jianrong $\mathrm{Wu}$, Barry Shulkin

\section{Foetal/neonatal (FN) Saturday 14:00-16:00}

Room 2

Moderators: Freddy Avni, Richard Barth

Keynote: Catherine Garel, MRI Evaluation of the foetal bowel 14 presentations

FN-1

Results of the SPR Fetal Imaging Task Force Survey

Lucia Carpineta, Judy Estroff, Christopher Cassady

FN-2

Diffusion-weighted imaging (DWI) of the fetal brain in utero: reproducibility study and normal values.

Marianne Alison, Agnès Sartor, Nadia Belarbi, Bogdana Tilea, Emilie Josserand, Corinne Alberti, Jean Francois Oury, Monique Elmaleh-Berges, Guy Sebag

\section{FN-4}

Dynamic Evaluation of the Secondary Palate During Fetal Swallowing: A Novel Application for Cine FIESTA MRI

Neil Lester, Susan Connolly, Carol Barnewolt, Robert Mulkern, Judy Estroff

\section{FN-5}

Predictive factors in fetal survival with isolated left congenital diaphragmatic hernia

Teresa Victoria, Michael Bebbington, Enrico Danzer, Alan W Flake, Mark P Johnson, Scott N Adzick, Holly Hedrick

\section{FN-6}

Prenatal US imaging of congenital lung lesions (CLL): proper reporting of salient findings alleviates postnatal confusion

Laurent Garel, Françoise Rypens, Andrée Grignon, Josée Dubois, Chantale Lapierre, Denis Filiatrault, MarieClaude Miron, Julie Dery, Jean Claude Decarie, Gilles Perreault

\section{FN-7}

Antenatal and post natal diagnosis and follow-up of renal vein thrombosis

Freddy Avni, Michel Wlasdorff

FN-8

Ultrasonographic study of postnatal renal growth in premature infants

Yun-Jung Lim, Woo Sun Kim, Su-Mi Shin, Jung-Eun Cheon, In-One Kim, Yoo Jin Kim, Ji Young Kim, Kyung Mo Yeon 


\section{FN-9}

Hypoxic ischemic injury: Intestinal appearances and perfusion measurements using Ultrasound and dynamic color Doppler sonography in neonates submitted to therapeutic hypothermia.

Guilherme Cassia, Ricardo Faingold, Linda Morneault, Guilherme Sant'Anna, Anna Ben Ely

\section{FN-10}

Thrombosis associated with umbilical artery catheterization Natalia Simanovsky, Zivanit Ergaz Shaltiel, Katya Rozovsky, Nurith Hiller, Benjamin Bar Oz

FN-11

Cerebellar Injury in Very Low Birth Weight Infants Preliminary Results at a Tertiary Institution

Michalle Soudack, Lisa Raviv-Zilka, Aviva Ben-Shlush, Jeffrey Jacobson

\section{FN-12}

The spectrum of associated brain lesions in cerebral sinovenous thrombosis (CSVT): relation to gestational age and outcome

Rutger A.J. Nievelstein, K. Kersbergen, F. Groenendaal, M. Benders, H. Van Straaten, R. Nievelstein, L. De Vries

FN-13

Brain MRI based choice of best time for TGA surgery: inside brain protection.

Yevgeniya Yershova, Tetyana Yalynska, Andrey Maximenko, Illya Yemets

FN-14

A Potential New Marker for Fetal Karyotype Abnormality: Dense, premature Ossification of the Calcaneum on Post Mortem Fetal Radiograph

Susan Morris, Denise Robinson, Edgar Lazda, Gordon Vujanic

FN-R1

National Survey of Obstetric and Pediatrics Specialists' Attitudes Regarding Pregnancy Management

Stephen Brown, Jeffrey Ecker, Johanna Mailhot, Elkan Halpern, Sadath Sayeed, Terry Buchmiller, Christine Mitchell, Karen Donelan

\section{FN-R2}

Correlations between pre- and postnatal cerebral MRI

Amira Dhouib, Eléonore Blondiaux, Marie-Laure Moutard, Thierry Billette de Villemeur, François Chalard, Jean-Marie Jouannic, Hubert Ducou le Pointe, Catherine Garel
Musculo-skeletal 1 (MS1) Saturday 15:00-16:00

Room 1

Moderators: Thara Persaud, Jonathan Dillman

7 presentations

MS1-1

Ultrasound of brachial plexus birth injury in infants: experience in a series of 80 patients

Maura Valle, Nunzio Catena, Filippo Senes, Maria Grazia Calevo, Carlo Martinoli

MS1-2

Ultrasound of Poland Syndrome

Maura Valle, Maria Grazia Calevo, Anwar Baban, Michele Torre, Carlo Martinoli

MS1-3

Variability of femoral condylar ossification on MRI: imaging features, frequency and age distribution.

Lennart Jans, Jacob Jaremko, Michael Ditchfield, Koenraad Verstraete

MS1-4

Assessment of cortical bone loss with quantitative ultrasound, peripheral CT and micro-CT in postmortem knee specimens of a rabbit model of inflammatory arthritis Afsaneh Amirabadi, Jackson Wang, Christopher Gordon, Christopher Tomlinson, Marc Grynpas, Rahim Moineddin, Andrea Doria

\section{MS1-5}

Avascular necrosis of bone in adolescents with classical Hodgkin's Lymphoma- a single centre experience Michael Steward, Peter Boavida, Joseph Cooney, Ananth Shankar, Stephen Daw, Paul Humphries

MS1-6

Early assessment of the efficacy of digital infrared thermal imaging in pediatric extremity trauma

Cicero Silva, Nausheen Naveed, Syed Bokhari, Kenneth Baker, Lawrence Staib, Thomas Goodman

MS1-7

Lumbar back pain and the use of plain lumbar radiographs Tom Watson, Jeremy Jones, Annmarie Jeanes

MS1-R1

Mechanisms of injury in children less than 3 years of age presenting to an emergency department Amaka Offiah, Jessica Hume, Sally Gibbs, Alan Sprigg, Derek Burke 


\section{Cardio-vascular (CV) Saturday 16:20-18:00}

Room 2

Moderators: Zhu Ming, Phalla Ou

Keynote: Andrew Taylor, Use of cardiac imaging to influence new treatments in congenital heart disease

11 presentations

\section{CV-1}

Quantification of the distribution of the normal human fetal circulation using MRI

Mike Seed, Christopher Macgowan, Lars Grosse-Wortmann, Derek Wong, Grattan Michael, Edgar Jaeggi, Susan Blaser, Shi- Joon Yoo

CV-2

Preliminary experience with magnetic resonance imaging in evaluation of fetal congenital heart disease

Zhu Ming

CV-3

Anomalous aortic origin of coronary artery: pre- and postoperative cross sectional imaging features in children Andrada Popescu, Cynthia K. Rigsby, R. Andrew deFreitas, Sunjay Kaushal, Stanley T. Kim

\section{CV-4}

Assessment of pulmonary insufficiency in Fallot patients by cine MRI-is cine imaging sufficient?

Erich Sorantin, Luis Riera, Robert Marterer, Franz Quehenberger

\section{CV-5}

Evaluation of the pulmonary valve function under physical stress using cMRI-could it be a prognostic value in the follow up of TOF patients in the future?

Robert Marterer, Erich Sorantin, Bert Nagel

\section{CV-6}

Systemic-pulmonic collateral flow differences observed in children with functional single ventricles from bidirectional Glenn to Fontan palliations

Adeka McIntosh, Marc Keller, Matthew Harris, Mark Fogel, Kevin Whitehead

\section{CV-7}

Evaluation of asplenia syndrome with bilateral tracheal bronchi using multidetector CT and MRI

Zhu Ming

\section{CV-8}

Late Gadolinium enhancement (LGE) MR in the assessment of Restrictive RV Fibrosis After Biventricular Repair of Pulmonary Atresia and Intact Ventricular Septum

Wendy Lam, Xc Liang, Eddie Cheung, Sj Wong, Yf Cheung

CV-9

Post processing noise reduction restores image quality of low dose CTA

$S$ Bruce Greenberg, Sadaf Bhutta

CV-10

Quantitative Assessment of Blood Flow with 4D PhaseContrast MRI and Autocalibrating Parallel Imaging Compressed Sensing

Albert Hsiao, Michael Lustig, Marcus Alley, Mark Murphy, Shreyas Vasanawala

CV-11

Pediatric Cardiomyopathies: Evaluation with Advanced Magnetic Resonance Imaging

Shobhit Madan, Michael Mishra, Gayathri Sreedhar, Sameh Tadros

CV-R1

CT Determination of Intramural Course of Malignant Aberrant Coronary Artery

Frandics Chan, Deirdre Sheahan, Shreyas Vasanawala, Richard Mainwaring, Mohan Reddy, Frank Hanley, Beverly Newman

\section{Neuro 1 (NE1) Sunday 14:00-16:00}

Room 1

Moderators: Manohar Shroff, Maria Argyropolou

Keynote: Robert McKinstry, Advances in paediatric diffusion tensor imaging

14 presentations

\section{NE1-1}

3-Tesla Intraoperative MRI in the management of paediatric cranial tumours- initial experience

Shivaram Avula, Laurence Abernethy, Barry Pizer, Conor Mallucci

\section{NE1-2}

An MR System for Imaging Neonates in the NICU

Jean Tkach, Randy Giaquinto, Wolfgang Loew, Ronald 
Pratt, Barret Daniels, Blaise Jones, Lane Donnelly, Charles Dumoulin

\section{NE1-3}

DTI and $1 \mathrm{H}$ in-vivo MRS Study in Normally Developing Children, and in Children with Hypoxic-Ischemic Encephalopathy

Zinayida Rozhkova, Elena Dolia

\section{NE1-4}

Perinatal brain injury assessed by dynamic FDG-PET in newborn piglets

Charlotte de Lange, Eirik Malinen, Hong Qu, Berit $\mathrm{H}$ Munkeby

\section{NE1-5}

Neurodevelopmental Outcomes in Preterm Infants With Diffuse Excessive High Signal Intensity Seen on MR images at Near Term-equivalent Age

Ji Hye Kim, Tae Yeon Jeon, So-Young Yoo, Hong Eo, Jung Yi Kwon, Jee Hoon Lee, Yoon Sil Chang, Won Soon Park

\section{NE1-6}

The alteration of gray matter volume in children with mental retardation: An optimal voxel-based morphometry study

Xinyu Yuan, Sheng Xie, Jiangxi Xiao, Chunhua Jin

\section{NE1-7}

Functional connectivity evaluation of mesial temporal lobes in epilepsy, potential replacement of Wada memory tests; preliminary studies.

Dennis Shaw, Andrew Poliakov, Edward Novotny, Khanna Paritosh, Gisele Ishak, Jeffrey Ojemann

\section{NE1-8}

Utilization of Diffusion Tensor Imaging (DTI) Fiber Tractography in Children Undergoing Corpus Callosotomy Susan Palasis, Robert Flamini, Laura Hayes, Richard Jones, Damien Grattan-Smith

\section{NE1-9}

Role of Diffusion Tensor Imaging in the post-surgical MR of pediatric patients with pharmacologically resistant epilepsy undergoing hemispherotomy.

Carlo Cosimo Quattrocchi, Daniela Longo, Luciana Nogueira Delfino, Olivier Delalande, Elisabetta Genovese, Nicola Specchio, Lucia Fusco, Federico Vigevano, Vittorio Cannatà, Bruno Bernardi, Francesco Randisi
NE1-11

Blunt Head Trauma in a Community Health Care Setting: a description of patients and use of Computed Tomography Jane McMillan, MD, Patrick Van Winkle Van Winkle, MD, Casey Vibbard, MD, MsPH, Ngoc Ho, PhD, Laura Sirikulvadhana, MPH

NE1-12

Brain perfusion in trigonocephaly. Arterial spin labelling in children

Francis Brunelle, David Grevent, Federico di rocco, Christian sainte-rose, Nathalie Boddaert

NE1-13

Spinal Drop Metastases Revealed with (RS) EPI Diffusion Tensor Imaging

Laura Hayes, Richard A Jones, Damien J Grattan-Smith, Susan Palasis, Dolly Aguilera, Claire Mazewski

NE1-14

Feasibility of non-invasive quantitative MRI measurements of cerebral vascular reactivity using a computer controlled stimulus in children with sickle cell disease

Andrea Kassner, Jackie Leung, Fatima Nathoo, Manohar Shroff, Gabrielle deVeber, Suzan Williams

\section{NE1-R1}

Evaluating number of acquisitions for non fiber tracking DTI applications in pediatric neuroimaging

Salil Soman, Samantha Holdsworth, Stefan Skare, Jalal Andre, Murat Aksoy, Roland Bammer, Patrick Barnes, Kristen Yeom

\section{NE1-R2}

The Spectrum \& Evolution of MRI findings in Children with Cerebral Palsy

Charuta Dagia, Susan Reid, Michael Ditchfield, Dinah Reddihough

\section{Chest (CH) Sunday 14:00-16:00}

Room 2

Moderators: Katherine Halliday, Dolores Bustello

Keynote: Pilar Garcia Peña, Chest CT In children - what to do and when to do it

15 presentations

CH-1

Alveolar growth abnormalities: not just BPD

Zeyad Metwalli, Robert Guillerman, Claire Langston 


\section{$\mathrm{CH}-2$}

Evaluation of infant respiratory distress syndrome and surfactant therapy effects using lung ultrasonography Jovan Lovrenski, Erich Sorantin, Sanja Stojanović

\section{CH-3}

Role of transabdominal sonography of lung bases (TASL) in diagnosis and follow up of hyaline membrane disease (HMD) in premature neonates with respiratory distress soon after birth.

Akshay Saxena, Chirag Ahuja, Kushaljit Sodhi, Praveen Kumar, Niranjan Khandelwal

\section{CH-4}

Prediction of bronchopulmonary dysplasia using lung ultrasonography within the first $24 \mathrm{~h}$ of life

Jovan Lovrenski, Erich Sorantin, Sanja Stojanović

\section{CH-5}

Volumetric inspiratory/expiratory chest computed tomography findings in bronchopulmonary dysplasia

Frederick Long, Yuchung Yan, Robert Castile

\section{CH-6}

Usefulness of the Doppler US in the diagnosis of pulmonary pathology in children

Gloria del Pozo Garcia, Carmen Gallego, Julio Arevalo, David Coca, Miguel Rasero, Gabino Gonzalez de Orbe

\section{CH-7}

Preoperative MDCT Evaluation of Congenital Lung Anomalies in Children: Comparison of Axial, Multiplanar, and 3D Images

Edward Lee, Donald Tracy, Soran Mahmood, Christopher Weldon, David Zurakowski, Phillip Boiselle

\section{CH-8}

Diagnosis of Tracheobronchomalacia - At last a reliable, noninvasive four-dimensional technique

Zhi Yie Judith Tan, Michael Ditchfield, Ramsden Andrew, Marcus Crossett

\section{CH-9}

Evaluation of the baseline pre-HAART chest $\mathrm{x}$-ray in pediatric patients

Nasreen Mahomed, Mbaliso Mbakaza

$\mathrm{CH}-10$

Serial evaluation of children following lung transplantation for bronchiolitis obliterans; comparison of high resolution computed tomography with detailed lung function assessment including lung clearance index.

Jim Carmichael, Alister Calder, Helen Spencer

\section{$\mathrm{CH}-11$}

Limited, fast-MRI as an alternative to CT for preoperative evaluation of Pectus Excavatum

Krista Birkemeier, Daniel Podberesky

\section{CH-12}

Comparison of radiation dose, image quality, and scan time in pediatric high-resolution chest CT using volumetric 320detector row, helical 64-detector row, and non-contiguous axial acquisitions

Daniel Podberesky, Alan Brody, Terry Yoshizumi, Erin Angel, Greta Toncheva, John Egelhoff, Colin AndersonEvans, Chris Alsip, David Dow, Shelia Salisbury, Donald Frush

\section{CH-13}

Ultrafast sub-milliSievert Flash CTA of the chest Sjirk Westra, Xinhua Li, Bob Liu, Mithya Barreto, Sarabjeet Singh, Mannudeep Kalra, Suhny Abbara, James Thrall

\section{CH-14}

Low-dose radiation CT angiograms are as accurate as standard chest $\mathrm{CT}$ in the diagnosis of congenital lung lesions

Monica Epelman, Dustin Bermudez, Zhu Xiaowei, Kreiger Portia, Kenneth Liechty, Jeffrey Hellinger

\section{$\mathrm{CH}-\mathrm{R} 1$}

Mediastinal stacking and aorto-carinal syndrome in children with right lung volume loss - a cause of contralateral left main bronchus compression

Savvas Andronikou, Matthys J van Wyk, Pierre Goussard, Robert P Gie

\section{$\mathrm{CH}-\mathrm{R} 2$}

Low dose dynamic pulmonary computed tomography in infants and small children

S Bruce Greenberg

\section{CH-R3}

The pulmonary HRCT findings of Langerhans cell histiocytosis in infants

Xinyu Yuan, Surong Li, Li Che 


\section{Neuro 2 (NE2) Sunday 16:20-17:20}

Room 1

Moderators: Catherine Adamsbaum, Richard Roberson Keynote: Santiago Medina, Evidence based Imaging of headaches in children

4 presentations

\section{NE2-1}

Difference in Shape and Relative Alignment of Semicircular Canals in Adolescent Idiopathic Scoliosis (AIS) Comparing with Normal Controls: High Resolution MR Imaging and Morphometry Study

Winnie CW Chu, Defeng Wang, Lin Shi, Darshana D Rasalkar, Pa Heng, Jack CY Cheng

\section{NE2-2}

Establishment of normative neurosonographic indices, including resistive index,based on a longitudinal study of newborns followed through infancy with normal neurodevelopmental outcomes

Don Soboleski, Maya Leitner, Cody Li, Safeeq Salahudeen, Jessica Beiderman, Maxine Clarke, Ian Silver, Michael Flavin, Elizabeth VanDenKerkhof

\section{NE2-3}

Cerebral Perfusion Measurements using dynamic Color Doppler Sonography in Neonates with Hypoxic Ischemic Encephalopathy (HIE) treated with therapeutic hypothermia. Ricardo Faingold, Guilherme Cassia, Christine SaintMartin, Linda Morneault, Guilherme Sant'Anna

\section{NE2-4}

Trilateral retinoblastoma: neuroimaging characteristics and the potential value of brain MRI screening on admission

Firazia Rodjan, Pim de Graaf, Annette C. Moll, Paolo Galluzzi, Philippe Maeder, Sophia Göricke, Hervé Brisse, Jonas A. Castelijns

\section{NE2-R1}

Skeletal Features in Cerebroretinal Microangiopathy with Calcifications and Cysts

Sanna Toiviainen-Salo, Tarja Linnankivi, Anne Saarinen, Mervi Mäyränpää, Riitta Karikoski, Outi Mäkitie

\section{Genito-urinary (GU) Sunday 16:20-18:00}

Room 2

Moderators: David Stringer, Paolo Tomà

Keynote: Lil-Sofie Ording-Muller, UTI workup-top down or down up?

11 presentations

\section{GU-1}

Uterus didelphys with unilateral vaginal atresia: Is multicystic dysplastic kidney the precursor of "renal agenesis" and the key to early diagnosis of this genital anomaly?

Ingmar Gassner, Ursula Kiechl-Kohlendorfer, Theresa Geley, Kathrin Maurer

GU-2

Prognostic Implications of MR Urography in the evaluation of UPJ Obstruction

Damien Grattan-Smith, Richard Jones, Wolfgang Cerwinka, Stephen Little, Hal Scherz, Andrew Kirsch

GU-3

A Novel Method of Identifying Ureteropelvic Junction Obstruction: A Comparative Study of Imaging Modalities in Assessing Renal Function and Degree of Obstruction in a Swine Model.

Jeanne Chow, Courtney Rowe, Brian Minnillo, Alan Retik, Hiep Nguyen

GU-4

Defining urinary collecting system distension in ultrasound reports: a survey of referring physicians

Seth Crapp, J. Herman Kan, Marta Hernanz-Schulman, Kathy Jabs, John Brock, John Thomas

GU-6

Predictors of vesicoureteric reflux in infants with UTI using NICE criteria

Neil Gupta, Osama Abulaban, Tom Goodfellow, Emma Helm

GU-7

The role of second generation echo-enhanced voiding urosonography in the first year of life

Damjana Kljucevsek, Mojca Tomazic, Nina Battelino, Rajko B Kenda, Tanja Kersnik Levart

\section{GU-8}

Voiding Urosonography with a second generation contrast agent as a first step study for the diagnosis and grading of vesicoureteric reflux in children

Frederica Papadopoulou, Katerina Ntoulia, Fotis Papachristou, Ekaterini Siomou, Kostantinia Sarantidou, Kassa Darge

GU-9

Voiding Urosonography: Normal and Abnormal Appearance of the Urethra

Carmina Duran Feliubadaló, Luis Riera Soler, Cesar Martin Martinez, Francesc Novell Teixido 
GU-10

The Mickey Mouse sign: a useful sonographic finding in the diagnosis of torsion of the testicular appendages (TTA). Anna Ben Ely, Ricardo Faingold, Guilherme Cassia

GU-11

Pediatric Testicular Microlithiasis: Experience at a single institution

Matthew Cooper, Boaz Karmazyn

GU-R1

Uterine artery pulsatility index (PI) in diagnosis of puberty and in monitoring treatment for precocious puberty

Vincenza De Iorgi, Gianni Russo, Matilde Ferrario, Francesco

De Cobelli, Pierluigi Paesano

GU-R2

Applying the Updated Transvaginal Ultrasound Criteria for Polycystic Ovarian Syndrome (PCOS) to Transabdominal Ultrasound in Overweight Girls

Valerie Ward, Carol Barnewolt, S. Jean Emans, Amy DiVasta

\section{Non-accidental injury (NA) Sunday 17:20-18:00}

Room 1

Moderators: David Yousefzadeh, Andrew Rickett

6 presentations

\section{NA-1}

Dating of fractures: an analysis of key radiological features of fracture healing in children aged 5 years and under and inter-observer agreement

Ingrid Prosser, Alison Kemp, Alison Evans, Sara Harrison, Susan Morris, Sabine Maguire, Zoe Lawson

\section{NA-2}

Suspected Non-accidental Trauma- Comparison between Confirmed and Indeterminate Cases in a Large 12 year Review Eglal Shalaby-Rana, Allison Jackson, Tanya Hinds, Natalie Kissoon, Robert McCarter, Dorothy Bulas

\section{NA-3}

Validation of a CT Based Finite Element Bone Model for Investigating Mechanisms of Injury in Child Abuse Amaka Offiah, Nick Emerson, Matt Carre, Gwen Reilly, Hayley Morris

\section{NA-4}

Prevalence of rachitic changes in deceased infants: a radiologic and pathologic study

Jeannette Perez-Rossello, Anna G McDonald, Andrew E Rosenberg, Susan L Ivey, Joann M Richmond, Paul K Kleinman
NA-5

Long bone fracture detection in suspected child abuse: contribution of lateral views

Boaz Karmazyn, Ryan Duhn, S. Gregory Jennings, Matthew Wanner, Bilal Tahir, Roberta Hibbard, Ralph Hicks

NA-6

Upper and lower limb fractures in non-ambulatory children: are we doing enough skeletal surveys?

Raj Das, Mark Ingram, Samantha Negus

NA-R1

Fracture Dating in Infant Abuse: A Scientific System to Improve Radiologist Performance

Michele Walters, Peter Forbes, Sarah Bixby, Carlo Buonomo, Paul Kleinman

\section{Musculo-skeletal 2 (MS2) Monday 14:00-16:00}

Room 1

Moderators: Amaka Offiah, Peter Strouse

Keynote: Karen Rosendahl, Juvenile idiopathic arthritisrecent advances

14 presentations

MS2-1

Prevalence of Hip Dysplasia in 18-year-old Norwegians Ingvild Engesceter, Trude G Lehmann, Lene B Laborie, Lars B Engesæter, Karen Rosendahl

\section{MS2-2}

Long term effects of different ultrasound screening strategies for DDH

Lene Bjerke Laborie, Ingvild Ø. Engesæter, Trude G. Lehmann, Lars B. Engesæter, Deborah M. Eastwood, Francesco Sera, Karen Rosendahl, Carol Dezateux

MS2-3

When should treatment for developmental delay of the neonatal hip be commenced?

Michael Jackson, Sally Wilkinson, Alastair Graham Wilkinson

MS2-4

Relationship of acetabular and femoral head morphology to stability in ultrasound examination of neonatal hips

Alastair Wilkinson

MS2-5

Dynamic Contrast Enhancement MR Image of Pediatric Patients after Reduction of Dysplastic Hips: Quantitative MR Perfusion Analysis for Predicting Avascular Necrosis Ji Young Kim, Jung-Eun Cheon, Yun-Jung Lim, Woo Sun Kim, In-One Kim, Kyung Mo Yeon 


\section{MS2-6}

Frequencies of 3 longitudinal dysplasia phenotypes based on sonographic assessments in the newborn and radiological assessments at skeletal maturity

Trude Gundersen Lehmann, Lene Bjerke Laborie, Ingvild Øvstebø Engesæter, Lars Birger Engesæter, Fransesco Sera, Deborah Eastwood, Carol Dezateux, Karen Rosendahl

\section{MS2-7}

Radiographic and biologic assessment of cam-type femoroacetabular impingement morphology of developing hips in asymptomatic children and adolescents: a pilot study.

Hal Dunlap, Sasha Carsen, Paul Beaule, Baxter Willis, Leanne Ward, Kawan Rakhra, Paul Moroz

\section{MS2-8}

Osteonecrosis in Children after Allogenic Bone Marrow Transplantation: Study of Prevalence, Risk factors and longitudinal changes using MRI

Shelly Sharma, Wing-Hang Leung, Deqing Pei, Jie Yang, Shengping Yang, Richard Rochester, Lunetha Britton, Michael Neel, Kirsten Ness, Sue Kaste

MS2-9

MRI of Paediatric Wrist and Hand Trauma-What Gives? Mary-Louise Greer, Michael Guandalini, Anubhav Sarikwal, David Lisle, Kieran Frawley, Trevor Gervais, Geoff Donald

MS2-10

Ultrasound as an ALARA alternative to fluoroscopy for shoulder injection

Tyler Ternes, Kamran Ali, John Knudtson, Debbie Desilet-Dobbs

\section{MS2-11}

Water-Bath Method for Sonographic Evaluation of Superficial Structures of the Extremities in Children

Rajesh Krishnamurthy, Hyun Yoo Jeong, Michael Callahan

\section{MS2-12}

Subtalar coalition with sparing of the middle facet: Is the abnormal morphology of the sustentaculum tali a clue to etiology?

Sarah Bixby, Delma Jarrett, Susan Mahan, Samantha Spencer, Paul Kleinman

\section{MS2-14}

Intramuscular Hemangioma-Small Vessel Type (IH-SVT): Radiologic-Pathologic Correlation.

Sabri Yilmaz, Harry Kozakewich, Steven Fishman, Ahmad Alomari, Gulraiz Chaudry
MS2-R1

Magnetic Resonance Imaging and Joint Outcomes in Boys with Severe Hemophilia A Treated with Tailored Primary Prophylaxis in a Multicentric Clinical Trial in Canada

Andrea Doria, Jeanette Kraft, Paul Babyn, Christine Demers, Sara Israelis, Mohan Pai, Man-Chiu Poon, Georges Rivard, John Wu, Majorie McLimont, Victor Blanchette

MS2-R2

Whole-body MRI (WB-MRI) in the diagnostic work-up of patients with chronic recurrent multifocal osteomyelitis (CRMO)

Tina Stuber, Norbert Heim, Toni Hospach, Micha Langendörfer, Peter Winkler, Thekla von Kalle

\section{Emerging techniques (EM) Monday 14:00-16:00}

Room 2

Moderators: Winnie CW Chu, Rick R. van Rijn

Keynote: Marilyn Siegel, MR elastography-New wave of hepatic imaging

14 presentations

EM-1

Liver elastometry in healthy children and patients with cystic fibrosis (CF)

Clemens Wirth, Verena Wiegering, Kerstin Klotz, Negar Mahlmeister, Meinrad Beer

EM-2

Value of quantitative viscoelasticity mapping of paediatric liver using supersonic shear imaging in the assessment of hepatic fibrosis : a preliminary clinical study

Stephanie Franchi-Abella, Lucie Corno, Monique Fabre, Emmanuel Gonzales, Danièle Pariente

\section{EM-3}

Acoustic radiation force impulse (ARFI): a preliminary study of liver elastography in children

Mehrak Anooshiravani, Michela Tempia, Anne-Laure Rougemont, Sylviane Hanquinet

EM-4

Cine MRI Technique in Pediatric Radiology

Tamara Feygin, Larissa T. Bilaniuk, Avrum N. Pollock, Arastoo Vossough, Leslie Sutton, Robert A. Zimmerman

\section{EM-5}

Pineapple juice for neonatal gut MRI

Owen Arthurs, Martin Graves, Andrea Edwards, Ilse Joubert, Pat Set, David Lomas 


\section{EM-6}

Utilizing Surgical Specimen Sonography to Improve US detection of Appendicitis and the Normal Appendix in Patients with Abdominal Pain

Terri Love, MD, John Wendel, Sandra Allbery, Lisa Wheelock

\section{EM-7}

How much better is small intestine contrast sonography (SICUS) than sonography in diagnosing IBD in children? Ildikó Várkonyi, Anna Nyitrai M.D., Gábor Veres M.D., Éva Kis M.D.

EM-8

Diffusion Weighted Imaging as a marker of activity in paediatric Crohn's disease

Jorge Davila, Nagwa Wilson, David Grynspan, David Mack, Barry Smith, Elka Miller

\section{EM-9}

Intestinal MRI in Inflammatory bowel disease in paediatric patients: The added value of DWI.

Ignasi Barber, Lina Cadavid, Amparo Castellote, Marina Alvarez, Goya Enriquez

EM-10

NdH/dT: A New Quantitative Measure of Tumor Response Using Diffusion Weighted Imaging

Stephan Voss, Moti Freiman, Robert Mulkern, Simon Warfield

EM-11

Dedicated Pediatric High-Density Torso Phased-Array Coil for Submillimeter Isotropic Abdominal MRI

Shreyas Vasanawala, Thomas Grafendorfer, Paul Calderon, Greig Scott, Marcus Alley, Michael Lustig, Anja Brau, Arvind Sonik, Peng Lai, Vijay Alagappan, Brian Hargreaves

\section{EM-12}

Virtual neonatal autopsy- developing a clinically useful CT protocol.

Nathan Dobbs, Kamran Ali, Charles McGuire, Debbie Desilet-Dobbs, Curt Dorn, William Palko

\section{EM-13}

Dynamic 3D Pulmonary Perfusion in Cystic Fibrosis Janaka Wansapura, Tam Le, Ian Chaves, Rhonda VanDyke, Gary McPhail, Raouf Amin, Robert Fleck

\section{EM-14}

Oxygen-enhanced functional low-field MRI of the lung in very low birth weight infants with and without bronchopulmonary dysplasia (BPD)
Clemens Wirth, Sandra Weiß, Daniel Stäb, Helge Hebestreit, Herbert Köstler, Meinrad Beer

EM-R1

Comprehensive Cardiac Flow and Function Assessment with 3D Time-Resolved Volumetric Phase- Contrast MRI Albert Hsiao, Marcus Alley, Frandics Chan, Robert Herfkens, Shreyas Vasanawala

EM-R2

Dynamic imaging of conjoined twins

Kieran McHugh, Agostino Pierro, Edward Kiely

EM-R3

The Value of Hybrid Bone SPECT/CT in Children Helen Nadel

\section{Gastro-intestinal (GI) Tuesday 14:00-16:00}

Room 1

Moderators: Gloria del Pozo Garcia, Antonio Soares-Souza 19 presentations

\section{GI-1}

Should the abdominal radiograph be the initial imaging examination in the pediatric patient with abdominal pain?

Gloria del Pozo Garcia, Veronica MuÑoz Carpio, Amaya Hilario, Daniel Hernandez Aceituno, Gabino Gonzalez de Orbe, Carmelo Serrano

\section{GI-2}

The role of delayed repeat ultrasound in children with right lower quadrant pain

Hamzaini Abdul Hamid, Alan Daneman, Georges Azzie, Trent Mizzi

\section{GI-3}

Difference in size of abdominal nodes and bowel wall thickness in children with recurrent abdominal pain in comparison with age-matched controls

Winnie $C W$ Chu, Vivian YF Leung, Darshana Dattatray Rasalkar

\section{GI-4}

Prospective comparison of CT enterography and MR enterography for the evaluation of pediatric Crohn's disease Michael Gee, Keith Quencer, Mari Mino-Kenudson, Esther Israel, Jeffrey Biller, Aubrey Katz, Mukesh Harisinghani, Katherine Nimkin 


\section{GI-5}

Comparison of High Resolution Bowel Ultrasound (US) with MR enterography (MRE) in children with inflammatory bowel disease (IBD).

Sudha Anupindi, Emily Janitz, David Biko, Melkamu Adeb, Kassa Darge

\section{GI-6}

Comparison Of Gray Scale and Colour Doppler Sonographic Findings With Plain Radiography Findings In Neonates With Necrotizing Enterocolitis (NEC)

Akshay Saxena, Gaurav Arora, Kushaljit Sodhi, Praveen Kumar, Niranjan Khandelwal

\section{GI-7}

Sonographic Hepatic and Portal Blood Flows in Patients with Adolescent Idiopathic Scoliosis: The Effect of Prone Positioning Pierre Schmit, John Trask, P. Christopher Cook, Ron ElHawary

\section{GI-8}

Evaluation by Color-Doppler ultrasonography (CDU) in children benefiting from the Meso-Rex bypass (MRB) for extra-hepatic portal vein thrombosis

Cristina Lo Zupone, Lidia Monti, Arianna Bertocchini, Giuseppe D'Ambrosio, Alessandro Latini, Roberta Silvestri, Chiara Grimaldi, Fabrizio Gennari, Paolo Tomà, Jean De Ville de Goyet

\section{GI-9}

Impact of specialised ultrasound examination on the investigation of infants with neonatal cholestasis

Terry Humphrey, Narasimharaju Dantuluri, Sanjay Rajwal, Helen Woodley, Naved Alizai, Patricia McClean

\section{GI-10}

Abdominal sonography in the pre operative diagnosis of extrahepatic biliary atresia (EHBA) in children Akshay Saxena, Vinayak Mittal, Kushaljit Sodhi, Baburam Thapa, Katragadda Rao, Ashim Das, Niranjan Khandelwal

\section{GI-11}

Delineation and characterization of pediatric focal liver lesions using contrast enhanced ultrasound (CEUS): Preliminary results.

Joseph Jacob, Preena Patel, Annamaria Deganello, Dino Hadzic, Maria Sellars, Paul Sidhu

\section{GI-12}

Rapid MRI Techniques for Quantification of Hepatic Fat Content in Pediatric Patients with Non-alcoholic Fatty Liver Disease

Jie Deng, Mark Fishbein, Cynthia Rigsby, James Donaldson

\section{GI-13}

Measuring liver iron concentration with breath-hold GRE imaging. Richard Jones, Laura Hayes, Damien Grattan-Smith

\section{GI-14}

Limitations of using linear fitting after logarithmic transformation to estimate relaxation rates in iron-loaded liver Seth Friedman, Randolph Otto, Ferguson Mark, Kenneth Marro, Dennis Shaw, Ed Weinberger

\section{GI-15}

Does visceral fat volume predict duodenal compression in SMA syndrome?

Urmil Mehta, Owen Arthurs, Pat Set

GI-16

Differentiation between Hirschsprung alied disease and Hirschsprung's disease in childhood with Barium enema Shuochun Wu, Xinyu Yuan

\section{GI-17}

MRI predictors of treatment response for fistulizing Crohn's disease in pediatric patients.

Anuradha Shenoy-Bhangle, Katherine Nimkin, Dana Goldner, Esther Israel, Michael Gee

\section{GI-18}

Imaging features of irreducible or atypical intussusception Sophie Swinson, Annmarie Jeanes

\section{GI-19}

Is a retromesenteric location of the third portion of duodenum an indicator of malrotation?

Darshit Thakrar, Cynthia Rigsby, Katherine Barsness, Emma Boylan, James Donaldson

\section{Radiation safety (RS) Tuesday 14:00-16:00}

Room 2

Moderators: Annie Paterson, Sjirk Westra, M.D.

Keynote: Karen Thomas, Comparative Dose in Pediatric Radiology-Uncertainty, Estimates and Ballparks 9 presentations

\section{RS-1}

Quality Improvement Registry in CT Scans in Children (QuIRCC): Use of a new pediatric CT dose estimate (CTPD) to develop Diagnostic Reference Levels (DRL) for Abdominal CT

Marilyn Goske, Keith Strauss, Laura Coombs, Keith Mandel, Michael Callahan, Kassa Darge, Donald Frush, David Larson, Daniel Podberesky-Alexander Towbin, Jeffrey Prince, Sjirk Westra 
RS-2

Conversion of the dose-length product to effective dose for different voltages and anatomic regions for pediatric $\mathrm{CT}$ examinations

Yulia Smal, Willi A. Kalender

\section{RS-3}

New conversion coefficients for reconstruction of radiation doses applied during paediatric computer- tomographic (CT) examinations

Michael Seidenbusch, Karl Schneider

\section{RS-4}

Adaptive Statistical Iterative Reconstruction Technique of the Children: Radiation Dose Reduction of Computed Tomography Hong Eo, So-Young Yoo, Ji Hye Kim, Tae Yeon Jeon

\section{RS-5}

Clinical validation of optimized MDCT paediatric abdomen protocols with iterative reconstruction: Radiation dose and image quality assessment

Antonio Ciccarone, Philippe Coulon, Marco Esposito, Silvia Mazzocchi, Giovanna Zatelli, Claudio Fonda

\section{RS-6}

Automatic Exposure Controll in Pediatric CT-Does It Really Work?

Erich Sorantin, Dennis Boysen

\section{RS-7}

Combining Organ-based Dose Modulation Technology and Innovative Dosimetry: Refining Our Ability to Practically Estimate Patient and Age Specific Cancer Risk in Children from Chest MDCT

Brett Bartz, Donald Frush, Terry T. Yoshizumi, Ehsan Samei, Xiang Li, Greta Toncheva, Lynne Hurwitz, William Paul Segars, Xiaodong Zhou

\section{RS-8}

Comparison of radiation dose estimates and scan performance time in pediatric head and neck imaging using volumetric 320 row detector MDCT and helical 64

John Egelhoff, Alan Brody, Daniel Podberesky, Terry Yoshizumi, Erin Angel, Greta Toncheva, Colin AndersonEvans, A Barelli, Chris Alsip, Sheila Salisbury, Donald Frush

RS-9

Bismuth shielding and automatic tube current modulation during pediatric head $\mathrm{CT}$

Maria Raissaki, Antonis Papadakis, Kostas Perisinakis, John Damilakis
RS-10

Breast Dose Reduction Utilizing Breast Shield in Pediatric Cardiac Gated and Non-Gated CT Angiography

Beverley Newman, Juan Plata, Arundhuti Ganguly, Frandics Chan

RS-11

Radiation doses from CT guided Abdominal and Pelvic Interventional Procedures in Children at a Tertiary care General Hospital: Is there opportunity for improvement?

Shauna Duigenan, Debra Gervais, Bob Liu, Xinhua Li, Mueller Peter

RS-12

Comparing radiation dose from 3D O-arm imaging (3DOarm) with that of traditional CT and 2D imaging

Xiaowei Zhu, Marc Felice

RS-13

Quantitative Assessment of Overexposure in Pediatric Digital Chest X-Rays based on European Guidelines

Argjend Imeri, Erich Sorantin, Sabine Weissensteiner

RS-14

Assesment of Pediatric Radiation Exposure During Ureteroscopy Jeanne Chow, Paul Kokorowski, Keith Strauss, Melanie Pennison, Caleb Nelson

\section{RS-R1}

Pediatric MDCT of the abdomen: Evaluation of image quality with automated tube modulation for dose reduction. Zebedin Doris, Barbara Oberdabernig, Katrin Dorr, Erich Sorantin, Michael Riccabona

\section{RS-R3}

Evaluation of Cranial CT Utilization in Minor Head Trauma in Children

Marcus Kessler, Luke Linscott, Douglas Kitchin, Kimberly Quayle, Charles Hildebolt, Robert McKinstry, Steven Don

\section{Interventional (IR) Tuesday 16:20-17:10}

Room 1

Moderators: Timothy Cain, James Donaldson

Keynote: Josée Dubois, Percutaneous sclerotherapy: a cooking guide. Who? When? How?

5 presentations

IR-1

Safety and Efficacy of Ethylene Vinyl Alcohol (EVOH) Copolymer (Onyx) used in Pediatric Ali Shaibani 
IR-2

Endovenous Laser Ablation (EVLA): Usage in Children with Lower Extremity Vascular Malformations

Philip John, Joao Amaral, Alex Barnacle

IR-3

Is Balloon Burst Pyeloplasty a useful alternative to Open or Laparoscopic Pyeloplasty?

Boma Adikibi, Gordon A. MacKinlay, Alistair Graham Wilkinson

\section{IR-4}

Directed Tumoral Therapy of Aneurysmal Bone Cysts in Children William Shiels, James Murakami

IR-5

Review of Image-Guided Fine Needle Aspirations of Thyroid Lesions in Children

Sarah Deitch, Pauline Chou, Stanley Kim, Donald Zimmerman, James Donaldson

IR-R1

Delays in paediatric interventional radiology

Sam Stuart, Sam Chippington, Emma Stockton, Lonay Ridley, Toni Hall

\section{Oncology (ON) Tuesday 16:20-18:00}

Room 2

Moderators: Mervyn Cohen, Hervé Brisse

11 presentations

ON-1

Can preoperative MR imaging predict optic nerve invasion of retinoblastoma?

Hong Eo, Ji Hye Kim, So-Young Yoo, Tae Yeon Jeon

\section{$\mathrm{ON}-2$}

CT- and MR-imaging characteristics of second primary tumors after irradiation in retinoblastoma patients

Firazia Rodjan, Pim de Graaf, Esther Sanchez, Jonathan I. M.L. Verbeke, Annette C. Moll, Paolo Galluzzi, Philippe Maeder, Sophia Göricke, Hervé Brisse, Jonas A. Castelijns

\section{ON-3}

Incidence of Abdominal Tumors in Syndromic and Idiopathic Hemihypertrophy/Isolated Hemihyperplasia- A Retrospective Review

Molly Dempsey-Robertson, David Wilkes, Alec Stall, Patricia Bush, Edward Batista
ON-4

Imaging Studies in Multi-Center Trial of Hodgkin Lymphoma (HL): Importance of Central Review in Assuring Consistent Response Assessment

Stephan Voss, Frank Keller, Kathleen McCarten, Lu Chen, Steven Cho, James Nachman, Tj Fitzgerald, Louis Constine, Cindy Schwartz

ON-5

Pre-Treatment Nodal Apparent Diffusion Coefficient (ADC) Histographic Centile Measurements - predictors of early response in adolescent and paediatric lymphoma?

Paul Humphries, Alan Bainbridge, Stephen Daw, Ananth Shankar, Shonit Punwani

ON-6

The value of whole-body MRI on Hodgkin lymphoma in pediatrics

Henrique Lederman, Jose Schiavon, Rodrigo Regacini, Flavio Luisi

ON-7

Are the RECIST criteria useful in assessing response in paediatric rhabdomyosarcoma?

Reineke A. Schoot, Rick R. van Rijn, Kieran McHugh, Johannes H.M. Merks

ON-8

Off-therapy CT monitoring of patients with Wilms Tumor: Is Pelvic CT Necessary?

Brian Yee, Valerie McPherson, Yimei Li, Najat Daw, Robert Kaufman, Alberto Pappo, Sue Kaste, Samuel Brady

ON-9

Propranolol for treatment of infantile hemangiomas: utility of US for therapeutic effects

Jaroslaw Madzik, Maria Uliasz, Monika BekesinskaFigatowska, Katarzyna Bilska, Wojciech Wozniak, Hanna Bragoszewska

$\mathrm{ON}-10$

Incidence and etiology of new liver lesions in pediatric patients previously treated for malignancy

Ethan A. Smith, Shelia Salisbury, Rose Martin, Alexander J. Towbin

ON-11

Pancreatic neuroblastoma: imaging features of a rare entity Eithne DeLappe, Sara Abramson 


\section{ON-R1}

Suprarenal masses in newborns and infants: imaging characteristics, clinical correlation and follow up

Nina Rodrigues Stein, Alan Daneman, Oscar Navarro

\section{ON-R2}

Investigation of Ultrasonographic findings of infantile hepatoblastoma compared with surgical and pathological presentations Yingzi Su, Xinyu Yuan

\section{Miscellaneous (MI) Tuesday 17:10-18:00}

\section{Room 1}

Moderators: Timothy Cain, James Donaldson

Keynote: M. d'Alessandro, Connecting Your Radiology Learning To Your Clinical Practice: Using Personal Learning Environments, Learning Portfolios, and Communities of Practice

3 presentations
MI-1

Efficacy of two oral premedicants: midazolam or a low dose combination of midazolam-ketamine in children undergoing CT imaging

Babita Ghai, Kajal Jain, Akshay Saxena, Deepak Saini, Niranjan Khandelwal

\section{MI-2}

The diagnostic value of radiology in invasisve pantonvalentine leucocidin positive staphylococcus aureus infection. Afshin Alavi, Joanna Danin, Maria Nordlander, Mayai Seah, Linda Maruskova, Sam Walters

\section{MI-3}

How and Why an Australian Children's Hospital is planning for MR PET in 2011

Timothy Cain, Rodney Hicks 